\author{
UNIVERSIDADE DE SÃO PAULO \\ FFCLRP - DEPARTAMENTO DE BIOLOGIA \\ PROGRAMA DE PÓS-GRADUAÇÃO EM ENTOMOLOGIA
}

\title{
"Biologia térmica de Scaptotrigona depilis (Apidae, Meliponini): adaptações para lidar com altas temperaturas"
}

Ayrton Vollet Neto

Dissertação apresentada à Faculdade de Filosofia, Ciências e Letras de Ribeirão Preto da USP, como parte das exigências para a obtenção do título de Mestre em Ciências, Área:

Entomologia

RIBEIRÃO PRETO -SP 


\title{
Ayrton Vollet Neto
}

\section{"Biologia térmica de Scaptotrigona depilis (Apidae, Meliponini): adaptações para lidar com altas temperaturas"}

\author{
Dissertação apresentada à Faculdade \\ de Filosofia, Ciências e Letras de \\ Ribeirão Preto da USP, como parte \\ das exigências para a obtenção do \\ título de Mestre em Ciências, Área: \\ Entomologia
}

Orientadora: Profa. Dra. Vera Lucia Imperatriz Fonseca

RIBEIRÃO PRETO -SP 
Autorizo a reprodução e divulgação total ou parcial deste trabalho, por qualquer meio convencional ou eletrônico, para fins de estudo e pesquisa, desde que citada a fonte.

\section{Ficha Catalográfica}

Vollet-Neto, Ayrton

Biologia térmica de Scaptotrigona depilis (Apidae, Meliponini): adaptações para lidar com altas temperaturas. Ribeirão Preto, 2010.

97 p. : il. ; $30 \mathrm{~cm}$

Dissertação de Mestrado, apresentada à Faculdade de Filosofia Ciências e Letras de Ribeirão Preto/USP. Área de concentração: Entomologia.

Orientadora: Imperatriz-Fonseca, Vera Lucia.

1. Adaptações térmicas. 2. Termorregulação. 3. Sensibilidade térmica. 4. Abelhas sem ferrão. 5. Scaptotrigona depilis. 
Dedico este trabalho às minhas avós

Madalena D. Farinazzi (in memorian) e Odete L. Vollet 


\section{AGRADECIMENTOS}

À minha orientadora, Professora Vera Lúcia Imperatriz Fonseca, pela paciência, dedicação e companheirismo;

Aos membros da banca por aceitarem a tarefa de avaliarem o trabalho;

À Denise, pelo grande apoio na correção do trabalho;

Ao Michi pela ajuda nas análises estatísticas;

Ao pessoal do Laboratório de abelhas pelo apoio direto ou indireto na elaboração deste trabalho;

Ao pessoal da Enshark e da 41ํㅡ turma da Biologia pelo apoio na minha formação;

À Flora, por todo companheirismo e apoio em qualquer momento;

À minha família, por sempre estar do meu lado nas horas que mais precisei;

À Capes pelo apoio financeiro 


\section{ÍNDICE}

Resumo

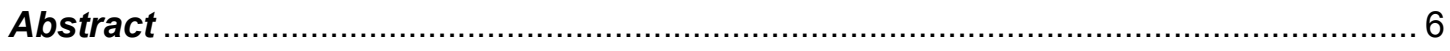

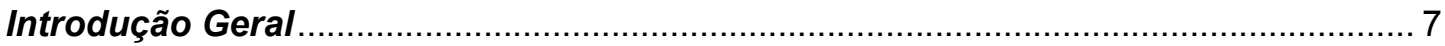

Referências Bibliográficas .......................................................................... 13

Capítulo 1. Regulação da temperatura e umidade relativa em condições de altas temperaturas em Scaptotrigona depilis (Apidae, Meliponini)

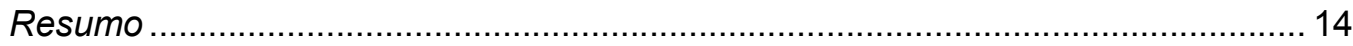

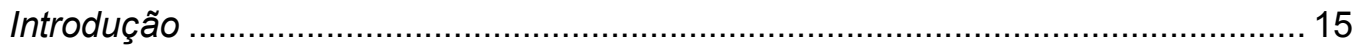

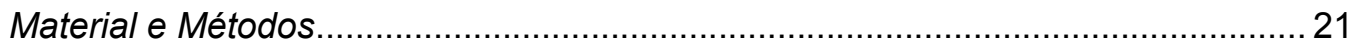

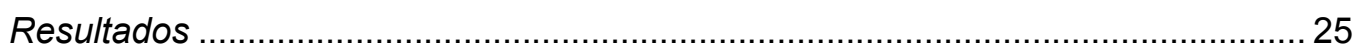

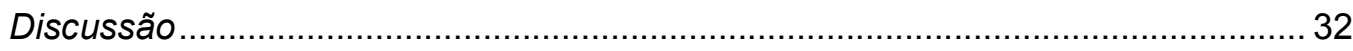

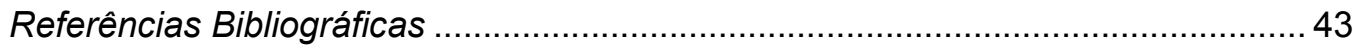

Capítulo 2. Mecanismos de resfriamento do ninho em Scaptotrigona depilis (Apidae, Meliponini)

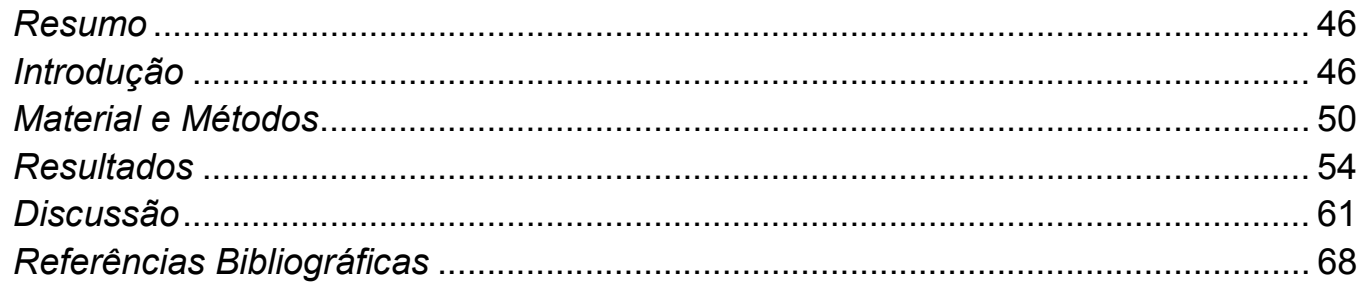

Capítulo 3. A sensibilidade térmica em Scaptotrigona depilis (Apidae, Meliponini): efeitos da variação da temperatura sobre a produção de células de cria e desenvolvimento dos imaturos

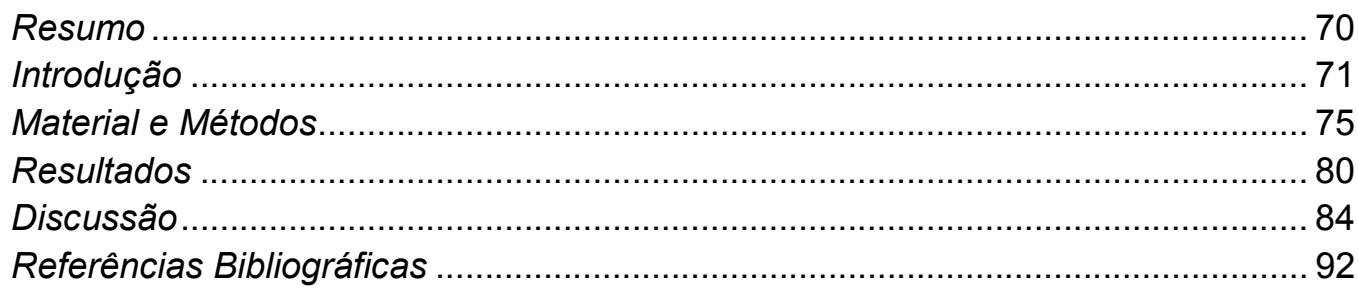

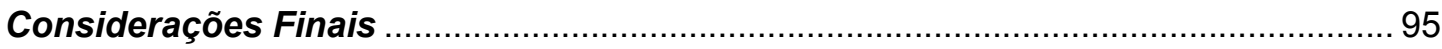

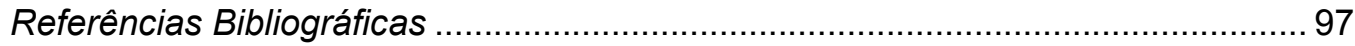




\section{RESUMO}

O grande sucesso ecológico dos insetos sociais se deve, em grande parte, ao controle das condições climáticas do ninho, entre as quais é possível destacar a temperatura como uma das variáveis mais importantes. Nas abelhas sem ferrão, um grupo de abelhas eussociais com cerca de 400 espécies distribuidas pela região Neotropical, apesar dos poucos estudos existentes é possível identificar uma grande variedade de estratégias para lidar com a heterogeneidade térmica do ambiente. Em comparação com Apis mellifera (o inseto social mais bem estudado no mundo), é possível verificar, de maneira geral, uma menor capacidade termorregulatória nas abelhas sem ferrão. Portanto, isto coloca as abelhas sem ferrão como importantes modelos que podem permitir a melhor compreensão da evolução da diversidade de estratégias de sucesso nos insetos sociais para lidar com a heterogeneidade térmica. Adicionalmente, as abelhas sem ferrão realizam a polinização, um serviço ambiental chave para a manutenção dos ecossistemas Neotropicais. Dessa forma é necessário conhecer as adaptações térmicas nestes organismos, principalmente as voltadas para as altas temperaturas, para que possam ajudar a prever os impactos das mudanças climáticas nestes organismos. Assim, o objetivo deste estudo foi investigar a capacidade e os mecanismos termorregulatórios em abelhas sem ferrão, bem como alguns aspectos da sensibilidade térmica sob condições de altas temperaturas, usando para isso a espécie Scaptotrigona depilis como organismo modelo. Verificamos que essas abelhas são capazes de resfriar o ninho e para isto, utilizam pelo menos dois mecanismos: a ventilação e a coleta de água para resfriamento evaporativo. Este último comportamento foi observado pela primeira vez em um contexto colonial e natural. Adicionalmente foi verificado que a umidade relativa do ar dentro dos ninhos varia consideravelmente menos que a umidade relativa do ar ambiente, muito provalvemente por conta das fontes de umidade (néctar e água) e do isolamento da cavidade de nidificação. Verificamos que a taxa de construção de células de cria sofre uma diminuição sutil com o aumento da temperatura ambiente e quase nenhuma influência da temperatura do ninho. Finalmente, verificamos que o tempo de desenvolvimento do estágio pupal até o adulto diminui conforme a temperatura de incubação aumenta. Da mesma forma acontece com a mortalidade, porém esta aumenta drasticamente após atingir uma temperatura limite. Demonstramos que existem adaptações claras para o resfriamento do ninho em $S$. depilis, contradizendo as hipóteses atuais de que a nidificação em cavidades termicamente isoladas seria a principal forma de manter a temperatura em níveis relativamente constantes, supostamente necessários para o crescimento e manutenção da colônia. Adicionalmente, sugerimos que a temperatura dos ninhos varia consideravelmente (mesmo com o isolamento das cavidades e com os mecanismos ativos de termorregulação), porém o desempenho das atividades das abelhas no ninho é regular dentro de uma ampla faixa de temperaturas, i.e., as abelhas sem ferrão devem suportar uma ampla variação de temperaturas. 


\section{ABSTRACT}

The great ecological success of the social insects is due, in large part, to their capacity of nest climate control, which it is possible to highlight the temperature as one of the most important variable. The stingless bees, a megadiverse group of eusocial bees with about 400 species on the Neotropical zone, show a great variety of strategies to deal with the thermal heterogeneity of the environment. Compared to Apis mellifera, (the social insect better studied in the world), it is possible to verify in general, that stingless bees have a low thermoregulatory capacity. Because of that different capacity and other biological features, stingless bees are excellent models to test hypothesis that focus on the evolution of diversity of strategies to deal with thermal heterogeneity in social insects and the consequent success in this group. Additionally, stingless bees are responsible for the pollination of an extensive number of vegetal species, which is a key environmental service to the maintenance of the tropical ecosystems. So, knowing their thermal adaptations, mainly the related to high temperatures, is indispensable in this moment, yet this knowledge will help to prevent the impact of global climate changes on this organisms. Thus, the aim of this study was to investigate the mechanisms and the thermoregulatory capacity in stingless bees, as well as some aspects of thermal sensibility under high temperature conditions, using the specie Scapotrigona depilis as model organism. We verified that the specie is capable of cool their nests and, for that, use at least two mechanisms: ventilation and water collection for evaporative cooling. This last behavior was observed for the first time in a colonial and natural context. Our results have shown that the air relative humidity inside the nests varies considerably less than the environmental air relative humidity, probably because of the humidity sources (nectar and water) and the nest cavity insulation. We also verified that the rate of brood production decrease with the increase of the environmental temperature and is slightly influenced by nest temperature. The developmental time of pupal stage to adult shows an inverse relationship with the rearing temperature. The same occurs with mortality, however it rises dramatically after reaching a temperature threshold. We demonstrated that there are adaptations for cooling the nest in $S$. depilis, contradicting the current hypothesis that the nesting behavior in thermal insulated cavity would be the main component on the maintenance of temperature in constant and stable levels, supposedly needed to the colony growth and maintenance. Additionally, we suggested that the nest temperature varies considerably (even with the cavity insulation and the actives mechanisms of thermoregulation), however the performance of their activities is regular within a wide range of temperatures, i.e., the stingless bees should support a extent variation of temperatures. 


\section{INTRODUÇÃO GERAL}

\section{Adaptações térmicas em abelhas sem ferrão}

Todo organismo vivo neste planeta está sujeito à influência da temperatura, porque esta afeta diretamente qualquer reação bioquímica, determinando se uma dada reação vai ocorrer e qual a velocidade dela . Portanto, a temperatura influencia toda e qualquer atividade de um organismo por conta do seu papel nas reações químicas do metabolismo, de forma que o desempenho de um organismo em uma determinada atividade (performance) varia de acordo com a temperatura deste organismo (Huey e Kingsolver, 1993).

Angilletta (2009) define muito bem como os organismos lidam com a heterogeneidade térmica do ambiente através da relação de duas estratégias adaptativas (Fig. 1). A primeira delas, a sensibilidade térmica, define o grau com que uma atividade depende da temperatura do organismo, variando de organismos que tenham performances altamente dependentes da temperatura (termo-especialistas), até organismos cuja performance é regular dentro de uma ampla faixa de temperaturas (termo-generalistas). A segunda estratégia tem como função otimizar a performance através da regulação da temperatura, definindo sua capacidade de termorregulação, variando de organismos que mantêm a temperatura quase constante com muita precisão (termorreguladores perfeitos) a organismos cuja temperatura é igual à temperatura do ambiente (termo-conformadores perfeitos) (Fig. 1). Todos os organismos vivos encontram-se em algum lugar do plano determinado por essas duas estratégias, podendo, inclusive, mudar de posição durante seu tempo de vida. 


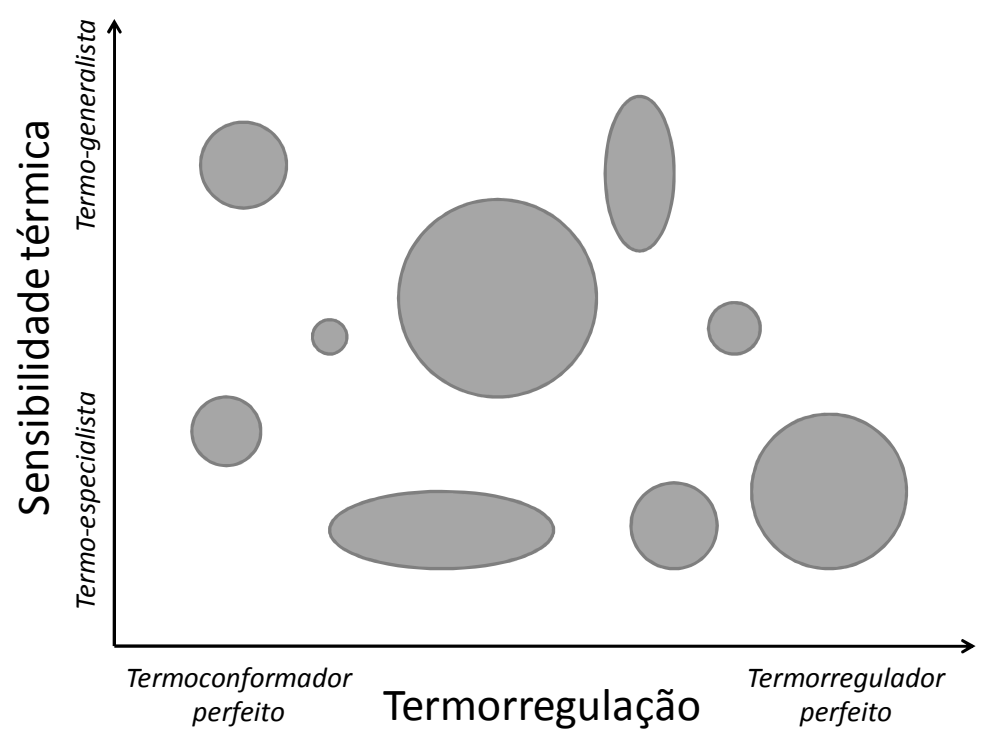

Fig. 1. Relação entre as estratégias de adaptações térmicas nos seres vivos: os círculos representam espécies hipotéticas que estão distribuídas através do plano cartesiano de acordo com sua capacidade de termorregulação e sua sensibilidade térmica. A variação intraespecífica é representada pela área dos círculos (adaptado de Angilletta, 2009).

Em linhas gerais, todos os organismos possuem diferentes formas de reagir à temperatura corporal (sensibilidade térmica). Muitos desenvolveram adaptações comportamentais e fisiológicas para manter a temperatura corporal dentro de limites para que seu desempenho seja o melhor. Portanto, a termorregulação evoluiu como um mecanismo para otimizar o desempenho dos organismos através da manutenção de uma temperatura ótima (ou próxima dela). Desde o início do século XIX, já é sabido que os insetos regulam a temperatura, produzindo calor metabólico (o que possibilita o voo em baixas temperaturas ambientais) e resfriando o corpo durante $o$ vôo para evitar o superaquecimento devido às altas taxas metabólicas desta atividade (Heinrich, 1981).

Os insetos sociais (que incluem também os cupins e formigas, e algumas abelhas e vespas) expandiram o controle da temperatura do nível individual para o coletivo, através da termorregulação social, na qual a temperatura do ninho, favorecendo principalmente o desenvolvimento da cria, que se desenvolve em temperaturas ótimas, permitindo a existência de cria durante o ano todo mesmo sob condições adversas de temperaturas ambientais (Jones e Oldroyd, 2007).

O grande sucesso ecológico dos insetos sociais (mostrada pela sua abundância em número de espécies e principalmente em biomassa em quase todos 
os biomas terrestres) é associado em sua maior parte ao controle das condições climáticas do ninho. Este controle resulta em certa independência fisiológica das variações do ambiente e garante temperaturas ótimas para o desempenho de suas atividades (Wilson, 1971; Jones e Oldroyd, 2007).

A abelha Apis mellifera (Apidae: Meliponini) é o melhor exemplo de independência fisiológica, uma vez que possui uma fascinante capacidade de manter precisamente a temperatura do seu ninho dentro de uma estreita faixa de temperatura (de 33 a $36^{\circ} \mathrm{C}$, mesmo com temperaturas ambientais acima de $40^{\circ} \mathrm{C}$ ou abaixo de $0^{\circ} \mathrm{C}$ ) (Heinrich, 1993). Indivíduos expostos a temperaturas ligeiramente acima ou abaixo dessa faixa ótima durante seu estágio pupal, quando sobrevivem, sofrem deficiências morfológicas, fisiológicas e/ou comportamentais quando adultos (Mardan e Kevan, 2002; Tautz et al., 2003; Jones et al., 2005), mostrando que a sensibilidade térmica dos imaturos é muito alta nessa espécie .

Em comparação com $A$. mellifera, relativamente pouco se sabe sobre as abelhas sem ferrão (Apidae: Meliponini) com respeito à capacidade de controle da temperatura do ninho e sobre os efeitos da variação da temperatura na performance (a sensibilidade térmica) dos indivíduos. As abelhas sem ferrão são um grupo diverso de abelhas altamente eussociais com distribuição geográfica nas regiões tropicais, abrangendo mais do que 400 espécies na região Neotropical (Camargo e Pedro, 2007). Vivem em colônias perenes as quais contêm de algumas centenas, até milhares de operárias (Michener, 1974).

Até agora uma porcentagem mínima dessa diversidade de espécies foi investigada quanto às suas adaptações térmicas. Zucchi \& Sakagami (1972), ao estudarem sete espécies de abelhas sem ferrão, encontraram pelo menos três níveis de capacidades termorregulatórias (baixa, intermediária e alta). Essa diversidade de estratégias de adaptações térmicas inclusive muito diferentes das de $A$. mellifera, colocam as abelhas sem ferrão em uma posição chave para compreensão das adaptações térmicas. Mais especificamente em compreender a evolução da diversidade de estratégias de sucesso nos insetos sociais para lidar com a heterogeneidade térmica. 


\section{A importância das belhas sem ferrão e do estudo de suas adaptações térmicas}

As abelhas sem ferrão são organismos-chave para a conservação de ambientes naturais. Elas realizam a polinização de inúmeras plantas na região tropical do planeta, incluindo plantas cultivadas economicamente importantes (Heard, 1999). Além disso, muitas espécies de abelhas sem ferrão possuem importância econômica direta para muitas famílias através da exploração de seus produtos (mel, pólen, cera) (Cortopassi-Laurino et al., 2006).

As abelhas - e consequentemente as plantas por elas polinizadas - estão em situação de risco no mundo todo por conta da diminuição das áreas naturais (Brown et al. 2001; Biesmeijer et al 2006) e, principalmente, das mudanças climáticas previstas para as próximas décadas (Marengo et al., 2009). Análises recentes mostraram que as espécies ectotérmicas tropicais possuem maiores riscos de extinção por conta das mudanças climáticas, como um resultado de sua baixa tolerância ao aquecimento (Deutsch et al., 2008). O importante papel que a temperatura desempenha nos padrões de distribuição das espécies proporciona motivação para investigar os efeitos da temperatura nos organismos vivos e como estes reagem em todos os níves (desde a fisiologia até o comportamento). Essa investigação pode oferecer indicações sobre como mudanças futuras na temperatura global podem impactar a distribuição e o status fisiológico dos organismos (Hochachka e Somero, 2002). Portanto, o estudo da biologia térmica de algumas espécies-chave poderia contribuir para determinar estratégias de conservação das abelhas sem ferrão frente às mudanças climáticas e, consequentemente, ajudar na preservação de ecossistemas que dependem da presença desses importantes polinizadores.

\section{Objetivos e organização geral}

Nosso objetivo geral foi investigar a capacidade e os mecanismos termorregulatórios, bem como alguns aspectos da sensibilidade térmica sob condições de altas temperaturas em abelhas sem ferrão, usando para isso a espécie Scaptotrigona depilis como organismo modelo. Diferentes razões nos levaram a utilizar esta espécie, sendo que a principal delas é por ocorrer naturalmente no local dos experimentos (Ribeirão Preto/SP), o que mostra que está adaptada às condições climáticas locais (Camargo e Pedro, 2007), significativamente quentes 
durante a estação de verão (dezembro a março). Adicionalmente, é uma das poucas espécies de abelhas sem ferrão que possui grande quantidade de dados na literatura sobre sua biologia e seus enxames são de fácil obtenção e resistentes à manipulação humana.

Dentro deste contexto geral três questões específicas são investigadas:

(a) S. depilis é capaz de resfriar o ninho durante condições de superaquecimento?

(b) Quais os mecanismos utilizados por S. depilis para resfriamento do ninho?

(c) Como as operárias (adultas e imaturas) de Scaptotrigona depilis reagem às temperaturas altas?

Dessa forma, a dissertação foi dividida em três capítulos, cada um deles referentes a uma das perguntas formuladas. A seguir os objetivos de cada capítulo são apresentados.

Capítulo 1: Regulação da temperatura e umidade relativa em condições de altas temperaturas em Scaptotrigona depilis (Apidae, Meliponini)

Nosso objetivo foi verificar se operárias de $S$. depilis são capazes de diminuir a temperatura do ninho em condições de altas temperaturas. Adicionalmente monitoramos a umidade relativa interna do ninho e, pela primeira vez em estudos com abelhas sem ferrão, associamos com a regulação da temperatura

Capítulo 2: Mecanismos de resfriamento do ninho em Scaptotrigona depilis (Apidae, Meliponini)

Neste capítulo os objetivos foram (1) verificar se o comportamento de coleta água e (2) ventilação das operárias são desencadeados pelo aumento da temperatura do ninho. Adicionalmente verificamos a relação da umidade relativa com os comportamentos e com temperatura.

Capítulo 3: A sensibilidade térmica em Scaptotrigona depilis (Apidae, Meliponini): efeitos da variação da temperatura sobre a produção de células de cria e desenvolvimento dos imaturos 
Investigamos a influência de diferentes temperaturas (sensibilidade térmica), principalmente as altas, em duas atividades: (1) no desenvolvimento do estágio pupal, e (2) na produção de células de cria. 


\section{REFERÊNCIAS BIBLIOGRÁFICAS}

ANGILLETTA, M. J. Thermal adaptation: a theoretical and empirical synthesis. Oxford University Press, USA, 2009.

CAMARGO, J. M. F.; PEDRO, S. R. M. Meliponini Lepeletier, 1836. In: MOURE, J. S.;URBAN, D., et al (Ed.). Catalogue of Bees (Hymenoptera, Apoidea) in the Neotropical Region. Curitiba: Sociedade Brasileira de Entomologia, 2007. p.272-578.

CORTOPASSI-LAURINO, M. et al. Global meliponiculture: challenges and opportunities. Apidologie, v. 37, n. 2, p. 275-292, Mar-Apr 2006.

DEUTSCH, C. A. et al. Impacts of climate warming on terrestrial ectotherms across latitude. Proceedings of the National Academy of Sciences, v. 105, n. 18, p. 6668, 2008.

HEARD, T. A. The role of stingless bees in crop pollination. Annual Review of Entomology, v. 44, p. 183-206, 1999.

HEINRICH, B. Insect thermoregulation. Wiley Interscience John Wiley \& Sons Inc., 1981.

The hot-blooded insects. Cambridge, Massachussets: Harvard University Press, 1993. 601

p.

HOCHACHKA, P. W.; SOMERO, G. N. Biochemical adaptation: mechanism and process in physiological evolution. Oxford University Press, USA, 2002.

HUEY, R. B.; KINGSOLVER, J. G. Evolution of resistance to high temperature in ectotherms. American Naturalist, p. 21-46, 1993.

JONES, J. C. et al. The effects of rearing temperature on developmental stability and learning and memory in the honey bee, Apis mellifera. Journal of Comparative Physiology a-Neuroethology Sensory Neural and Behavioral Physiology, v. 191, n. 12, p. 1121-1129, 2005.

JONES, J. C.; OLDROYD, B. P. Nest thermoregulation in social insects. Advances in Insect Physiology, v. 33, p. 153-191, 2007.

MARDAN, M.; KEVAN, P. G. Critical temperatures for survival of brood and adult workers of the giant honeybee, Apis dorsata (Hymenoptera: Apidae). Apidologie, v. 33, n. 3, p. 295-302, 2002.

MARENGO, J. A. et al. Future change of temperature and precipitation extremes in South America as derived from the PRECIS regional climate modeling system. international Journal of Climatology, $v$. 29, n. 15, p. 2241-2255, 2009.

MICHENER, C. D. The Social Behavior of the Bees. Massachusetts: Harvard University Press, 1974.

TAUTZ, J. et al. Behavioral performance in adult honey bees is influenced by the temperatura experienced during their pupal development. Proceedings of the National Academy of USA, v. 100, n. 12, p. 7343-7347, 2003.

WILSON, E. O. The Insect Societies. Cambridge, Massachusetts: Harvard University Press, 1971.

ZUCCHI, R.; SAKAGAMI, S.; CRUZ-LANDIM, C. Capacidade termoreguladora em Trigona spinipes e em algumas outras espécies de abelhas sem ferrão (Hymenoptera: Apidae: Meliponinae). Homenagem à WE Kerr, p. 301-309, 1972. 


\section{CAPÍTULO 1. Regulação da temperatura e umidade relativa em condições de altas temperaturas em Scaptotrigona depilis (Apidae, Meliponini)}

\section{RESUMO}

O controle da temperatura do ninho é um dos fatores que contribui para o enorme sucesso dos insetos sociais. Já foi verificado que Scaptotrigona depilis é capaz de aquecer o ninho quando submetida a temperaturas abaixo do ideal para seu melhor desempenho. Porém nenhum estudo foi realizado com relação à sua capacidade de resfriamento do ninho, uma informação que, associada à sua sensibilidade térmica, pode ajudar a prever como este importante polinizador reagirá a um provável aumento de temperatura em suas regiões de ocorrência por conta das mudanças climáticas globais. Investigamos a capacidade de $S$. depilis em diminuir a temperatura interna do ninho sob condições de altas temperaturas. Adicionalmente verificamos a variação da umidade relativa do ar dentro dos ninhos desta espécie em comparação com as variações na umidade relativa e a temperatura externas ao ninho. Nossos resultados mostraram que colônias de S. depilis são capazes de resfriar o ninho em até $3,2^{\circ} \mathrm{C}$, mostrando uma diferença estatisticamente significativa entre a temperatura na região dos favos de cria e a temperatura de uma caixa vazia (controle) sob condições de altas temperaturas. A umidade relativa do ar no interior do ninho é mantida em média a $69 \%$ nos dias quentes (quando a temperatura máxima ambiente é maior que $34^{\circ} \mathrm{C}$ ). Concluímos que $S$. depilis possui uma capacidade significativa de resfriamento do ninho. Sugerimos que a pressão seletiva para evitar o aumento excessivo da temperatura do ninho é alta, pois o aumento de 1 ou $2^{\circ} \mathrm{C}$ acima da temperatura máxima crítica (próxima às temperaturas mantidas pelas colônias para o adequado desenvolvimento da cria) pode levar à morte das pupas e adultos. Contrariamente, o limiar crítico mínimo está mais distante das temperaturas ideais mantidas pelas colônias. Mesmo assim observamos que a capacidade termorregulatória em $S$. depilis é menor que em Apis mellifera. Nossa hipótese para explicar esta diferença é que, além da nidificação em cavidades termicamente isoladas, as abelhas sem ferrão devem ser menos sensíveis à variação de temperatura, apresentando um desempenho regular em uma faixa de temperaturas mais ampla que $A$. mellifera. O comportamento de nidificação em cavidades foi apontado como o principal fator para a manutenção da umidade relativa do ar constante dentro dos ninhos, associado à coleta de néctar, provavelmente a principal fonte de umidade. 


\section{INTRODUÇÃO}

\section{Capacidade termorregulatória em abelhas eussociais}

Dentro do grupo das abelhas sociais, Apis mellifera (Apini) é a espécie mais estudada e, atualmente é o principal modelo biológico em estudos de termorregulação. Quando submetida a temperaturas ambientais externas extremas, ou seja, acima de $40^{\circ} \mathrm{C}$ ou abaixo de $0^{\circ} \mathrm{C}$ (Southwick, 1987), essa espécie mantém precisamente a temperatura da região do favo com crias entre 33 e $36{ }^{\circ} \mathrm{C}$ (Heinrich, 1981; Seeley e Visscher, 1985). O mecanismo de controle de temperatura nessas abelhas se baseia em dois compenentes simples: a) com a produção de calor metabólico pelas operárias quando a temperatura ambiental está abaixo da faixa ideal de temperatura, principalmente, para o desenvolvimento da cria $\left(33\right.$ a $\left.36{ }^{\circ} \mathrm{C}\right)$; b) com o resfriamento do ninho, se a temperatura ambiental está acima da faixa ideal, por meio da: b1) ventilação (fanning), que consiste no batimento sincronizado das asas que forma correntes de ar que expulsam o calor em excesso; b2) associação da ventilação à coleta de água e sua distribuição sobre estruturas do ninho, comportamento conhecido como "resfriamento evaporativo" (evaporative cooling) (Jones e Oldroyd, 2007).

Outro grupo bastante estudado quanto à sua capacidade de termorregulação é o das mamangavas (Bombini). Embora seus ninhos contenham de dezenas a pouco mais de centenas de indivíduos os mecanismos de controle de temperatura são bem parecido com os utilizados por $A$. mellifera. Tanto a rainha quanto as operárias possuem a capacidade de incubar a cria através da produção de calor metabólico no tórax, ao movimentarem os músculos do vôo (Vogt, 1986a; b; Heinrich, 1993). Sob condições de altas temperaturas, as operárias batem as asas para ventilar o ninho, evitando que a região da cria superaqueça (Weidenmuller, 2004). Contudo, diferente de $A$. mellifera, não há indícios de resfriamento evaporativo pela coleta de água.

Em comparação com $A$. mellifera e Bombus, as abelhas sem ferrão são relativamente pouco estudadas quanto às capacidades termorregulatórias. Além disso, com a ampla distribuição geográfica e a alta diversidade de espécies (ca. de 400 apenas na região Neotropical (Camargo e Pedro, 2007), acredita-se que o grupo compreenda um mosaico de histórias evolutivas e adaptações distintas para lidar 
com as condições climáticas locais, o que dificulta qualquer generalização para o grupo.

Dos poucos estudos existentes sobre a capacidade termorregulatória nos Meliponini, a maioria investigou as temperaturas que ocorrem em diferentes regiões do ninho em comparação com as temperaturas ambientais externas (Tabela 1). Em especial, verificou-se que o controle da temperatura, embora com níveis variados entre as diferentes espécies, é mais efetivo na região dos favos de cria (Zucchi et al., 1972; Jones e Oldroyd, 2007).

Tabela 1. Variação das temperaturas $\left({ }^{\circ} \mathrm{C}\right.$ ) internas (das regiões do favo de cria e da periferia do ninho) e externas (ambiental) reportadas em abelhas sem ferrão.

\begin{tabular}{|c|c|c|c|c|}
\hline \multirow{2}{*}{ Espécie } & \multicolumn{3}{|c|}{ Temperatura $\left({ }^{\circ} \mathrm{C}\right)$} & \multirow{2}{*}{ Referência } \\
\hline & cria & periferia & ambiental & \\
\hline Frieseomelitta nigra & $21,0-31,0$ & $20,5-27,5$ & $17,5-22,5$ & Torres et al., 2009 \\
\hline Frieseomelitta varia & $18,0-29,6$ & & $15,5-28,0$ & Zucchi \& Sakagami, 1972 \\
\hline Leurotrigona muelleri & $16,5-29,2$ & & $15,5-28,0$ & Zucchi \& Sakagami, 1972 \\
\hline Melipona beecheii & $25,4-34,0$ & $21,0-30,5$ & $18,2-36,0$ & Moo-Valle et al., 2000 \\
\hline Melipona quadrifasciata & $25,0-31,7$ & & $15,5-28,0$ & Zucchi \& Sakagami, 1972 \\
\hline \multirow[t]{2}{*}{ Melipona rufiventris } & $31,0-32,4$ & $27,1-31,3$ & $22,8-29,9$ & Roubik, 1983 \\
\hline & $30,3-34,0$ & & $15,5-28,0$ & Zucchi \& Sakagami, 1972 \\
\hline \multirow[t]{2}{*}{ Melipona scutellaris } & $30,23-31,4^{(1)}$ & $26,9-27,9^{(1)}$ & $18,9-34,5^{(1)}$ & Roldão et al., 2009 \\
\hline & $25,8-28,1^{(2)}$ & $21,4-23,1^{(2)}$ & $2,5-30,5^{(2)}$ & Roldão (com. pess.) \\
\hline Melipona seminigra & $31,0-31,9$ & $28,0-29,5$ & $23,0-29,9$ & Roubik, 1983 \\
\hline Plebeia droryana & $20,0-29,5$ & & $15,5-28,0$ & Zucchi \& Sakagami, 1972 \\
\hline Scaptotrigona depilis & $27,6-31,8$ & & $15,5-28,0$ & Zucchi \& Sakagami, 1972 \\
\hline \multirow[t]{2}{*}{ Scaptotrigona postica } & $29,5-34,0$ & $28,0-32,0$ & $20,0-31,5$ & Engels et al., 1995 \\
\hline & $32,0-39,0^{(2)}$ & $29,0-39,0^{(2)}$ & $26,0-44,0^{(2)}$ & \\
\hline Tetragonisca angustula & $27,5-31,5$ & $18,5-20,5$ & $14,0-24,0$ & Torres et al., 2007 \\
\hline \multirow[t]{2}{*}{ T. a. angustula } & $29,0-35^{(1)}$ & $20,0-35,0^{(1)}$ & $19,0-36,0^{(1)}$ & Proni \& Hebling, 1996 \\
\hline & $26,0-30^{(2)}$ & $16,0-25,0^{(2)}$ & $15,0-25,0^{(2)}$ & \\
\hline \multirow[t]{2}{*}{ T. a. fiebrigi } & $28,0-34,0^{(1)}$ & $24,0-37,0^{(1)}$ & $20,0-35,0^{(1)}$ & Proni \& Hebling, 1996 \\
\hline & $27,0-30,0^{(2)}$ & $12,0-25,0^{(2)}$ & $10,0-22,0^{(2)}$ & \\
\hline Trigona carbonaria & $25,0-30,0$ & $20,0-30,0$ & $10,0-28,0$ & Amano et al., 2000 \\
\hline \multirow[t]{2}{*}{ Trigona (Plebeina) denoti } & $30,0-31,5$ & $21,0-27,5$ & $15,0-31,5$ & Fletcher \& Crewe, 1981 \\
\hline & 32,0 & & $30,9-60,9$ & Moritz \& Crewe, 1988 \\
\hline Trigona spinipes & $33,3-36,2$ & $16,0-27,7$ & $8,2-30,2$ & Zucchi \& Sakagami, 1972 \\
\hline Trigona ventralis & $23,7-32,0$ & $19,1-24,8$ & $15,5-25,5$ & Sung et al., 2008 \\
\hline
\end{tabular}

Estudo realizado durante o verão ${ }^{(1)}$ e o inverno ${ }^{(2)}$. 
Até o momento, o foco principal dos estudos com abelhas eusociais está na capacidade de resposta às baixas temperaturas ambientais. Para isso, os diferentes autores sugerem processos passivos e ativos estão ligados ao aquecimento do ninho (Jones e Oldroyd, 2007). Como exemplos de processos passivos, ou seja, aqueles em que as abelhas não participam diretamente para regulação da temperatura, mas possuem influência indireta, estão a escolha do local de nidificação e a construção de estruturas especializadas na manutenção da temperatura. O local de nidificação é de extrema importância, já que fornece isolamento térmico, e a estrutura dos ninhos construídas pelas abelhas, como o invólucro (lamelas de cerume que envolvem os favos de cria - ver Capitulo 2) conservam o calor na região dos favos. Já nos processos ativos, as operárias contribuem diretamente para a regulação da temperatura. A produção de calor metabólico, bem conhecida nas abelhas melíferas (Jones e Oldroyd, 2007), é o principal exemplo desse processo (para mais detalhes, ver Capítulo 2).

De todos os trabalhos realizados com termorregulação em abelhas sem ferrão, apenas em quatro deles as temperaturas ambientais externas excedem a temperatura da região de cria em algum momento, ou seja, a maioria dos estudos visou investigar somente a capacidade das espécies em termorregular de maneira a aumentar a temperatura (Tabela 1). Proni (1996) trabalhando com duas subespécies de Tetragonisca angustula, encontraram temperaturas externas cerca de $4,5{ }^{\circ} \mathrm{C}$ maiores que as temperatura internas da região de cria, mas apesar da grande diferença de temperatura, afirmaram que o efeito regulatório não foi tão aparente quanto no inverno, e atribuíram a diferença de temperatura principalmente ao local de nidificação e arquitetura do ninho, e uma possível ventilação no túnel de entrada, mas não discutiram mais nada a respeito.

Moo-Vale et al. (2000) encontraram uma temperatura ambiente $2{ }^{\circ} \mathrm{C}$ acima da temperatura da cria de duas colônias de Melipona beecheii, no México. Este fato não foi interpretado pelos autores como um processo de resfriamento do ninho, justamente porque o experimento ocorreu durante os períodos mais frios da região, e esta diferença ocorreu durante a manhã, quando os ninhos estavam com uma temperatura baixa e a temperatura ambiente sobe rapidamente. Além disso, no 
trabalho foi concluído que a espécie em questão não é uma boa termorreguladora, dependendo largamente do local de nidificação.

Já em Trigona (Plebeia) denotti, Moritz e Crewe (1988) encontraram uma temperatua externa muito extrema, de $60^{\circ} \mathrm{C}$, porém uma temperatura amena internamente, de $32^{\circ} \mathrm{C}$. Os autores atribuíram a grande diferença principalmente ao local de nidificação da espécie, em cavidades no solo com cerca de 0,8 a 1 metro de profundidade, mas não investigaram se haveria a possibilidade de uma termorregulação ativa, nem mesmo mediram a temperatura do solo na profundidade média em que as cavidades do ninho se encontram.

E finalmente, no único trabalho que trata da termorregulação em condições de altas temperaturas, Engels e colaboradores (1995) trabalharam com Scaptotrigona postica, espécie do mesmo gênero que a espécie utilizada neste trabalho. Os autores induziram em um único dia um superaquecimento do ninho através de uma caixa de incubação - externa à caixa que mantinha o ninho - que possui um certo controle de temperatura. Os resultados mostraram que ao atingirem temperaturas externas de $44^{\circ} \mathrm{C}$ a temperatura da cria ficou um pouco mais fria, cerca de $40^{\circ} \mathrm{C}$, porém não utilizaram uma caixa controle vazia para desconsiderar o isolamento da caixa. Conforme a temperatura externa subia em direção ao máximo utilizado no experimento $\left(44^{\circ} \mathrm{C}\right)$, as operárias apresentaram um comportamento de ventilação do ninho, através do batimento das asas, até que na temperatura máxima este comportamento cessou, e foi substituído por um comportamento de desoperculação das células de cria recém construídas, momento em que o experimento foi finalizado. Neste trabalho a temperatura externa à caixa de incubação (T. ambiente) estava bem diferente da temperatura induzida, cerca de $25^{\circ} \mathrm{C}$, o que pode trazer resultados experimentais diferentes dos observados na natureza, uma vez que essa discrepância não existe em um sistema natural, podendo ser considerado como um artefato do experimento que pode ter prejudicado algumas conclusões no trabalho. Apesar das evidências, os autores concluíram que $S$. postica não mostrou indícios de coleta de água ou de resfriamento evaporativo, ou qualquer outro mecanismo de resfriamento, exceto uma ventilação através do batimento temporário das asas (que não foi quantificada). Para eles, portanto, o superaquecimento da região da cria não pode ser evitado em temperaturas ambientais extremas. Além disso, sugerem que o isolamento do local de nidificação e a arquitetura do ninho são suficientes para 
impedir um aumento da temperatura da região de cria acima de $35^{\circ} \mathrm{C}$, o que teria dificultado a evolução de uma possível adaptação ao superaquecimento nas abelhas sem ferrão.

Apesar das conclusões dos trabalhos existentes, existem algumas evidências que indicam a possibilidade de uma capacidade de resfriamento do ninho em $S$. depilis: (1) altas temperaturas podem exercer uma pressão seletiva grande, já que podem causar prejuízos maiores para a cria do que as baixas temperatura (Ver capítulo 3), sendo que a temperatura ótima do ninho observada nas espécies sociais é mais próxima de temperaturas letais máximas do que mínimas; (2) a existência de espécies perenes em localidades geográficas onde estas temperaturas muito elevadas são atingidas constantemente na época do verão; e (3) a presença de mecanismos aparentemente voltados para o resfriamento do ninho (Ver capítulo 2). Além disso, conhecer a capacidade de resfriamento do ninho em $S$. depilis pode contribuir para o melhoramento das técnicas de criação destas abelhas (a meliponicultura - Cortopassi-Laurino, 2006; Costa e Venturieri, 2007) e para auxiliar a prever como esta espécie vai reagir às mudanças climáticas previstas para o futuro próximo (Deutsch et al., 2008; Marengo et al., 2009), associado ao conhecimento de sua sensibilidade térmica.

\section{Umidade Relativa nos ninhos de abelhas eussociais}

Assim como a temperatura, a umidade relativa do ar nos ninhos de $A$. mellifera também é mantida em níveis relativamente constantes. De acordo com Human et al. (2006), tanto na região da cria como no estoque de mel, a umidade relativa fica em média em torno de $40 \%$, mesmo em épocas de seca. Porém, ainda não se sabe se essa regulação se dá de forma ativa pelas operárias, coletando e trazendo água para o ninho, ou passiva, através da transpiração, da desidratação do néctar (Human et al., 2006). Como verificado por Simpson (1961), a desidratação do néctar coletado tem papel considerável na manutenção de determinado nível de umidade no ninho, já que colônias privadas de água e submetidas a altas temperaturas preferem coletar néctar mais diluído. As estruturas do ninho também podem agir como estoques de água, conforme verifica por Ellis (2010), que mostrou que os casulos de seda descartados armazenam ca. de $11 \%$ de sua massa em água. Como mecanismo ativo para diminuir a umidade relativa, Ellis et al. (2008) verificaram que 
altos níveis de umidade relativa desencadeiam o comportamento de ventilação nas operárias, com o objetivo de diminuir a umidade dos ninhos de $A$. mellifera. Como a ventilação é um mecanismo também utilizado para regulação da temperatura e concentração de gases respiratórios (Simpson, 1961) a regulação da umidade relativa do ar pode sofrer "trade-offs" com outros parâmetros biofísicos, dificultando sua regulação (Human, 2006).

Doull (1976) identificou que a umidade relativa do ninho adequada para o desenvolvimento larval é maior que 90\%. Portanto, provavelmente a umidade relativa dentro das células de cria onde se desenvolvem as larvas é bem maior que os $40 \%$ encontrados por Human et al. (2006) na região da cria. Apesar de depender largamente da umidade relativa de fora, a umidade interna da célula de cria deve ser bem maior no fundo desta, provavelmente devido aos altos níves de água na geléia real, que serve de alimento para a larva, e que é constantemente depositada.

Nos Bombini, a umidade relativa não é um fator controlado ativamente pelas operárias. Experimentos não mostraram correlação significativa entre o número de operárias ventilando o ninho e a umidade relativa do ar, enquanto essa correlação foi encontrada entre a temperatura ou concentração de $\mathrm{CO}_{2}$ com o número de operárias ventilando (Weidenmuller et al., 2002; Weidenmuller, 2004).

Já para os Meliponini, não existem trabalhos que investigaram, de nenhuma maneira, a umidade relativa dentro dos ninhos. Assim como para Apis, acredita-se que altos níveis de umidade relativa sejam requeridos dentro dos ninhos, uma vez que influencia diretamente a sobrevivência dos adultos e, principalmente, da cria em experimentos de desenvolvimento in vitro (Menezes, 2010). Além disso, a umidade está estreitamente relacionada com a conservação dos recursos alimentares estocados no ninho. Isso porque ela influencia diretamente a concentração de água no mel e, consequentemente, sua conservação (Human et al., 2006) e cria condições microclimáticas necessárias à manutenção de uma possível fauna microbiana associada ao pólen (Camargo et al., 1992).

\section{Objetivos}

Dentro deste contexto nosso objetivo neste capítulo é de investigar como a temperatura e a umidade relativa dos ninhos de $S$. depilis se comportam sob condições de altas temperaturas. 
Especificamente, um dos objetivos deste capítulo é verificar se colônias de $S$. depilis são capazes de resfriar o ninho em condições naturais de superaquecimento, e qual o nível de precisão e eficiência deste processo. A hipótese levantada é de que os comportamentos de ventilação e outros ainda desconhecidos são capazes de reduzir consideravelmente a temperatura do ninho, mantendo uma temperatura estável dentro da região de cria, sob condições de superaquecimento. Assim, esperamos encontrar diferenças significativas entre as temperaturas internas e externas durante períodos de temperatura ambiental extremas.

Adicionalmente, tendo em vista a escassez de dados sobre os níveis de umidade relativa dentro dos ninhos de abelhas sem ferrão, vamos investigar se $S$. depilis regula de alguma maneira a umidade relativa dentro do ninho, ou como a umidade varia em relação à umidade relativa do ar ambiente. Também será verificado a relação da umidade relativa com a temperatura dentro do ninho, que pode indicar algum mecanismo de controle da última.

\section{MATERIAIS E MÉTODOS}

\section{Espécie e local de estudo}

Os experimentos foram realizados no laboratório de abelhas da Faculdade de Filosofia Ciências e Letras de Ribeirão Preto - Universidade de São Paulo, Departamento de Biologia, campus de Ribeirão Preto/SP. Foram utilizadas cinco colônias de $S$. depilis, mantidas em caixas de madeira ("cedrinho" - de 2cm de espessura medidas externas $43 \times 25 \times 14 \mathrm{~cm}$ ), pintadas de cor branca (Fig. 1A). As caixas foram mantidas fora do laboratório, sobre prateleiras a 1,2 metros de altura, cobertas com telhas para proteção contra chuva.

\section{Monitoramento da temperatura e umidade relativa do ar}

Para monitorar a temperatura e a umidade relativa dentro dos ninhos, sensores (15 x 5 mm; SENSIRION, modelo SHT75; precisão: 0,3 ${ }^{\circ} \mathrm{C} / 1,8 \%$ - Temp/UR) foram introduzidos nas caixas através de furos nas laterais. Esses dados foram coletados e armazenados em um computador a intervalos de 5 minutos.

Nos ninhos, os sensores foram posicionados de forma a obter dados de temperatura e umidade relativa dos potes de alimento ( $\mathbf{T}_{\text {POTES }} / \mathbf{U R}_{\text {POTES) }}$ e da região 
dos favos de cria ( $\boldsymbol{T}_{\text {CRIA }} / \mathbf{U R}_{\text {CRIA }}$ ) (Fig. 1B). A temperatura e umidade relativa ambiental ( $\left.\mathbf{T}_{\mathrm{AMB}} / \mathbf{U} \mathbf{R}_{\mathrm{AMB}}\right)$ também foram monitoradas através de um sensor localizado próximo aos ninhos estudados, em local sombreado. A quarta e última região monitorada, que representa com maior fidelidade a temperatura e a umidade relativa que as colônias estavam submetidas, exluindo-se qualquer mecanismo comportamental, fisiológico ou estrutural de regulação ("temperatura operacional"; Angilleta, 2000) é a caixa controle (T ConTR $_{\text {C }} \mathbf{R}_{\text {ConTR }}$ ) (Fig. 1C e D), uma caixa das mesmas dimensões, material e cor das utilizadas para manter as colônias. A caixa controle representa um modelo físico da cavidade que a colônia nidificou, no caso, uma caixa de madeira vazia, que teve sua temperatura e umidade relativa monitorada continuamente, denominada controle ( $\left.T_{\text {CONTR }} / U_{\text {CONTR }}\right)$, caracterizando as condições de troca de calor e umidade relativa a que as abelhas estariam submetidas. Este tipo de modelo não considerou a presença das operárias adultas e dos imaturos, uma vez que o tamanho pequeno das abelhas dificultou 0 desenvolvimento de modelos físicos, (ver Resultados). Foi considerada a possibilidade de colocar as estruturas construídas pelas abelhas na caixa controle (somente as estruturas de cerume, como por exemplo, o invólucro), porém rejeitamos esta condição e consideramos que as estruturas servem também como mecanismos de regulação e precisavam ser quantificados.

O superaquecimento dos ninhos foi obtido através da exposição das caixas ao sol por cerca de 6 horas diárias (das 9 às 15 horas), durante os períodos quentes do ano (dezembro a março). 


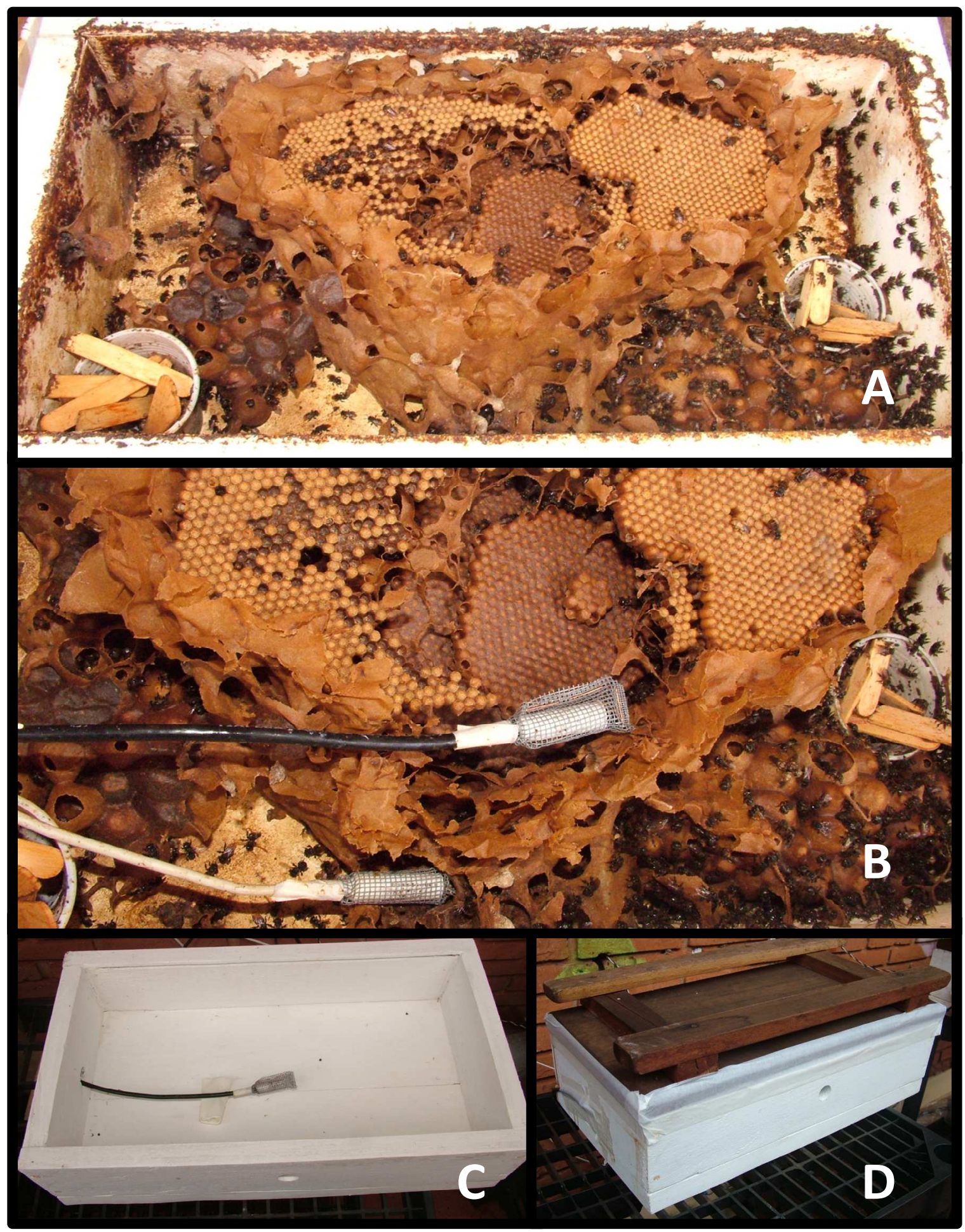

Fig. 1. A - caixa (sem a tampa) contendo as colônias utilizadas no experimento; B - posicionamento dos sensores; C - caixa controle com o sensor posicionado (sem encostra no fundo); e D - caixa controle com tampa e vedada; 


\section{Capacidade termorregulatória}

Foram selecionados seis dias com altas temperaturas para as cinco colônias (duas colônias foram amostradas em fevereiro/2010 e três em fevereiro/2011). Esses dias foram escolhidos, baseando-se nos intervalos dos dias em que a TCONTR foram maiores que a temperatura interna dos ninhos, indicando que poderia haver um controle da temperatura. Para esse período, referiremos a de período de termorregulação.

Para verificar a existência do resfriamento do ninho, a T CONTR foi comparada com a T $\mathrm{CRIA}$ durante os períodos de termorregulação através do teste de MannWhitney (índice do teste: $U$ ). Valores de $P$ menores que 0,05 foram considerados significativos.

Para verificar a capacidade termorregulatória, ou seja, o quanto a espécie consegue resfriar o ninho, foram utilizados dois parâmetros: (1) a duração do período em que a $\mathrm{T}_{\text {CONTR }}$ fica maior que a $\mathrm{T}_{\mathrm{CRIA}}$, e (2) a amplitude desta diferença.

\section{Regulação da Umidade Relativa}

Como descrito no item anterior, os mesmo dias selecionados para as análises de controle de temperatura foram utilizados nas análises da umidade relativa. Para verificar se existe algum tipo de regulação da umidade relativa, as UR $\mathrm{R}_{\mathrm{CRIA}}, \mathrm{UR}_{\mathrm{POTES}}$, $U_{\text {AMB }}$ e UR $\mathrm{R}_{\text {CONTR }}$ foram comparadas através do teste Kruskal-Wallis (índice do teste: $H$ ). Para verificar a diferença entre cada região foi feito o teste a posteriori de Tukey. Valores de $P$ menores que 0,05 foram considerados significativos.

\section{Relação entre Umidade Relativa e Temperatura}

A umidade relativa pode influenciar ou ser influenciada pela temperatura, podendo, portanto, servirem como mecanismos de regulação (Varejão-Silva, 2005; veja também Capítulo 2). Para verificar a existência de alguma possível relação entre estas variáveis, foi feita uma correlação de Pearson entre a Umidade Relativa e a Temperatura para cada uma das regiões amostradas. 


\section{RESULTADOS}

\section{Capacidade termorregulatória}

Durante os seis dias amostrados, as cinco colônias foram significativamente diferentes quando comparamos todas as temperaturas das diferentes regiões amostradas ( $\mathrm{T}_{\text {CRIA }}, \mathrm{T}_{\text {POTES, }} \mathrm{T}_{\mathrm{AMB}}$ e $\left.\mathrm{T}_{\text {CONTR }}\right)(\mathrm{H}=138,7 ; \mathrm{P}<0,001)$. Para as cinco colônias, a média ( \pm desvio-padrão) da $T_{\text {CRIA }}$ foi de $30,53{ }^{\circ} \mathrm{C}( \pm 3,1)$, a da $T_{\text {POTES }}$ foi de $28,9{ }^{\circ} \mathrm{C}( \pm 4,0)$, da $\mathrm{T}_{\text {CONT }}$ de $27,7{ }^{\circ} \mathrm{C}( \pm 5,0)$ e da $\mathrm{T}_{\mathrm{AMB}}$, de $26,5^{\circ} \mathrm{C}( \pm 5,3)$ (Fig. 2 , Tabela 2).
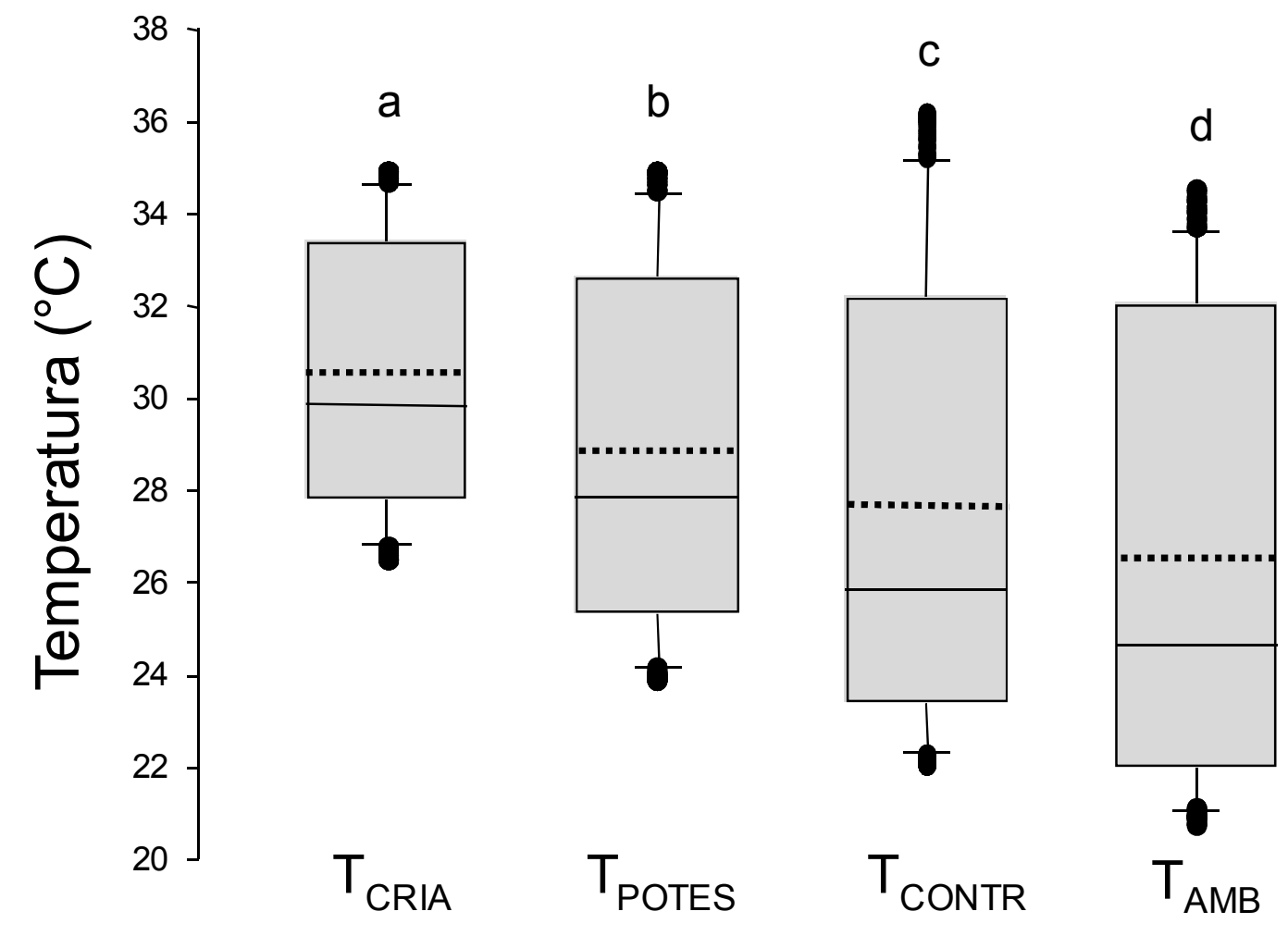

Fig. 2. Temperatura nas quatro regiões amostradas ( $T_{\text {CRIA }}, T_{\text {POTES, }}, T_{A M B}$ e $T_{\text {CONT }}$ ). Os dados correspondem às médias para cada horário amostrado ( 5 em 5 minutos de um intervalo de 24 horas) das cinco colônias durante os seis dias amostrados. Boxplots: A linha inteira dentro das caixas indica a mediana, enquanto que a pontilhada indica a média. Os limites inferiores e superior das caixas indicam o quartil inferior e superior, respectivamente. As hastes delimitam a distribuição de $95 \%$ dos dados. Os valores fora dos limites de $95 \%$ estão representados individualmente (outliers). Letras sobrescritas diferentes (a-d) indicam grupos de dados diferentes (Tukey test, $P<0,05$ ) 
A $T_{\text {CRIA }}$ máxima média das cinco colônias nos seis dias $\left(35,0^{\circ} \mathrm{C}\right)$ foi menor que a $\mathrm{T}_{\text {CONTR }}$ máxima média $\left(36,2^{\circ} \mathrm{C}\right)$ (Tabela 2$)$, porém a média da $\mathrm{T}_{\mathrm{CRIA}}\left(30,5^{\circ} \mathrm{C}\right)$ foi consideravelmente maior que a da $\operatorname{T}_{\text {CONTR }}\left(27,7^{\circ} \mathrm{C}\right)$. Esta diferença aconteceu por conta da capacidade de manutenção da temperatura da cria realizada por $S$. depilis durante a noite, nos quais a $T_{\text {CRIA }}$ se mantém consideravelmente maior que a TCONTR, camuflando os períodos mais quentes do dia, nos quais o resfriamento do ninho acontece.

Tabela 2. Temperaturas média ( \pm desvio-padrão), máxima e mínima dos favos de cria ( $\left.T_{\text {CRIA }}\right)$ e dos potes de alimento ( $\mathrm{T}_{\text {POTES }}$ ) de cinco colônias de Scaptotrigona depilis, de uma caixa controle ( $\left.T_{\text {CONTR }}\right)$ e do ambiente $\left(\mathrm{T}_{\mathrm{AMB}}\right)$ durante os seis dias de amostragem.

\begin{tabular}{lcccc}
\hline \multirow{2}{*}{ Parâmetro } & Colônia & \multicolumn{3}{c}{ Temperatura $\left({ }^{\circ} \mathrm{C}\right)$} \\
\cline { 3 - 5 } & & média $( \pm d \mathbf{d p})$ & máxima & mínima \\
\hline $\mathrm{T}_{\text {CRIA }}$ & C 1 & $30,4( \pm 3,2)$ & 36,4 & 24,7 \\
& C 2 & $31,0( \pm 2,5)$ & 35,0 & 27,0 \\
& C 3 & $29,6( \pm 3,6)$ & 36,3 & 23,1 \\
& C 4 & $30,7( \pm 3,2)$ & 35,9 & 24,2 \\
média & C 5 & $31,0( \pm 2,7)$ & 35,2 & 25,5 \\
$T_{\text {POTES }}$ & & $30,5( \pm 2,9)$ & 35,0 & 26,5 \\
& C 1 & $29,6( \pm 3,9)$ & 36,2 & 22,7 \\
& C 2 & $29,0( \pm 3,8)$ & 35,6 & 23,0 \\
& C 3 & $27,9( \pm 4,5)$ & 35,8 & 20,7 \\
média & C 4 & $29,0( \pm 4,3)$ & 35,9 & 21,6 \\
$T_{\text {CONTR }}$ & C 5 & $29,0( \pm 3,7)$ & 35,2 & 22,1 \\
$T_{\text {AMB }}$ & & $28,9( \pm 3,8)$ & 35,0 & 23,9 \\
\hline
\end{tabular}

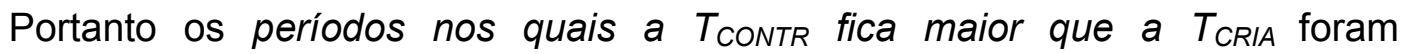
selecionados e estudados separadamente (Fig. 3), passando a ser chamados de períodos de termorregulação. A T POTES foi desconsiderada das análises posteriores, pois se manteve, na maioria das vezes, menor que a $T_{\text {CRIA }}$ e comportou-se praticamente da mesma forma. 


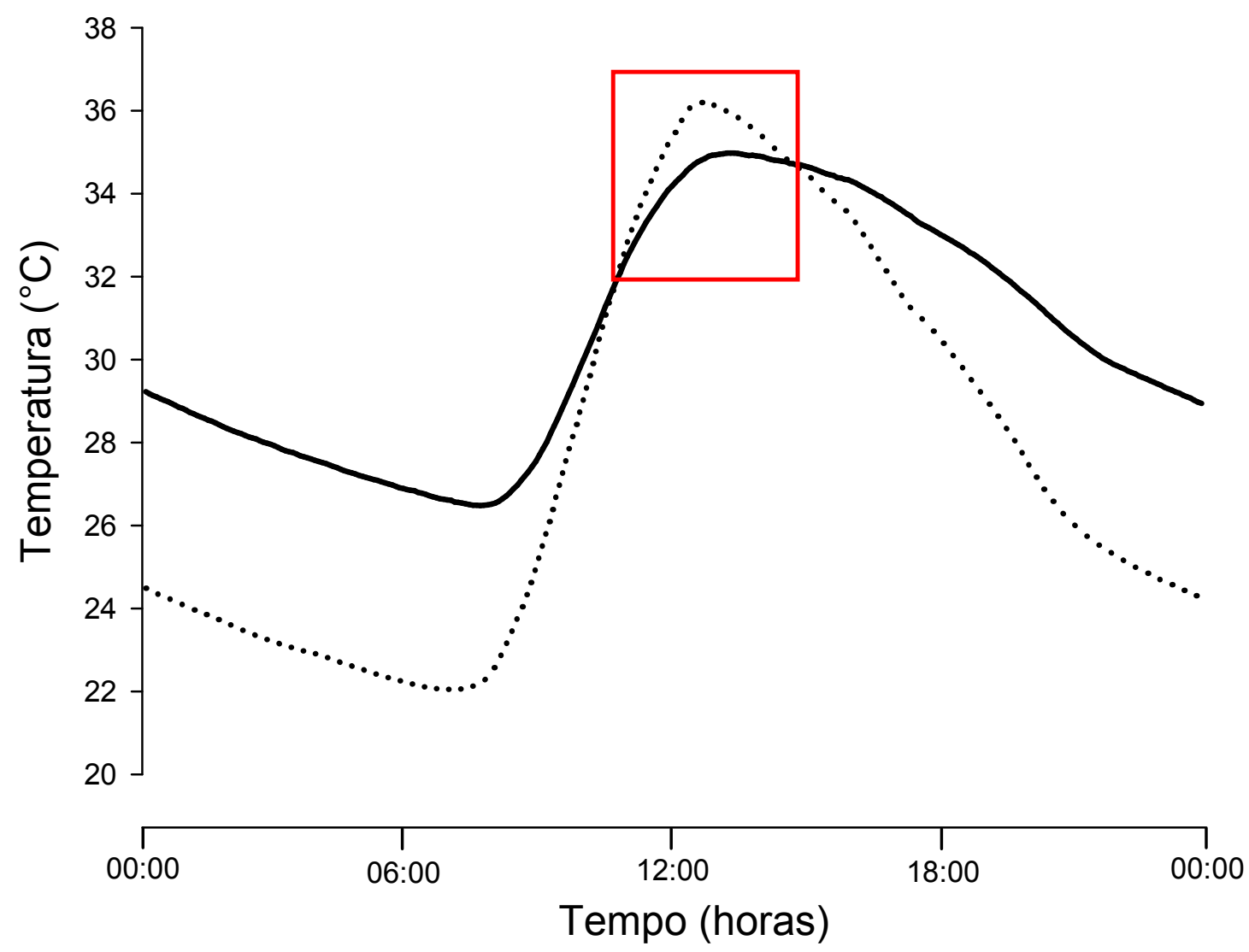

Fig. 3. Variação diária média da temperatura da cria ( $T_{C R I A}$ - linha contínua) e da temperatura da caixa controle ( $T_{\text {CONTR }}$ - linha pontilhada) em cinco colônias de $S$. depilis durante seis dias amostrados $(n=$ 30). A caixa vermelha evidencia os pontos em que a $T_{\text {CONT }}$ passa a ser maior que a $T_{\text {CRIA, }}$, determinando o período de termorregulação que vai ser estudado.

Nas cinco colônias, durante os seis dias, totalizaram-se 30 períodos de termorregulação. O período iniciou-se com uma $\mathrm{T}_{\text {CRIA }} / \mathrm{T}_{\text {CONTR }}$ média de 31,3 \pm $1,9^{\circ} \mathrm{C}$, e durou em média $263,3 \pm 85,8 \mathrm{~min}$, concentrando-se das 10 :00 às $14: 00$ horas. Durante estes períodos, a $\mathrm{T}_{\text {Contr }}$ (média $34,9 \pm 1,6^{\circ} \mathrm{C}$ ) é maior e significativamente diferente da $\mathrm{T}_{\mathrm{CRIA}}$ (média $\left.34,0 \pm 1,4^{\circ} \mathrm{C}\right)(\mathrm{U}=1.561 .510,0 ; \mathrm{P}<$ 0,001 ), ao contrário do verificado ao examinar o período diário inteiro, no qual a $T_{\text {CRIA }}$ é maior que o $\mathrm{T}_{\text {ContR }}$ (Fig. 4). Estes resultados indicam haver algum mecanismo de termorregulação durante esse período. 


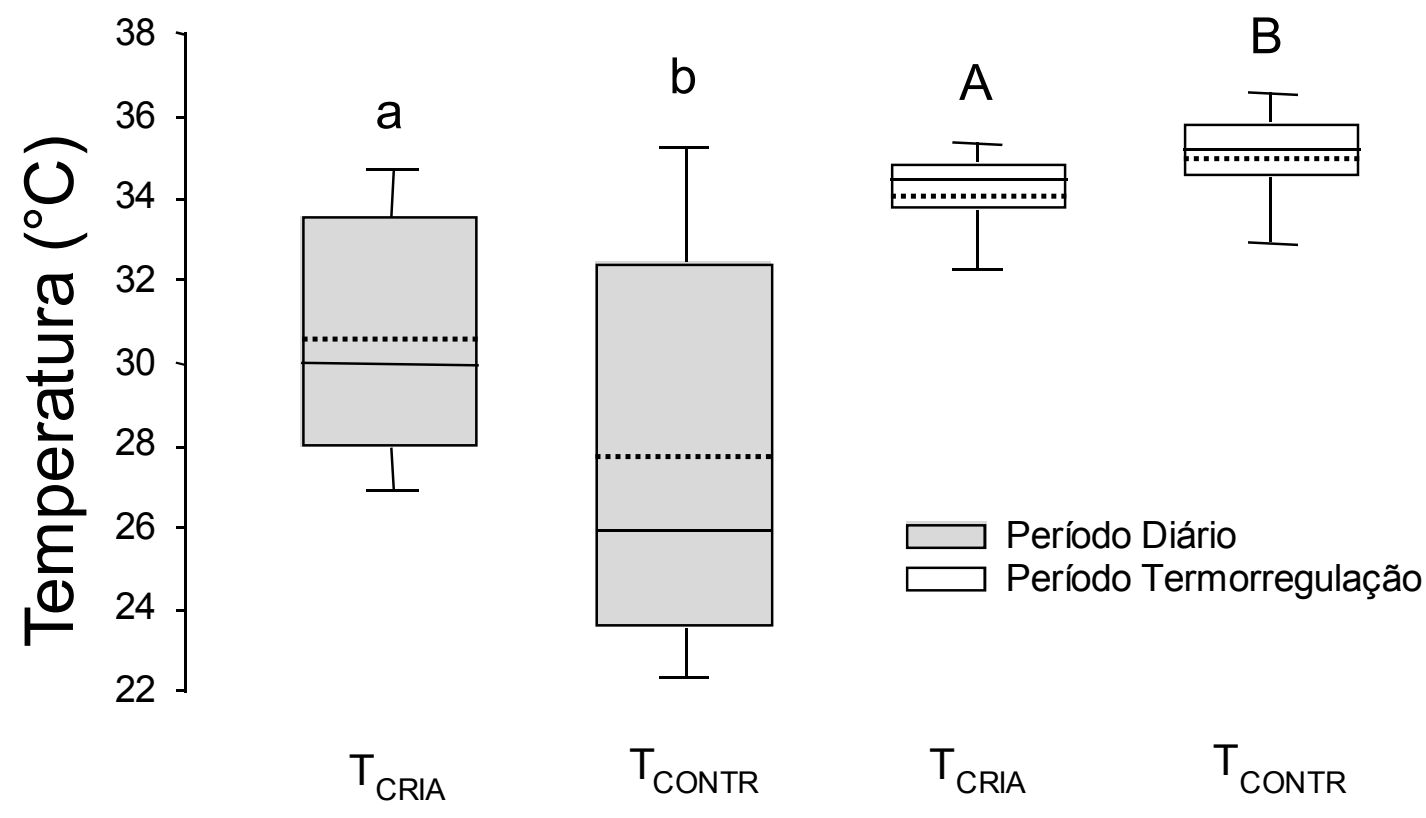

Fig. 4. Temperatura da cria $\left(T_{\text {CRIA }}\right)$ das cinco colônias e temperatura da caixa controle $\left(T_{\text {CONTR }}\right)$ durantes seis dias, considerando-se dois horários diferentes: médias de cada horário amostrado (5 em 5 minutos) considerando o dia inteiro (período diário - barras de cor cinza) e considerando somente o período em que a $\mathrm{T}_{\text {CONTR }}$ está maior que a $\mathrm{T}_{\mathrm{CRIA}}$ (período de termorregulação - barras de cor branca). Boxplots: a linha inteira dentro das caixas indica a mediana, enquanto que a pontilhada indica a média. Os limites inferiores e superior das caixas indicam o quartil inferior e superior, respectivamente. As hastes delimitam a distribuição de $95 \%$ dos dados. Letras sobrescritas diferentes (a-b e A-B) indicam grupos de dados significativamente diferente (U-Mann-Whitney, $\mathrm{P}<0,001$ detalhes no texto texto)

Para verificar a eficiência da termorregulação não bastou analisar a diferença entre a média da $T_{\text {CRIA }}$ e da $T_{\text {CONTR, }}$ pois apesar desta diferença ter sido somente cerca de $1^{\circ} \mathrm{C}$ menor do que a $T_{\text {CONTR, a diferença entre a temperatura nessas }}$ regiões ( $T_{\text {CONTR }}-T_{\text {CRIA }}$ ) atingiu níveis maiores, indicando que a capacidade de termorregular não se limita a diminuir $1^{\circ} \mathrm{C}$. A média mostrou que os valores de temperatura foram muito próximas umas das outras e que, muitas vezes, predominaram durante esses períodos. Esse resultado pode ser interpretado como se as temperaturas fossem muito semelhantes. Porém ao analisar as diferenças ( $T_{\text {CONTR }}-T_{\text {CRIA }}$ ) máximas, observamos que a capacidade de diminuir a temperatura da região dos favos de cria em $S$. depilis é maior. A diferença das médias (entre as três colônias) das máximas temperaturas atingidas no dia, considerando-se todos os 
dias amostrados, é de $1,6^{\circ} \mathrm{C}$. Considerando-se um dia em especial em que todas as colônias atingiram uma máxima diferença alta (provavelmente por conta das elevadas temperaturas no dia), a média das diferença máximas foi de $2,3^{\circ} \mathrm{C}$. Umas das colônias chegou a mostrar uma diferença de $3,2^{\circ} \mathrm{C}$.

\section{Regulação da Umidade Relativa}

De todas as regiões amostradas apenas a UR $R_{C R I A}$ e UR $R_{\text {POTES }}$ não diferiram estatisticamente entre si $(H=231,4 ; P<0,001$, Tukey test $P<0,05)$ (Fig. 5). A $U_{\text {CRIA }}$ se manteve mais constante que a UR $R_{\text {POTES }}$ (menor desvio padrão e menor distribuição de 95\% dos dados) (Tabela 3; Fig. 5).

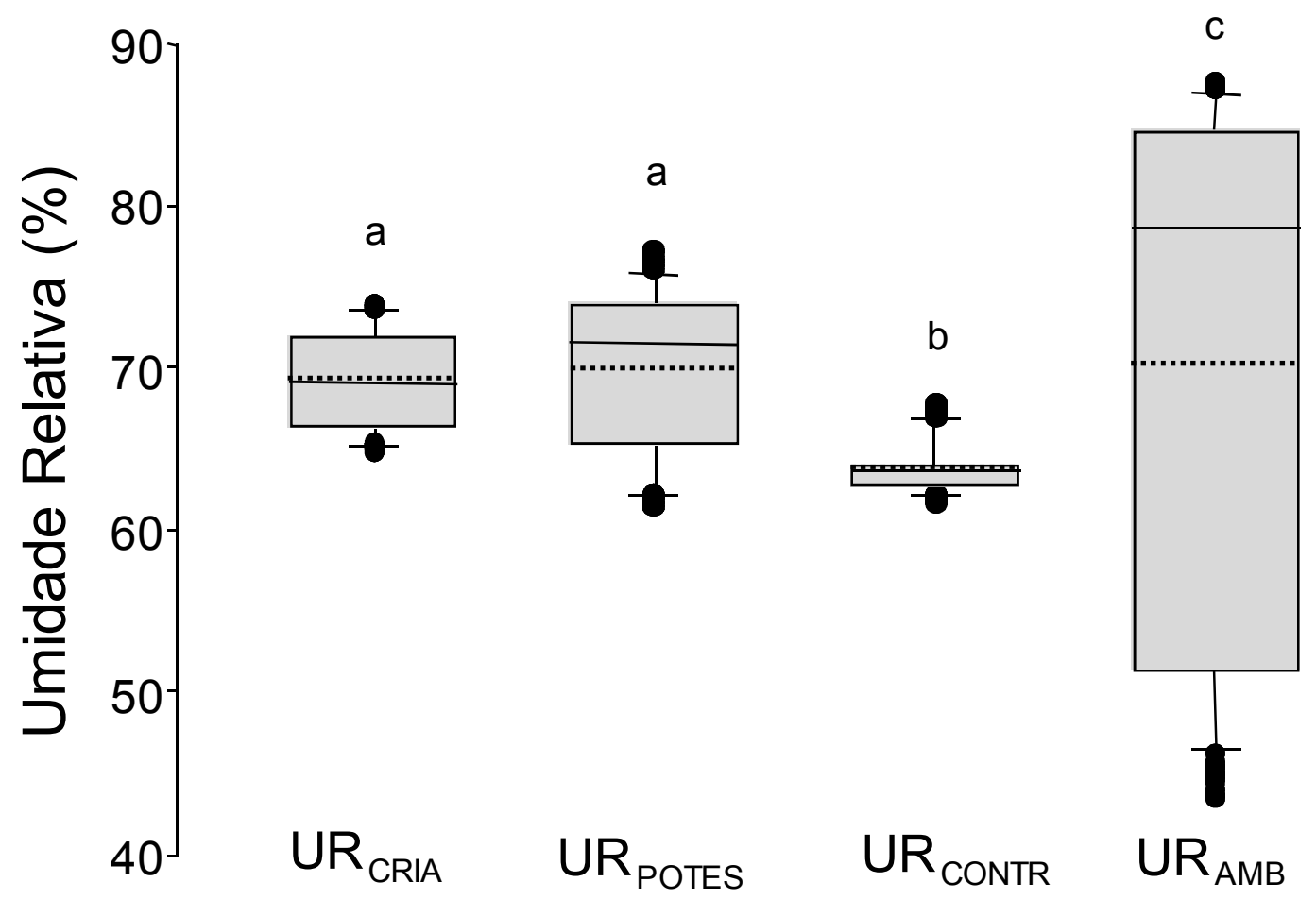

Fig. 5. Umidade relativa nas quatro regiões amostradas (UR $R_{C R I A}, U R_{P O T E S}, U R_{A M B}$ e U $\left.U R_{C O N T}\right)$. Os dados correspondem às médias para cada horário amostrado ( 5 em 5 minutos de um intervalo de 24 horas) das 05 colônias durante os 6 dias amostrados. A linha inteira dentro das caixas dos boxplots indica a mediana, enquanto que a pontilhada indica a média. Os limites inferiores e superior das caixas indicam o quartil inferior e superior, respectivamente. As hastes delimitam a distribuição de $95 \%$ dos dados. Os valores fora dos limites de $95 \%$ estão representados individualmente (outliers). ). Letras sobrescritas diferentes $(a-c)$ indicam grupos de dados diferentes (Tukey test, $P<0,05$ ) 
A $U R_{A M B}$ apresentou uma média muito parecida com a UR $R_{C R I A}$ e UR (Tabela 3) porém variou consideravelmente mais que qualquer outra região amostrada, como mostra o seu elevado desvio-padrão (Tabela 3; Fig. 5).

Tabela 3: Média, desvio padrão e mediana da umidade relativa no favos de cria ( $T_{\text {CRIA }}$ ) e dos potes de alimento ( $\mathrm{T}_{\text {POTES }}$ ) de cinco colônias de Scaptotrigona depilis, de uma caixa controle ( $\mathrm{T}_{\text {CONTR }}$ ) e do ambiente $\left(\mathrm{T}_{\mathrm{AMB}}\right)$ durante os seis dias de amostragem.

\begin{tabular}{|c|c|c|c|c|}
\hline & \multicolumn{4}{|c|}{ Umidade Relativa (\%) } \\
\hline & Cria (UR & Potes (UR POTES $_{\text {) }}$ & Ambiente (UR $\left.\mathbf{R}_{\mathrm{AMB}}\right)$ & Controle (UR CONTR $\left._{\text {C }}\right)$ \\
\hline média & 69,2 & 69,8 & 70,3 & 63,8 \\
\hline desvio-padrão & 3,4 & 5,7 & 17,1 & 3,4 \\
\hline mediana & 69,1 & 71,4 & 78,5 & 63,6 \\
\hline
\end{tabular}

A UR $R_{\text {CONTR }}$ foi significativamente diferente da $U R_{A M B}$ (Tukey test, $P<0,05$ ). Também apresentou uma oscilação muito pequena, evidenciada pelo baixo desvio-

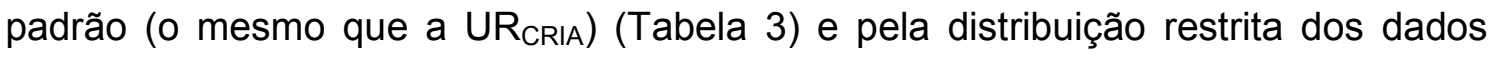
(Fig. 5). Esse resultado mostra que a caixa de madeira tem função importante na

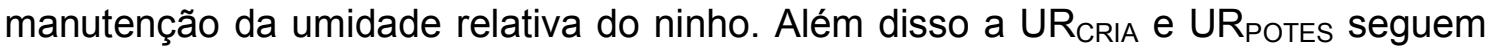

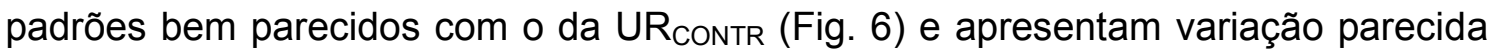
(Tabela 3 - desvio padrão). A UR $\mathrm{CRIA}_{\mathrm{e}}$, em média, 5,4\% maior que a UR $\mathrm{R}_{\mathrm{CONTR}}$, sendo que a variação diária de ambas são muito parecidas. $A U_{\text {CRIA }}$ e a UR $\operatorname{R}_{\text {CONTR }}$ apresentam-se significativamente correlacionadas $(\rho=0,93, P<0,001)$. A UR CONTR $_{\text {C }}$ também apresenta um comportamento interessante próximo ao nascer do sol (07:00h), quando a $U R_{A M B}$ sofre um declínio súbito e a UR $R_{C O N T R}$ mostra um comportamento inverso, de aumento (Fig. 6).

A UR POTES ficou maior que a UR $_{\text {CRIA }}$ durante a noite (menores temperaturas e maior $U R_{A M B}$ ), sofrendo um declínio maior e mais súbito que a $U R_{C R I A}$ no intervalo entre 09:00h e 10:00h, chegando a ficar com valores menores que a UR $\operatorname{CRIA}_{\mathrm{C}} \mathrm{a}$ UR $_{\text {CONTR }}$ (Fig. 6). Este comportamento pode estar associado a mecanismos de termorregulação (ver Capítulo 2). 


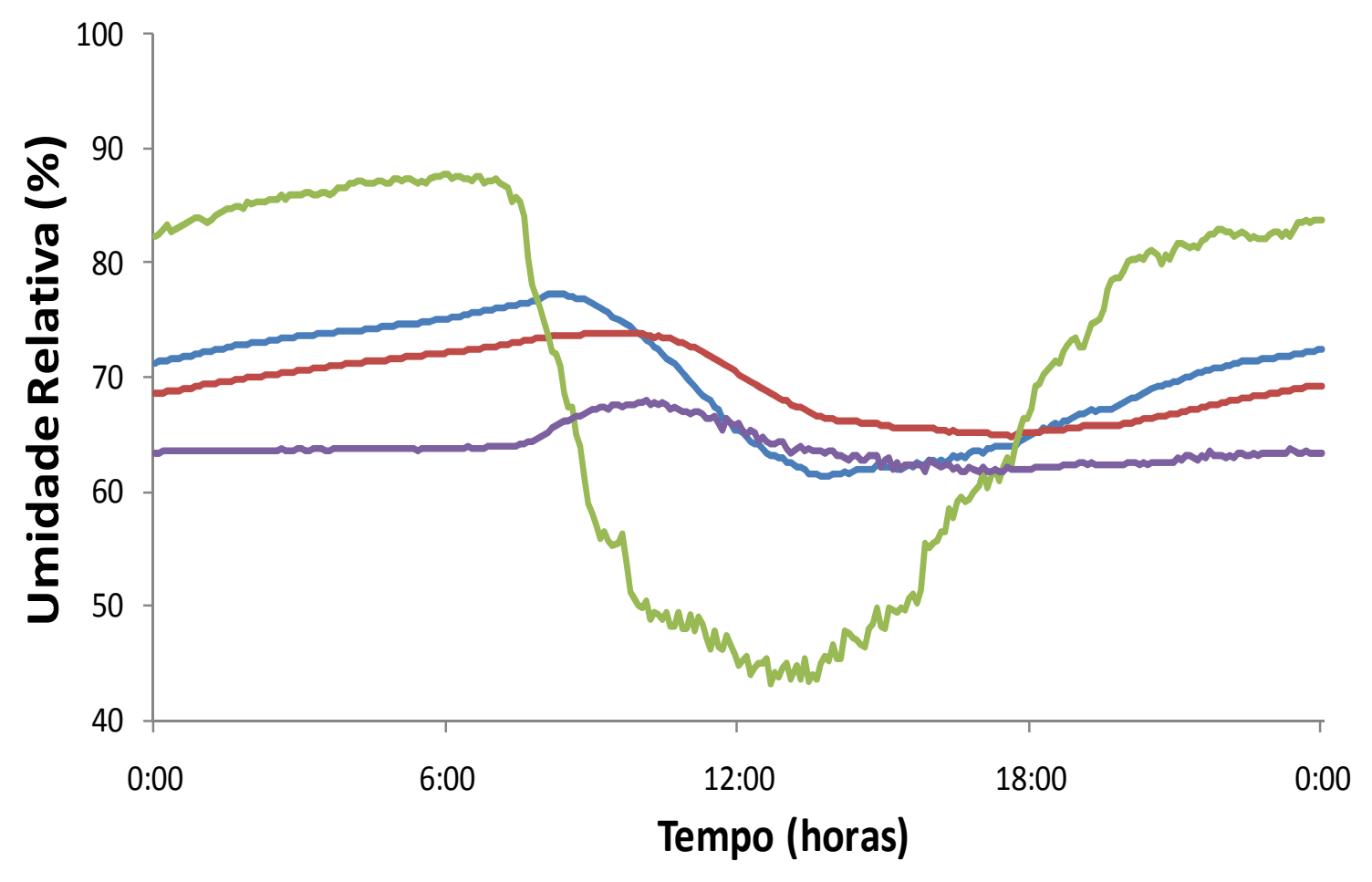

Fig. 6. Variação média diária (durante seis dias) da umidade relativa medida na região dos favos de

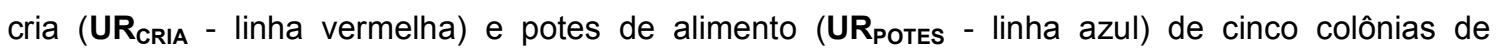
Scaptotrigona depilis, bem como a da caixa controle (UR $\mathbf{R}_{\text {CoNTR }}$ - linha roxa) e a ambiental $\left(\mathbf{U R}_{\mathrm{AMB}}\right.$ linha verde).

\section{Relação entre Umidade Relativa e Temperatura}

A correlação negativa entre a $T_{A M B}$ e a $U R_{A M B}$ foi significativa, ao contrário da ausência de correlação entre a $T_{\text {CONTR }}$ e a U $R_{\text {CONTR }}$ (Tabela 4). Este último resultado pode ter ocorrido por conta do comportamento da UR $R_{\text {CONTR, }}$ que foi bem diferente da UR $R_{\text {AMB }}$, que, aumentou seus valores no início do aumento da $T_{\text {CONTR }} e$, posteriormente, sofre um leve decréscimo (Fig. 7).

Tabela 4. Correlação de Pearson entre a temperatura e umidade relativa considerando-se as regiões dos favos de cria e potes de alimento de seis ninhos de Scaptotrigona depilis, em caixa vazia de madeira (controle) e a ambiental. Valores de $\mathrm{P}<0,05$ foram considerados significativos..

\begin{tabular}{ccccc} 
& \multicolumn{4}{c}{ Correlação UR x Temperatura } \\
\cline { 2 - 5 } & AMBIENTE & POTES & CRIA & CONTROLE \\
\hline Coeficiente de Correlação & $-0,99$ & $-0,92$ & $-0,69$ & $-0,008$ \\
de Pearson $(\rho)$ & 0 & $<0,05$ & $<0,05$ & 0,89
\end{tabular}


A UR $R_{\text {POTES }}$ e UR $R_{\text {CRIA }}$ mostram correlações negativas e significativas com a $T_{\text {POTES }}$ e $T_{\text {CRIA }}$ (Tabela 4), respectivamente.
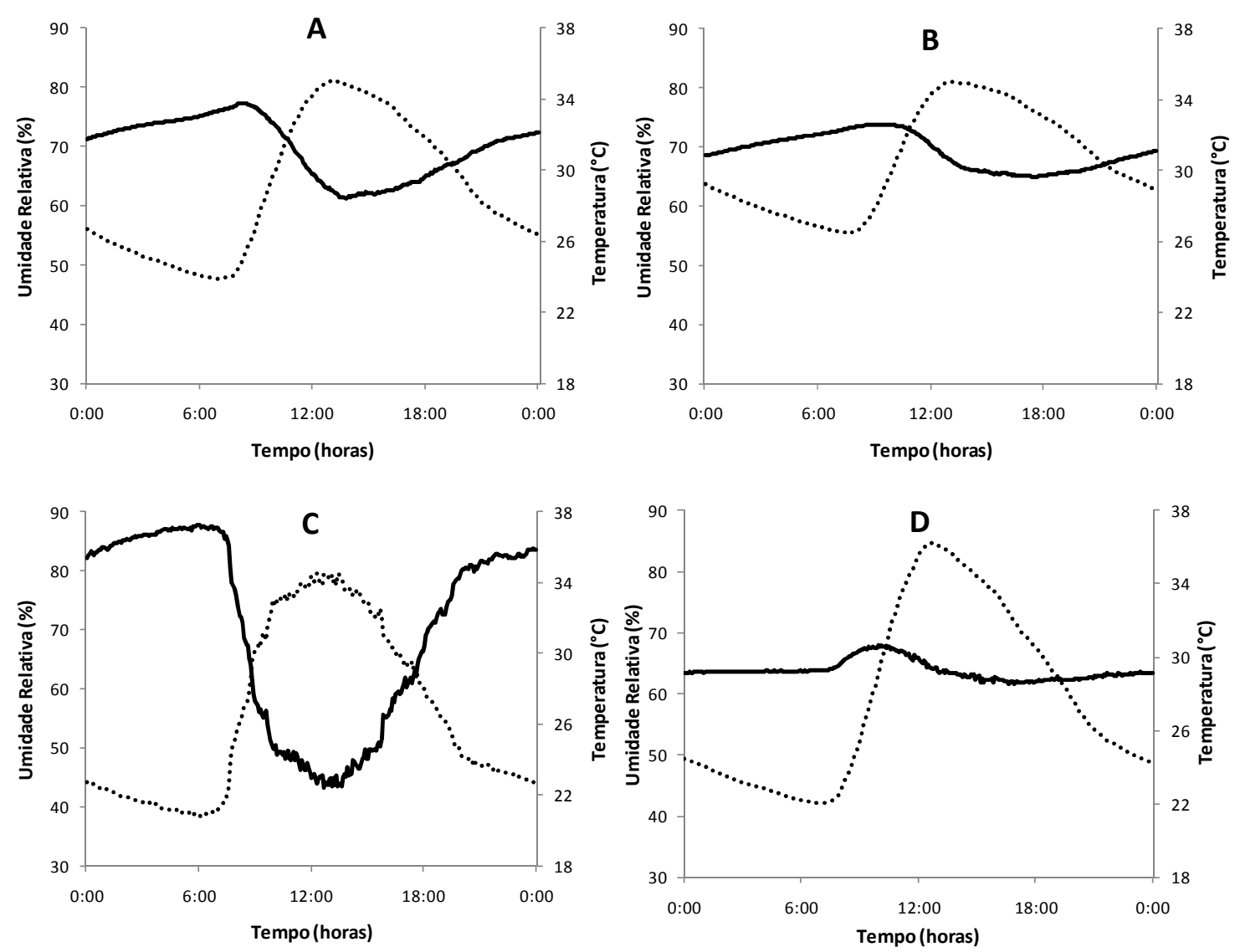

Fig. 7. Variação média da temperatura (linhas pontilhadas) e umidade relativa (linhas cheias) médias ( 5 colônias, 6 dias, $\mathrm{n}=30$ ) diárias nas quatro regiões amostradas ( $\mathbf{A}$ - Potes; $\mathbf{B}$ - Cria; $\mathbf{C}$ - Ambiente; e D - Controle).

\section{DISCUSSÃO}

\section{Capacidade termorregulatória}

Apesar das conclusões de Engels et al. (1995) (ver também a revisão de Jones e Oldroyd, 2007) de que $S$. postica dependeria quase que exclusivamente do local de nidificação para impedir o superaquecimento da região da cria, nossos resultados mostraram que colônias de $S$. depilis são capazes de diminuir a temperatura interna do ninho ( $T_{\text {CRIA }}$ ) quando exposta a temperaturas extremas ( $T_{\text {CONTR }}$ ) (maiores que $31,3^{\circ} \mathrm{C}$ ). Foram observadas diferenças máximas da $T_{\text {CONTR }}$ em relação à $T_{\text {CRIA, nos }}$ 
períodos quentes do dia, de $1,6^{\circ} \mathrm{C}$ em média, chegando a atingir valores de até $3,2^{\circ} \mathrm{C}$ em uma das colônias, mostrando uma capacidade temorregulatória considerável. Em média, a T CRIA variou de 26,5 a $35^{\circ} \mathrm{C}$. Além disso, a duração média do período de termorregulação foi maior que 4 horas, o que corresponde a quase 1/6 do período diário. Esta diferença entre a $T_{\text {CRIA }}$ e a $T_{\text {CONTR }}$ se deve a soma de dois tipos diferentes de controle de temperatura: (1) os mecanismos fisiológicos/comportamentais (ativos) e (2) os estruturais (passivos). Nossos resultados não possibilitaram distinguir a parcela de contribuição de cada um dos mecanismos

Nas abelhas do gênero Apis (sendo $A$. mellifera a espécie mais estudada), a capacidade de resfriamento do ninho é muito mais alta, quando comparada às abelhas sem ferrão. Elas mantêm a temperatura da cria dentro de um limite máximo de $36{ }^{\circ} \mathrm{C}$, mesmo quando as temperaturas ambientais chegam a quase $60{ }^{\circ} \mathrm{C}$ (Heinrich, 1981). Está claro que nas abelhas sem ferrão, incluindo Scaptotrigona, não há uma capacidade termorregulatória tão eficiente quanto à das abelhas do gênero Apis. A principal hipótese que explica a menor capacidade de resfriamento das abelhas sem ferrão é a de que o comportamento de nidificação em cavidades bastante isoladas seria suficiente para evitar o superaquecimento da cria (Heinrich, 1981; Engels et al., 1995; Jones e Oldroyd, 2007). As cavidades serviriam como isolantes térmicos, que diminuiriam a amplitude das variações de temperatura dentro da cavidade, diminuindo a pressão seletiva no sentido de adaptações para o controle da temperatura. A maioria dos autores (Zucchi et al., 1972; Heinrich, 1981; Roubik e Peralta, 1983; Engels et al., 1995) propõe que as principais adaptações das abelhas sem ferrão são voltadas para o aquecimento do ninho através da endotermia. Ou seja, o frio seria a principal pressão, levando a adaptações fisiológicas e/ou comportamentais que permitam as abelhas termorregularem ou aumentarem a sensibilidade térmica.

Apesar disso, as abelhas sem ferrão têm uma ampla distribuição geográfica de clima predominantemente tropical, onde as temperaturas do ar mínimas raramente são letais, ao contrário das máximas, que atingem níveis bastante extremos. Além disso, altas temperaturas possuem um efeito prejudicial muito maior na maioria dos animais, por conta do efeito causado, em última instância, nos processos metabólicos celulares (Angilletta, 2009), quando comparado com as baixas 
temperaturas a que as abelhas estão submetidas. Nós sugerimos que, apesar da variação da temperatura das cavidades de nidificação das abelhas sem ferrão não ser tão grande, existem adaptações (estruturais e comportamentais/fisiológicas) para o resfriamento do ninho de $S$. depilis que são capazes de diminuir significativamente a $\mathrm{T}_{\mathrm{CRIA}}$ durante períodos de temperaturas extremas. Além disso, A. mellifera, espécie filogeneticamente próxima dos Meliponini e o principal exemplo de inseto social com a maior capacidade de reduzir a temperatura do ninho, também nidifica em cavidades, mas apresenta complexos mecanismos ativos de resfriamento do ninho, mostrando que o isolamento térmico da cavidade não basta para explicar o controle das temperaturas internas do ninho, e que não existiria pressão seletiva para o sugimento de adaptações para resfriamento do ninho em espécies que nidificam em cavidades.

A menor capacidade termorregulatória de $S$. depilis (e nas abelhas sem ferrão em geral), quando comparada com $A$. mellifera, pode estar associada à capacidade de suportar variações maiores de temperatura. Isso faz com que performances de determinadas atividades não sejam tão eficientes, mas que possuem valores significativos em uma amplitude maior de temperaturas. Esta análise está baseada no conceito de sensibilidade térmica, que prevê que a temperatura influencia toda e qualquer atividade de um organismo (por conta da influência nas reações metabólicas), de maneira que o desempenho em uma dada atividade (performance) aumenta com a elevação da temperatura, atingindo uma temperatura ótima, a partir da qual passa a decair (em geral, abruptamente) até a temperatura letal (Huey e Kingsolver, 1989; Hochachka e Somero, 2002; Angilletta, 2009). Assim, os organismos podem ser classificados de acordo com a sensibilidade térmica para determinadas atividades, onde os organismos que possuem perfomances que ocorrem em pequenas faixas de temperatura são considerados termo-especialistas, e os que possuem um desempenho regular em um intervalo maior de temperaturas são considerados termo-generalistas (Angilletta, 2009). Portanto, o desempenho das atividades de $A$. mellifera ocorreriam, relativamente, em uma faixa estreita de temperaturas (espécie termo-especialista), do que quando comparada com $S$. depilis, que teria performance regulares de suas atividades dentro de uma faixa maior de temperaturas (termo-generalista), o que poderia explicar a menor precisão na termorregulação (ver também Capítulo 3). 
Outro aspecto, a ser considerado para explicar a menor capacidade termorregulatória de $S$. depilis ser relativamente menor que a de $A$. mellifera, é a diversidade genética das operárias, devido ao número de acasalamentos realizados pelas rainhas. Jones et al. (Jones et al., 2004) verificaram que colônias de $A$. mellifera com maior diversidade genética (devido aos múltiplos acasalamentos da rainha - poliandria) mantêm a temperatura do ninho mais constante do que as colônias menos diversas geneticamente (devido ao acasalamento único da rainha monandria). Um dos argumentos dados se refere à maior estabilidade num sistema poliândrico, pois a diversidade genética modula o limiar de resposta das operárias às variações de temperatura, evitando uma resposta exagerada da colônia às flutuações de temperatura. Porém, não é simplesmente a estrutura genética das colônias que causa a grande diferença na capacidade de controle da temperatura entre os dois grupos. Isso porque a diferença encontrada entre colônias de $A$. mellifera monândricas e poliândricas foi mínima (a média da temperatura dos ninhos dos dois grupos foi igual, diferindo apenas na variância, i.e. as temperaturas dos ninhos poliândricos foram mais estáveis). Assim, acreditamos que a condição de monandria (considerada como regra para as abelhas sem ferrão; veja Peters et al., 1999) não é a única causa da baixa precisão na termorregulação de S. depilis, quando comparada à de $A$. mellifera. Porém, esse é um aspecto a ser considerado e que pode ser um fator que explica a menor precisão do controle de temperatura em S. depilis, sendo necessários mais estudos relacionados com o assunto para se ter uma idéia melhor da importância da variação genética entre as operárias na realização e eficiência de tarefas.

Apesar dos benefícios, a termorregulação também apresenta custos (de risco de mortalidade, energéticos e de perda de oportunidades) que podem ser facilmente relacionados com o fitness (Angilletta, 2009). Operárias de S. depilis gastam tempo e energia em atividades de termorregulação, enquanto poderiam direcionar seus esforços para, por exemplo, produção de mais cria e coleta de recursos. Existe, portanto, um "trade-off' entre o custo e benefício da atividade termorregulatória que está no centro da questão da sensibilidade térmica e da regulação da temperatura em S. depilis. Nós sugerimos que os altos custos de manutenção de uma temperatura em uma faixa muito estreita em $S$. depilis poderiam ser maiores que os benefícios, porém considerando que nos extremos de temperatura os benefícios 
seriam maiores que os custos (no caso a morte ou a não reprodução), levando à sensibilidade térmica maior. Isto é, seria uma estratégia mais termo-generalista, porém com capacidade de termorregulação significativa para lidar com os extremos de temperatura, principalmente com as mais elevadas, que no ambiente em que vivem se encontram mais próximas da temperatura letal máxima.

Regulação da Umidade relativa (UR)

Como um primeiro registro da variação da umidade relativa em um ninho de uma espécie de abelha sem ferrão, nossos dados mostraram que a umidade relativa interna do ninho de $S$. depilis (representada pela UR POTES e UR $_{\text {CRIA }}$ ) é significativamente maior que a umidade relativa externa $\left(U R_{A M B}\right)$ e controle

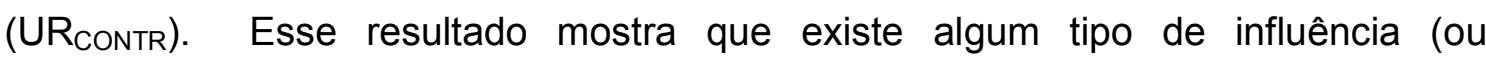
mecanismo de controle), fisiológica, comportamental ou estrutural, da presença das abelhas que altera a umidade relativa nessa espécie. A umidade relativa foi mantida em média a $69 \%$ na região de cria $\left(U_{\mathrm{CRIA}}\right)$ e mostrou a menor variação entre as regiões amostradas.

Ao contrário dos esforços realizados quanto à investigação da termorregulação em ninhos de $A$. mellifera, pouco foi investido nos estudos sobre a regulação da umidade, devido às dificuldades técnicas de mensuração dessa variável - apenas recentemente os sensores de pequeno porte foram desenvolvidos, possibilitando medir a umidade nas diferentes regiões do ninho - e também porque as abelhas melíferas não regulam a umidade tão precisamente quanto regulam a temperatura (Human et al., 2006). Os primeiros estudos sobre a regulação da umidade em $A$. mellifera concluíram que não havia um sistema de controle. Sugeriram que aglomerados de operárias durante baixas temperaturas e as altas taxas de evaporação de água durante altas temperaturas tenderiam a estabilizar a umidade (Simpson, 1961). Human et al. (2006) investigaram mais a fundo e com maior precisão a regulação da umidade. Eles verificaram que a presença das operárias influenciam a umidade, de maneira que existe um ajuste ativo (coleta de água) e/ou passivo (desidratação do néctar e transpiração dos adultos) da umidade relativa, que a mantém por volta de $40 \%$ durante o inverno, caracterizado pela seca extrema. Mais tarde Ellis et al. (2008) acrescentam que a ventilação é desencadeada 
por altos níveis de umidade relativa, demonstrando que esse é um comportamento ativo de regulação da umidade. Já em Bombus terrestris, foi verificado que o aumento da umidade relativa não conduziu a um comportamento de ventilação como resposta (Weidenmuller et al., 2002).

A diferença apresentada na média da umidade relativa entre $A$ mellifera (Human et al., 2006) e a encontrada para S. depilis deve ser interpretada cautelosamente. Não é correto afirmar que $S$. depilis controla mais eficientemente a umidade relativa, nem que mantém os níveis mais altos. As condições ambientais em cada experimento eram muito diferentes, tanto que a média umidade relativa da caixa controle (UR $\left.\mathrm{R}_{\mathrm{CONTR}}\right)$ por este estudo $(63,8 \%)$ se mostrou bem maior que a média encontrada para $A$. mellifera (40\%; Human et al., 2006), nos levando a concluir que as condições eram bem diferentes.

A umidade do ninho nas abelhas determina o quanto os indivíduos estão sujeitos à desidratação através da transpiração cuticular e respiratória (Ellis et al., 2008). Os ovos da abelha Apis mellifera não eclodem em umidades relativas inferiores a 50\%, apresentando maior taxa de eclosão em umidades relativas entre 90 e 95\% (Doull, 1976). Além disso, Kraus \& Velthuis (1997) demonstraram que altos níveis de umidade relativa diminuem a proliferação do ácaro parasita Varroa jacobsoni.

Nas abelhas sem ferrão, aparentemente, a umidade relativa está bastante relacionada com o desenvolvimento da cria. Durante o aprimoramento das técnicas de criação in vitro de rainhas de S. depilis, Menezes (2010) verificou que as larvas se desenvolvem melhor em umidades relativas altas (próximas a 100\%) durante as fases iniciais de desenvolvimento, seguidas por um decréscimo relativamente pequeno $(75 \%)$ durante a fase pupal. Quando a umidade não foi controlada, tanto as larvas quanto o alimento larval desidrataram, levando à morte da larva. Conforme nossos dados mostraram, a umidade relativa da região de cria em $S$. depilis varia dentro de uma faixa abaixo de $75 \%$, a menor das umidades relativas utilizadas por Menezes (2010). Porém, pode ser que os níveis de umidade relativa não precisam, necessariamente, ser tão altos na região de cria, mas podem ser criados microclimas dentro de cada célula de cria, em consequência do conteúdo líquido do alimento larval, que poderiam gerar os níveis necessários para a sobrevivência das 
larvas. A umidade da região da cria deve ser o suficiente para evitar a desidratação da cera que constitui a célula de cria, evitando a perda de água do alimento larval.

Apesar disso, a manutenção de altos níveis de umidade relativa pode dificultar alguns processos relacionados à conservação dos recursos alimentares estocados pelas abelhas. Camargo et al. (1992) sugeririam que a diminuição da umidade do pólen de Ptilotrigona pode servir como método de conservação, evitando a proliferação de microorganismos indesejáveis. Adicionalmente, o processo de desidratação do néctar para produção do mel é uma forma de evitar a proliferação de organismos indesejáveis nos recursos energéticos através de concentrações de açúcares e requer uma umidade relativa baixa, para que a água do néctar coletado evapore (Human et al., 2006; Nicolson, 2009).

A existência desse trade-off pode dificultar a regulação precisa da umidade relativa dentro dos ninhos das abelhas, uma vez que o desenvolvimento da cria e a desidratação do néctar requerem umidades relativas opostas (Human et al., 2006). Particularmente, em $S$. depilis pode existir uma separação física nos dois processos, de modo que a desidratação do néctar ocorra em uma região diferente da cria (o invólucro pode ajudar no isolamento dessa região). Observando a variação diária da umidade relativa nas diferentes regiões do ninho (Fig. 6), verificamos que a UR $R_{P O T E S}$ sofre um decréscimo repentino no início do dia, passando a mostrar valores menores

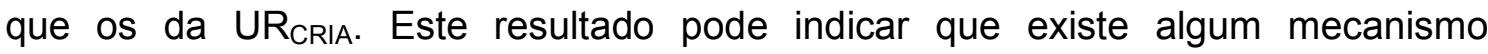
(provavelmente a ventilação) que diminui a umidade relativa na região dos potes durante o dia, para que a desidratação do néctar coletado aconteça mais facilmente (em A. mellifera, a desidratação ativa do néctar ocorre somente durante o dia, concomitantemente à coleta de néctar (Human et al., 2006). Além do isolamento dos favos de cria, provavelmente, o invólucro também sirva como uma barreira para a diminuição da umidade relativa nessa região.

O comportamento de ventilação pode ser o principal mecanismo para diminuir a umidade relativa do ninho, através da eliminação de ar com altos níveis de umidade e a consequente entrada de ar mais seco. Esse comportamento estaria associado à evaporação/desidratação do néctar e à coleta ativa de água (ver Capítulo 2), que são os mecanismos que aumentam a umidade relativa, de maneira que a umidade relativa pode ser ajustada dentro de limites discretos. Porém, podem existir outros trade-offs (além do apontado anteriormente para conservação e 
desidratação do néctar) que podem prejudicar o controle da umidade relativa. $A$ ventilação e a coleta de água são mecanismos utilizados para controle da temperatura (ver Capítulo 2) e concentração de gases $\left(\mathrm{CO}_{2} / \mathrm{O}_{2}\right)$ do ninho (Simpson, 1961; Weidenmüller et al., 2002). A regulação destas variáveis climáticas pode implicar em uma mudança inadequada na umidade relativa do ninho e vice-versa.

A regulação da umidade relativa em $S$. depilis parece estar, portanto, sujeita a vários trade-offs com a regulação de outros fatores climáticos importantes para o desempenho das colônias (temperatura e concentração de gases), dificultando a manutenção de uma umidade relativa ótima. Aparentemente, variações não muito drásticas acabam por não afetar o desempenho das atividades dos adultos e do desenvolvimento dos imaturos. Porém, é possível que existam mecanismos de controle da umidade relativa em $S$. depilis, assim como já verificado para $A$. mellifera (Ellis et al., 2008). Adicionalmente aos mecanismos passivos (transpiração dos adultos e imaturos e desidratação do néctar) e ativos (coleta de água e ventilação) de controle da umidade já verificados para $A$. mellifera (Ellis et al., 2008; Nicolson, 2009), pode ser que em $S$. depilis, bem como outras espécies de abelhas sem ferrão, o acúmulo nos ninhos de lixo, composto por abelhas mortas, restos de casulos e fezes (Roubik, 2006), pode ser uma fonte de umidade, já que em várias espécies o lixo colocado posteriormente para fora das colônias é aparentemente bem seco (observação pessoal). Ellis et al. (2010) mostraram que os casulos de seda de operárias eclodidas nos ninhos de A. mellifera, podem atuar como estoques de água, absorvendo cerca de $11 \%$ de sua massa em água, sendo que o lixo nos Meliponini poderiam ter a mesma função, uma vez que são compostos, em grande parte, por casulos de operárias recém eclodidas (Nogueira-Neto, 1997). Algumas espécies do gênero Melipona eliminam um líquido viscoso de cor marrom pela entrada da colônia que pode ser o resultado do acúmulo e condensação da umidade dentro da colônia (observação pessoal).

Apesar de todos estes mecanismos de regulação da umidade relativa, 0 simples fato da nidificação em cavidades aparenta ser a principal forma de manutenção de um alto nível de umidade relativa. Nossos resultados mostraram uma grande diferença entre a média e a variação diária da $U R_{A M B}$ e $U R_{C O N T R}$ (Fig. 6). A variação na umidade relativa da caixa controle é muito menor que a do ambiente e 
muito próxima da $U R_{\mathrm{CRIA}}$ (Fig. 6). O local de nidificação (no caso a caixa de madeira) tem, portanto, importância fundamental na manutenção da umidade relativa.

\section{Relação Umidade Relativa-Temperatura}

A umidade relativa possui uma relação estreita com a temperatura (referência). A umidade relativa mede a quantidade de umidade absoluta presente no ar em relação à quantidade máxima que o ar pode suportar até sua saturação (ponto em que o vapor d'água se transforma em líquido), i.e., a porcentagem de vapor d'água presente no ar em relação à capacidade máxima de vapor que pode estar presente (Varejão-Silva, 2005). A temperatura do ar determina a quantidade de vapor d'água necessária para atingir a saturação, de modo que quanto maior a temperatura maior a quantidade de água que pode ser dissolvida no ar (Gray e Wise, 1957). A umidade relativa é calculada segundo a seguinte fórmula:

$$
U R=\frac{e}{e_{s}}
$$

na qual "UR" representa a umidade relativa, "e" representa a umidade absoluta (quantidade de vapor dissolvido no ar) e " $e_{s}$ " representa o ponto de saturação (quantidade máxima de vapor que pode ser dissolvido em determinada temperatura (Gray e Wise, 1957).

A umidade relativa indica, então, o quão próximo o ar está da saturação, ao invés de indicar a real quantidade de vapor d'água no ar. Além disso, conforme a temperatura do ar aumenta, se mantido constante a umidade absoluta, a umidade relativa diminui, por conta do aumento da capacidade de saturação do ar. Uma consequência da diminuição da umidade relativa é que a taxa de evaporação - e consequente desidratação - aumenta (Varejão-Silva, 2005).

A forte correlação negativa entre a temperatura e umidade relativa ambientais $\left(T_{A M B} \times U_{A M B} ; \rho=-0,99, p=0\right.$; Tabela $\left.q\right)$ se deve ao fato de que conforme a temperatura aumenta, a umidade absoluta potencial que pode ser dissolvida no ar aumenta, diminuindo a proporção da umidade presente em relação à umidade potencial, i. e., diminuindo a umidade relativa (Fig 7. C).

Ao contrário da UR $\mathrm{R}_{\mathrm{AMB}}$, a UR $\mathrm{R}_{\mathrm{CONTR}}$ aumentou conforme a temperatura aumentou (Fig. 7 D). Nossa hipótese é que esse fenômeno pode ter ocorrido por causa do microclima formado no interior da cavidade da caixa, o qual não deixa a umidade absoluta diminuir, porque o vapor d'água fica preso na cavidade. $O$ 
aumento da temperatura causa um aumento na capacidade de saturação do ar, que levaria à diminuição da umidade relativa, porém a evaporação da água que pode ter se acumulado durante a madrugada dentro da cavidade pode ter aumentado a umidade absoluta ainda mais, aumentando a umidade relativa. A umidade absoluta vai então diminuindo durante o passar do dia, à medida que se difunde pelas frestas e pelo orifício de entrada da caixa controle, diminuindo a umidade relativa (Fig. 7-D).

A presença das abelhas nas caixas muda a relação da umidade relativa com a temperatura, quando comparados com a caixa controle, alcançando coeficientes de correlações mais parecidos com os da UR $R_{A M B} \times T_{A M B}$ (Fig. 7. - A e B; Tabela 4). Nós sugerimos que este fenômeno pode ser consequência da ventilação (ver Capítulo 2), tendo como função o resfriamento do ninho. Como resposta ao aumento da temperatura interna do ninho as abelhas aumentariam a ventilação do ninho através do batimento das asas, bombeando ar com alta umidade absoluta para fora do ninho, e consequentemente forçando a entrada de ar com baixa umidade absoluta para dentro do ninho. Este processo diminuiria a umidade relativa interna, aumentando a probabilidade de evaporação da água internamente ao ninho (presente no néctar e coletada ativamente - ver Capítulo 2), processo que promove a perda de calor e consequentemente o resfriamento do ninho. Em analogia com o sistema de resfriamento dos mamíferos, de acordo com a nossa hipótese as abelhas apresentariam um comportamento de "sudorese", que conforme acontece com os mamíferos, tem maior eficiência em ambientes com baixa umidade relativa, facilitando o processo de evaporação da água e consequentemente da perda de calor.

As formigas Acromyrmex heyeri (Hymenoptera, Formicidae) dependem de altos níveis de umidade relativa no ninho, principalmente para o pleno desenvolvimento dos jardins de fungos dentro de seus ninhos que servem de alimento para as larvas e adultos. As operárias respondem às variações de temperatura através de modificações na arquitetura do ninho, abrindo ou fechando orifícios na superfície do ninho, que promovem o resfriamento interno (Bollazzi e Roces, 2010). Bollazzi e Roces (2010) verificaram que existe um trade-off entre a regulação da umidade relativa e da temperatura do ninho nesta espécie, uma vez que as aberturas utilizadas para resfriar o ninho durante exposições à temperaturas extremas também acabam diminuindo a umidade relativa interna. Os autores 
demonstraram que em umidades relativas experimentalmente baixas as operárias fecharam os orifícios a temperaturas que em anteriormente, em umidades relativas mais altas, desencadearam o comportamento oposto, mostrando que, neste caso, as formigas parecem priorizar a manutenção da umidade do ninho.

Aparentemente este mesmo trade-off acontece em $S$. depilis. Os esforços para a manutenção de uma umidade relativa alta e melhor para o desenvolvimento da cria rivaliza com os esforços para o resfriamento do ninho em condições de altas temperaturas, além da necessidade de desidratação do néctar para melhor conservação. Nós sugerimos que $S$. depilis parece priorizar o resfriamento do ninho em condições extremas a manter os níveis altos de umidade relativa. 


\section{REFERÊNCIAS BIBLIOGRÁFICAS}

AMANO, K.; NEMOTO, T.; HEARD, T. A. What are stingless bees, and why and how to use them as crop pollinators? a review. Jarq-Japan Agricultural Research Quarterly, v. 34, n. 3, p. 183-190, 2000.

ANGILLETTA, M. J. Thermal adaptation: a theoretical and empirical synthesis. Oxford University Press, USA, 2009.

BOLLAZZI, M.; ROCES, F. Leaf-cutting ant workers (Acromyrmex heyeri) trade off nest thermoregulation for humidity control. Journal of Ethology, v. 28, n. 2, p. 399-403, 2010.

CAMARGO, J. M. F. et al. Notas previas sobre a bionomia de Ptilotrigona lurida (Hymenoptera, Apidae, Meliponinae): associacao de leveduras em polen estocado. Zoologia, v. 8, n.2, p. 391-395, 1992.

CAMARGO, J. M. F.; PEDRO, S. R. M. Meliponini Lepeletier, 1836. In: MOURE, J. S.;URBAN, D., et al (Ed.). Catalogue of Bees (Hymenoptera, Apoidea) in the Neotropical Region. Curitiba: Sociedade Brasileira de Entomologia, 2007. p.272-578.

CORTOPASSI-LAURINO, M. et al. Global meliponiculture: challenges and opportunities. Apidologie, v. 37, n. 2, p. 275-292, Mar-Apr 2006.

COSTA, L.; CRISTINO VENTURIERI, G. Caixas incubadoras para a formação e observação de colônias de abelhas sem ferão (Apidae: Meliponina). Bioscience Journal, v. 23, n. 0, 2007.

DEUTSCH, C. A. et al. Impacts of climate warming on terrestrial ectotherms across latitude. Proceedings of the National Academy of Sciences, v. 105, n. 18, p. 6668, 2008.

DOULL, K. M. The effects of different humidities on the hatch of the eggs of honeybees. Apidologie, v. 7, n. 1, p. 61-66, 1976.

ELLIS, M. B. et al. Hygropreference and brood care in the honeybee (Apis mellifera). Journal of Insect Physiology, v. 54, n. 12, p. 1516-1521, 2008. $\overline{429-433}, 2010$.

Brood comb as a humidity buffer in honeybee nests. Naturwissenschaften, v. 97 , n. 4, p.

ENGELS, W.; ROSENKRANZ, P.; ENGELS, E. Thermoregulation in the nest of the neotropical stingless bee Scaptotrigona postica and a hypothesis on the evolution of temperature homeostasis in highly eusocial bees. Studies on Neotropical Fauna and Environment, v. 30, n. 4, p. 193-205, Dec 1995.

FLETCHER, D.; CREWE, R. Nest Structure and Thermoregulation in the Stingless Bee Trigona (Plebeina) denoiti Vachal(Hymenoptera: Apidae). Journal of the Entomological Society of Southern Africa, v. 44, n. 2, p. 183-196, 1981.

GRAY, D. E.; WISE, H. American Institute of Physics Handbook. New York: McGraw-Hill 1957. 2364

HEINRICH, B. Insect thermoregulation. Wiley Interscience John Wiley \& Sons Inc., 1981.

. Bumblebees out in the cold. In: The hot-blooded Insects, v. -, p. 227-276, 1993.

HOCHACHKA, P. W.; SOMERO, G. N. Biochemical adaptation: mechanism and process in physiological evolution. Oxford University Press, USA, 2002.

HUEY, R. B.; KINGSOLVER, J. G. Evolution of thermal sensitivity of ectotherm performance. Trends in Ecology \& Evolution, v. 4, n. 5, p. 131-135, 1989. 
HUMAN, H.; NICOLSON, S. W.; DIETEMANN, V. Do honeybees, Apis mellifera scutellata, regulate humidity in their nest? Naturwissenschaften, v. 93, n. 8, p. 397-401, 2006.

JONES, J. C. et al. Honey bee nest thermoregulation: Diversity promotes stability. Science, v. 305, n. 5682, p. 402-404, Jul 2004.

JONES, J. C.; OLDROYD, B. P. Nest thermoregulation in social insects. Advances in Insect Physiology, v. 33, p. 153-191, 2007.

KRAUS, B.; VELTHUIS, H. H. W. High humidity in the honey bee (Apis mellifera L) brood nest limits reproduction of the parasitic mite Varroa jacobsoni Oud. Naturwissenschaften, v. 84, n. 5, p. 217218, 1997.

MARENGO, J. A. et al. Future change of temperature and precipitation extremes in South America as derived from the PRECIS regional climate modeling system. international Journal of Climatology, v. 29, n. 15, p. 2241-2255, 2009.

MENEZES, C. A produção de rainhas e a multiplicação de colônias em Scaptotrigona aff. depilis (Hymenoptera, Apidae, Meliponini). 2010. 110p. Tese (Doutorado). Entomologia, Universidade de São Paulo, Ribeirão Preto.

MOO-VALLE, $\mathrm{H}$. et al. Patterns of intranidal temperature fluctuation for Melipona beecheii colonies in natural nesting cavities. Journal of Apicultural Research, v. 39, n. 1-2, p. 3-7, 2000.

MORITZ, R. F. A.; CREWE, R. M. Air Ventilation in Nests of 2 African Stingless Bees Trigona denoiti and Trigona gribodoi. Experientia, v. 44, n. 11-12, p. 1024-1027, 1988.

Air Ventilation in Nests of Two African Stingless Bees Trigona denoiti and Trigona gribodoi. Experientia Basel, v. 44, n. 11-12, p. 1024-1027, 1988.

NICOLSON, S. W. Water homeostasis in bees, with the emphasis on sociality. Journal of Experimental Biology, v. 212, n. 3, p. 429-434, 2009.

NOGUEIRA-NETO, P. Vida e criação de abelhas indígenas sem ferrão. São Paulo: Editora Nogueirapis, 1997. $445 \mathrm{p}$.

PETERS, J. M. et al. Mate number, kin selection and social conflicts in stingless bees and honeybees. Proceedings of the Royal Society B: Biological Sciences, v. 266, n. 1417, p. 379, 1999.

PRONI, E. A.; HEBLING, M. J. A. Thermoregulation and respiratory metabolism in two Brazilian stingless bee subspecies of different climatic distribution, Tetragonisca angustula fiebrigi and $T$. a. angustula (Hymenoptera: Apidae: Meliponinae). Entomologia Generalis, v. 20, n. 4, p. 281-289, 1996.

ROLDÃO, Y.; HRNCIR, M. Thermal investigations of nests of the stingless bee Melipona scutellaris. In: Proceedings of the 46th Annual Meeting of the Animal Behavior Society. Pirenópolis, p. 141142, 2009.

ROUBIK, D. W. Stingless bee nesting biology. Apidologie, v. 37, n. 2, p. 124-143, Mar-Apr 2006.

ROUBIK, D. W.; PERALTA, F. J. A. Thermodynamics in Nests of 2 Melipona-spp in Brazil. Acta Amazonica, v. 13, n. 2, p. 453-466, 1983 (recd. 1984) 1983.

SEELEY, T. D.; VISSCHER, P. K. Survival of honeybees in cold climates: the critical timing of colony growth and reproduction. Ecol. Entom., v. 10, p. 81-88, 1985.

SIMPSON, J. Nest Climate Regulation in Honey Bee Colonie. Science, v. 133, n. 3461, p. 1327, 1961. 
SOUTHWICK, E. E. Cooperative metabolism in honey bees: an alternative to antifreeze and hibernation. Journal of Thermal Biology, v. 12, n. 2, p. 155-158, 1987.

SUNG, I.; YAMANE, S.; HOZUMI, S. Thermal Characteristics of Nests of the Taiwanese Stingless Bee Trigona ventralis hoozana (Hymenoptera: Apidae). Zoological Studies, v. 47, n. 4, p. 417-428, 2008.

TORRES, A.; HOFFMANN, W.; LAMPRECHT, I. Thermal investigations of a nest of the stingless bee Tetragonisca angustula Illiger in Colombia. Thermochimica Acta, v. 458, p. 118-123, 2007.

. Thermal investigations of a nest of the stingless bee Trigona (Frieseomelitta) nigra paupera provancher in colombia. Journal of Thermal Analysis and Calorimetry, v. 95, n. 3, p. 737-741, 2009.

VAREJÃO-SILVA, M. A. Meteorologia e climatologia: versão digital. Recife: INMET, 2005. 133

VOGT, F. D. Thermoregulation in bumble bee colonies. I. Thermoregulatory versus brood maintenance behaviors during acute changes in ambient temperatures. Physiol. Zool., v. 59 (1), p. 55-59, 1986a.

- Thermoregulation in bumble bee colonies. II. Behavioral and demographic variation throughout the colony cycle. Physiol. Zool., v. 59 (1), p. 60-68, $1986 \mathrm{~b}$.

WEIDENMULLER, A. The control of nest climate in bumblebee (Bombus terrestris) colonies: interindividual variability and self reinforcement in fanning response. Behavioral Ecology, v. 15, n. 1, p. 120-128, 2004.

WEIDENMULLER, A.; KLEINEIDAM, C.; TAUTZ, J. Collective control of nest climate parameters in bumblebee colonies. Animal Behaviour, v. 63, p. 1065-1071, 2002.

ZUCCHI, R.; SAKAGAMI, S.; CRUZ-LANDIM, C. Capacidade termoreguladora em Trigona spinipes e em algumas outras espécies de abelhas sem ferrão (Hymenoptera: Apidae: Meliponinae). Homenagem à WE Kerr, p. 301-309, 1972. 


\section{CAPÍTULO 2. Mecanismos de resfriamento do ninho em colônias de Scaptotrigona depilis (Apidae, Meliponini)}

\section{RESUMO}

A partir dos resultados obtidos previamente que mostraram que Scaptotrigona depilis é capaz de resfriar o ninho, nosso objetivo foi investigar quais os mecanismos que esta espécie utiliza para esta tarefa. Especificamente nosso objetivo foi verificar se os mecanismos comportamentais de ventilação e coleta ativa de água são desencadeados pelo aumento da temperatura (interna ou externa ao ninho) e se existe uma relação positiva entre a temperatura e os esforços para resfriar o ninho. Nossos resultados mostraram que tanto o comportamento de ventilação quanto o de coleta água se tornam mais frequentes conforme a temperatura do ninho aumenta. Pela primeira vez em uma espécie de abelha sem ferrão foi demonstrado que a coleta de água ocorre em condições naturais e em um nível colonial, ou seja, operárias trazendo água para a colônia em resposta ao superaquecimento do ninho. Sugerimos que os dois comportamentos estão intimamente relacionados. Isso significa que a ventilação por si só não diminui significativamente a temperatura do ninho, mas deve contribuir para a diminuição da umidade relativa do ninho, facilitando a evaporação da água coletada e consequentemente a liberação de calor. Portanto, o mecanismo de resfriamento nas abelhas sociais funcionaria de maneira análoga à sudorese dos mamíferos.

\section{INTRODUÇÃO}

Na maioria dos estudos sobre a termorregulação em abelhas sem ferrão o foco principal está na capacidade das abelhas em esquentar o ninho, ou seja, em aumentar a temperatura do ninho em relação à temperatura ambiente (Tabela 1; Capítulo 1). Consequentemente, a principal discussão está centrada em responder como as abelhas aumentam a temperatura do ninho. Por conta dos inúmeros estudos usando Apis mellifera como organismo modelo, sabe-se que o principal mecanismo de produção de calor metabólico é através do acionamento dos músculos das asas, desacolplados das mesmas para evitar o batimento (Winston, 1987; Kleinhenz et al., 2003). Nas abelhas sem ferrão ainda não existem evidências sobre como o calor é produzido. Duas hipóteses, não necessariamente exclusivas, mas que podem ser complementares, para explicar a produção de calor foram formuladas. Engels et al. (1995) sugeriram que, assim como ocorre em A. mellifera, as operárias adultas produziriam calor metabólico (provavelmente através de vibrações dos músculos desacoplados das asas), que seria transferido para a cria e 
outras regiões do ninho. Roubik e Peralta (1983) sugeriram que a própria cria (larvas e pupas) seria a fonte de calor, que seria então mantido dentro do ninho graças ao invólucro e outras estruturas isolantes, porém os dois autores não ofereceram nenhum indício que suporte suas respectivas hipóteses (Heinrich, 1993).

Os mecanismos de resfriamento do ninho nunca foram abordados para as abelhas sem ferrão. A maioria dos autores sugere que o principal fator que contribui para impedir o superaquecimento do ninho é o local de nidificação isolado termicamente (Engels et al., 1995; Jones e Oldroyd, 2007), porém nenhum mecanismo foi estudado. Também é sugerido que podem existir estruturas do ninho que facilitem o resfriamento. O batume, uma estrutura construída com barro e resina usada para vedar frestas do ninho e/ou delimitar a cavidade onde o ninho está alojado, muitas vezes possui poros muito pequenos que permitem a passagem de ar e, por isso, é conhecido como batume crivado (Nogueira-Neto, 1997).

O comportamento de ventilação do ninho já foi observado em muitas espécies de Meliponini (Nogueira-Neto, 1948; Engels et al., 1995; Macías-Macías et al., 2011). Embora nenhum estudo tenha correlacionado a temperatura com esse comportamento, observações esparsas realizadas por Engels (1995) indicam que a ventilação realizada pelas operárias está associada ao processo de resfriamento do ninho. Macías-Macías et al. (2011) mostraram que operárias de Melipona colimana realizam o comportamento de ventilação em condições artificiais de confinamento, sob temperaturas de $40^{\circ} \mathrm{C}$, sugerindo que o comportamento está relacionado com o resfriamento do ninho. Adicionalmente alguns autores sugerem que a ventilação nos Meliponini seja associada ao batume crivado. Moritz e Crewe (1988) estudando Trigona denotii, uma espécie que nidifica em cavidades no solo (cerca de 0,6 m de profundidade), sugeriram que o comportamento de ventilação está associado com a renovação do oxigênio e retirada do gás carbônico das cavidades do ninho, e não com a termorregulação.

A ventilação do ninho é um processo muito bem conhecido nos Apini e nos Bombini. Em ambos os grupos é um mecanismo de resfriamento do ninho, e consiste no batimento das asas de operárias, geralmente alinhadas, que cria fluxos de ar. Em colônias que nidificam em cavidades com uma única abertura, o fluxo de ar tende a sair ativamente pela abertura, de modo que correntes de ar entram passivamente, em função da menor pressão interna (Southwick e Moritz, 1987). O 
comportamento de ventilação, tanto nos Bombini quanto nos Apini, é desencadeado pelo aumento da temperatura e da concentração de $\mathrm{CO}_{2}$ no interior das colônias, sugerindo que este comportamento é utilizado como forma de controle destas variáveis (Simpson, 1961; Weidenmuller et al., 2002). Em Apis mellifera ele também é desencadeado pelo aumento da umidade relativa (Ellis et al., 2008).

O resfriamento evaporativo (evaporative cooling) é bem conhecido em $A$. mellifera, porém nunca foi constatado em Bombini e Meliponini. Sabe-se que muitas vespas sociais realizam este comportamento de uma maneira muito semelhante às abelhas melíferas (Jones e Oldroyd, 2007). Esse processo consiste na coleta ativa de água por forrageiras, que por sua vez podem transferí-la para operárias receptoras dentro do ninho. A água pode ser depositada diretamente sobre as margens das células de cria, ou mesmo evaporada nas partes bucais das operárias (tongue lashing; Simpson, 1961). A evaporação da água libera grande quantidade de energia, diminuindo a temperatura do ninho. Este comportamento sempre está associado com a ventilação do ninho, que faz com que o ar saturado de vapor d'água seja reposto por ar com uma umidade relativa menor, que facilite a evaporação (Gray e Wise, 1957). A água também é importante na regulação da temperatura das próprias operárias - através da evaporação - uma vez que o consumo de água aumenta consideravelmente quando operárias estão submetidas a temperaturas acima de $38^{\circ} \mathrm{C}$ (Heinrich, 1993; Mardan e Kevan, 2002; Nicolson, 2009).

Apesar de muitos autores observarem abelhas da tribo Meliponini coletando água ativamente, nunca este comportamento foi relacionado com algum mecanismo de termorregulação (Roubik e Peralta, 1983; Engels et al., 1995; Nogueira-Neto, 1997), apenas algumas especulações, por conta das observações desse comportamento serem realizadas em dias quentes. Recentemente Macías-Macías et al. (2011), realizaram bioensaios em condições artificiais e verificaram que operárias de Melipona colimana coletaram água e espalharam sobre as caixas em que estavam confinadas, quando submetidas a temperaturas de $40^{\circ} \mathrm{C}$. Os autores sugeriram que este comportamento é um reflexo do comportamento natural de coletar água e espalhar sobre as estruturas do ninho, para realizar o resframento evaporativo, porém atentam para a importância de se testar esta hipótese em um contexto colonial natural. Sabe-se que abelhas necessitam de água para manter o 
balanço osmótico corporal e para o alimento larval líquido, sugerindo que a coleta observada em abelhas sem ferrão tenham esses propósitos (Jones e Oldroyd, 2007). Geralmente a água é coletada "incidentalmente" ao coletarem néctar, que é composto por água em sua maior parte (Kuhnholz e Seeley, 1997).

Fica claro, portanto, que o conhecimento sobre os mecanismos de resfriamento do ninho são bastante escassos nos Meliponini. Sabe-se que existe a ventilação, mas não há um trabalho demonstrando a relação deste comportamento com a temperatura do ninho. Além disso, existe um consenso entre os autores de que as abelhas não utilizam a evaporação da água como mecanismo termorregulatório, apenas pelo fato de nunca terem observado este comportamento (Roubik e Peralta, 1983; Engels et al., 1995).

Partindo de observações anteriores sobre a capacidade de resfriamento do ninho em Scaptotrigona depilis (Ver capítulo 1), e da importância para a cria para a manter a temperatura do ninho inferior a um limiar crítico máximo (Ver capítulo 3), nossa hipótese é de que existem mecanismos complexos de resfriamento do ninho em resposta a elevações de temperatura. As operárias devem responder ao aumento de temperatura do ninho, através da ventilação e da coleta de água, quando um limiar máximo de temperatura é atingindo.

\section{Objetivos}

Dentro deste contexto, nosso objetivo geral é responder à pergunta "quais os mecanismos que $S$. depilis utiliza para resfriar o ninho?”. Especificamente vamos verificar se os mecanismos comportamentais de ventilação e coleta ativa de água são desencadeados pelo aumento da temperatura (interna ou externa ao ninho) e se existe uma relação positiva entre a temperatura e os esforços para resfriar o ninho (i.e. coleta de água e ventilação). Adicionalmente vamos investigar se a ventilação está relacionada com o resfriamento evaporativo. Esperamos encontrar uma diminuição da umidade relativa no interior do ninho, de maneira que facilite a evaporação da água (ou do néctar) e, consequentemente, o aumento da dissipação do calor. 


\section{MATERIAIS E MÉTODOS}

\section{Coleta de água}

Foram utilizadas duas colônias de Scaptotrigona depilis (C1 e C2), acondicionadas em caixas de madeira e monitorada com sensores, conforme descrito na metodologia do Capítulo 1. Os sensores monitoraram as temperaturas (T) e umidade relativa (UR) da cria ( $\left.T_{\mathrm{CRIA}} / \mathrm{UR}_{\mathrm{CRIA}}\right)$, potes de alimento ( $\left.T_{\text {POTES }} / \mathrm{UR}_{\mathrm{POTES}}\right)$, ambiente $\left(\mathrm{T}_{\mathrm{AMB}} / \mathrm{UR}_{\mathrm{AMB}}\right)$ e caixa de madeira vazia ( $\mathrm{T}_{\text {CONTR }} / \mathrm{UR}_{\mathrm{CONTR}}$ ), a cada cinco minutos. A condição de superaquecimento foi obtida naturalmente, expondo-se as caixas ao sol em dias quentes, quando a temperatura ambiente era superior a $34^{\circ} \mathrm{C}$ (de fevereiro a março).

À entrada das colônias foram acopladas mangueiras plásticas transparentes de $15 \mathrm{~cm}$ de comprimento e $4 \mathrm{~cm}$ de diâmetro. Uma abertura de $2 \times 3 \mathrm{~cm}$ foi feita na mangueira próximo à inserção com a caixa, por onde foram coletadas as forrageiras (Fig. 1A).

Iniciando-se às 08:00h e finalizando às 17:00h, cerca de cinco forrageiras que entravam na colônia foram coletadas em intervalos de uma hora, com o auxílio de um sugador de abelhas por meio da janela aberta na mangueira (Fig. 1A). As operárias escolhidas não carregavam pólen nas corbículas, indicando serem forrageiras de néctar ou água.

A fim obter o líquido regurgitado das forrageiras capturadas, utilizamos $\mathrm{CO}_{2}$ para facilitar o manuseio e pressionamos o abdômen na direção dorso-ventral (Fig. 1B). O conteúdo foi coletado com um capilar posicionado entre as mandíbulas da forrageira, que imediatamente foi liberada (Fig. 1C). O conteúdo do capilar foi colocado em um refratômetro digital (Krüss Optronic - Alemanha - DR201-95) para determinação de concentração de açúcares (\%)(Fig. 1D e E). Caso o volume do conteúdo fosse inferior a $7 \mu \mathrm{L}$ e, portanto, não fosse suficiente para medição no refratômetro, ele era descartado. As medições foram realizadas em 10 dias não consecutivos. Os líquidos regurgitados foram considerados como água quando suas concentrações de soluto eram inferiores a 2\% (Leonhardt et al., 2007). 


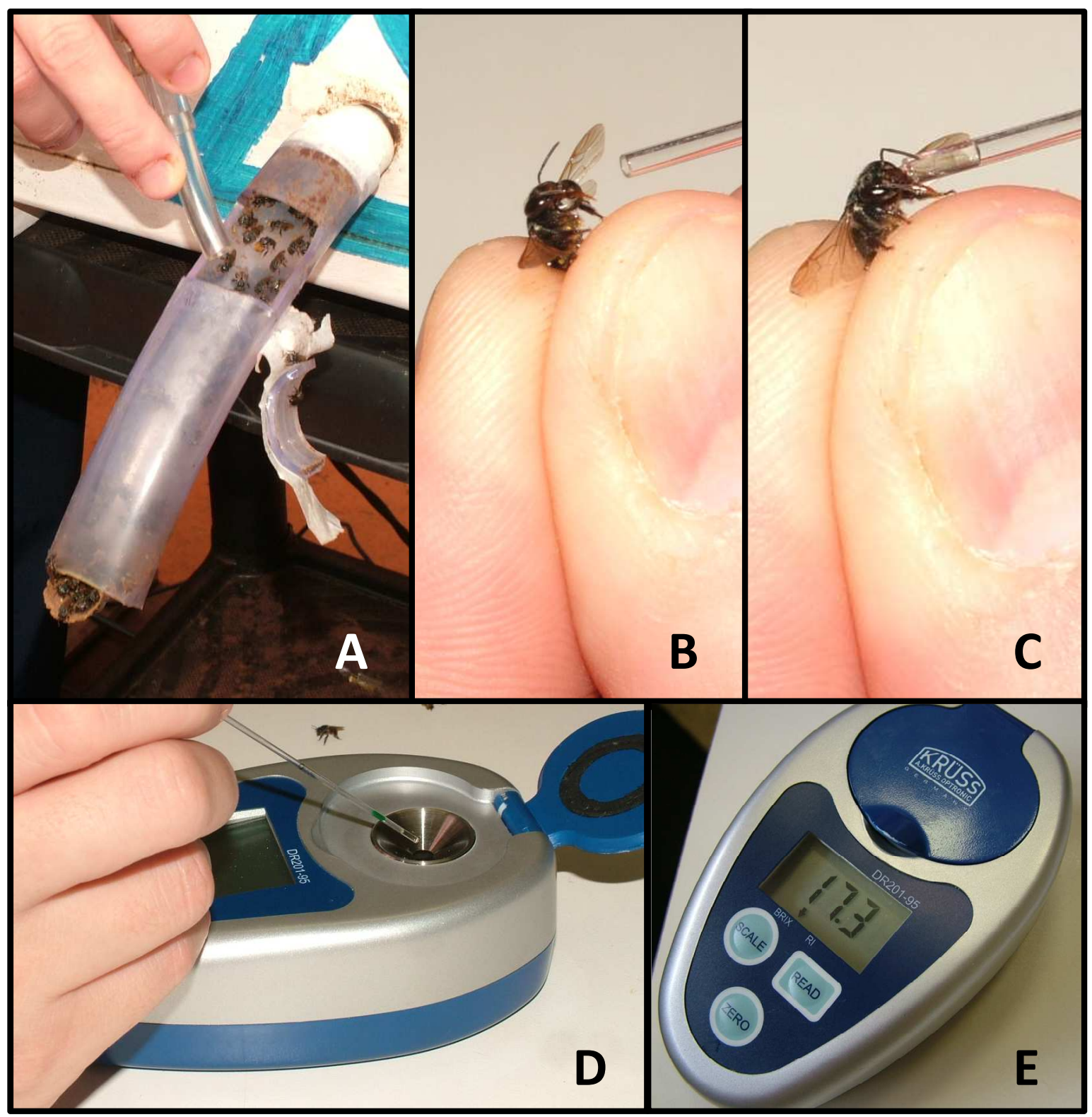

Fig. 1. Metodologia para verificar o comportamento de coletad e água. A - coleta das forrageiras com o uso do sugador através da abertura feita na mangueira; B - exposição do conteúdo regurgitado pela operária através da pressão em seu abdome; C - coleta do conteúdo regurgitado com um capilar; D e E - medição da concentração do conteúdo através de um refratômetro digital;

\section{Análise estatística}

Com objetivo de verificar o limiar mínimo da $\mathrm{T}_{\text {CRIA }}$ para início de coleta de água foi feita uma distribuição da frequência relativa de abelhas que coletaram água em intervalos de $1^{\circ} \mathrm{C}$. Para isto, a porcentagem de amostras de coletas de água foi obtida através da relação entre o número de indivíduos amostrados trazendo água e 
o número total de indivíduos amostrados em cada intervalo de $\mathrm{T}_{\mathrm{CRIA}}$ de $1{ }^{\circ} \mathrm{C}$. Para verificar se a frequência de coleta de água aumenta com o aumento da temperatura foi realizada uma regressão linear entre os intervalos de $T_{\text {CRIA }}$ e a frequência relativa de indivíduos coletando água .

Para verificar se a concentração do néctar é usada como um mecanismo de resfriamento através da coleta de néctar menos concentrado (com maior capacidade evaporativa) durante os períodos mais quentes, foi realizada uma regressão linear da concentração do líquido regurgitado (excluindo-se as amostras consideradas como água) com a $T_{\text {CRIA. }} O$ alto coeficiente de determinação $\left(R^{2}\right)$ e valores negativos de $b_{1}\left(y=b_{0}+b_{1} x\right)$, o índice de inclinação da reta, podem indicar que quanto maior a temperatura, menor a concentração do néctar.

Para investigar a existência do resfriamento evaporativo (evaporative cooling), mecanismo pelo qual a temperatura seria diminuída através da evaporação da água, a UR $\mathrm{RRIA}_{\mathrm{A}}$ foi correlacionada com a $\mathrm{T}_{\mathrm{CRIA}}$ das amostras de coleta de água, para verificar qual o comportamento da umidade relativa em relação à temperatura durante as coletas de água.

\section{Ventilação do ninho}

Foram utilizadas três colônias de $S$. depilis mantidas em caixas de madeira e monitorada com sensores, conforme descrito na metodologia do Capítulo 1. Os sensores monitoraram os mesmos parâmetros, nos mesmos intervalos que os descritos anteriormente para coleta de água. Na entrada de cada ninho foi acoplada uma mangueira plástica transparente de $12 \mathrm{~cm}$ de comprimento por $3 \mathrm{~cm}$ de diâmetro, que foi utilizada para estender o túnel de entrada e permitir a contagem dos indivíduos que ventilavam (Fig. 2A). Este comportamento é bastante característico e fácil de ser observado, já que as operárias ficam paradas, geralmente alinhadas, e com as pernas posteriores bem esticadas, batendo as asas constantemente (Fig. 2B).

Foram realizados seis ensaios experimentais nos quais a temperatura foi das caixas foi aumentada gradualmente,com lâmpadas de $15 \mathrm{~W}$ posicionadas sob a caixa. Após 45 min de aquecimento as lâmpadas foram desligadas. Foram contados

o número de abelhas ventilando nas mangueiras a cada 5 minutos, iniciando-se 
quando os aquecedores foram ligados, até a ventilação cessar (nenhuma abelha ventilando).

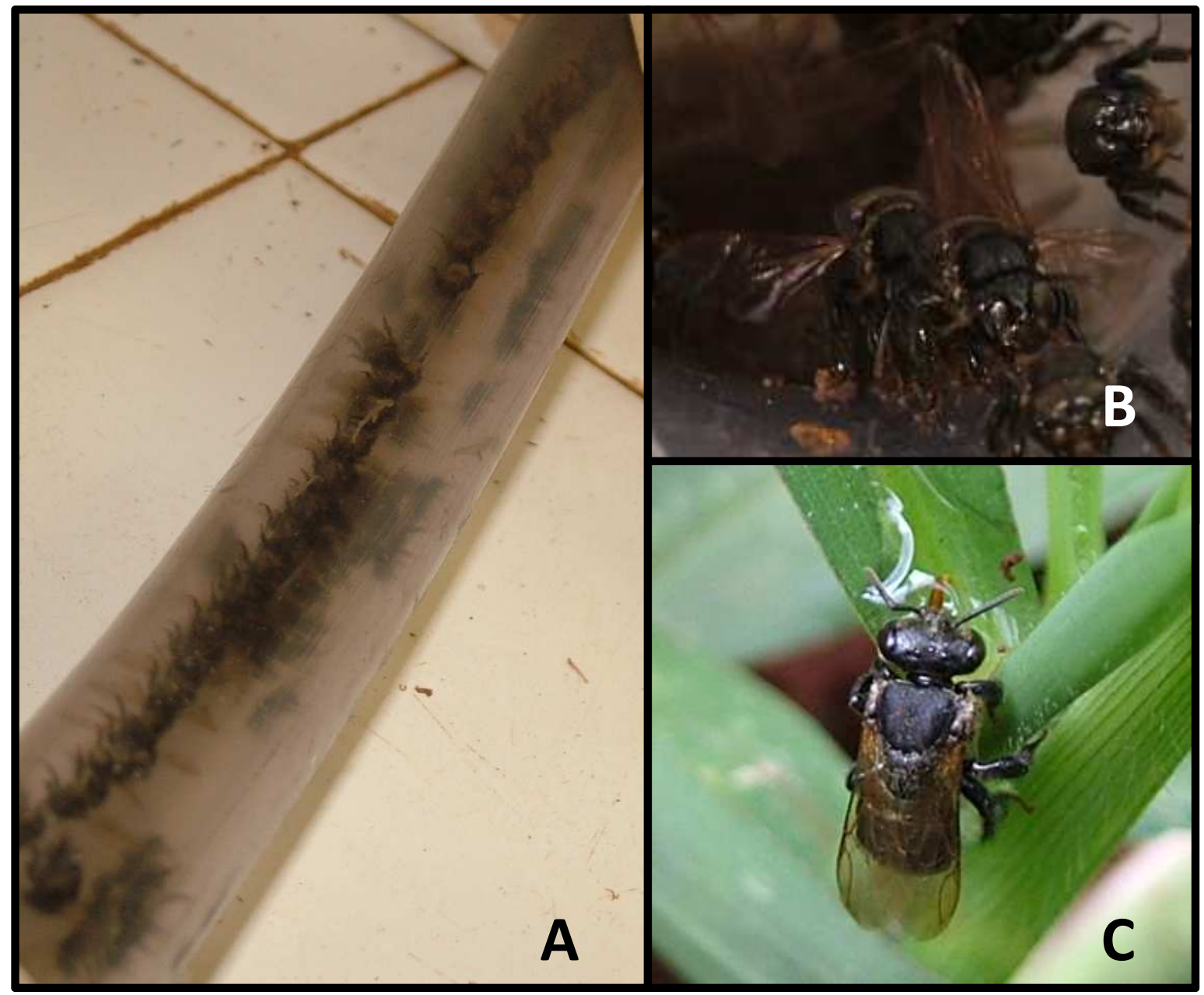

Fig. 2. A) comportamento de ventilação em uma mangueira transparente conectada ao orifício de entrada do ninho mostrando tendência em enfileirar-se; B) detalhe das operárias ventilando (pernas esticadas e abdome erguido); C) operária coletando água

\section{Analise estatística}

Para verificar se a ventilação é desencadeada por conta de altas temperaturas e a temperatura de qual região que desencadeia o comportamento, foi feito uma regressão linear entre as diversas regiões amostradas ( $T_{\text {CRIA }}$ e $T_{\text {POTES, }}$ ) e o número de abelhas ventilando nas três colônias estudadas. O maior coeficiente de determinação $\left(R^{2}\right)$ indica qual das temperaturas é a mais provável causa da ventilação. $A T_{A M B}$ e $T_{C O N T R}$ não foram utilizadas por conta da manipulação experimental das caixas com colônias (através do aquecedor), modificando a 
temperatura e umidade na qual estavam submetidas, de forma que a $T_{A M B}$ e $T_{\text {CONTR }}$ foram diferentes das que as colônias experimentaram.

Para verificar se o aumento da temperatura na região que desencadeou o comportamento de ventilação também aumenta o número de abelhas ventilando foi feita uma foi feita uma média do número de abelhas ventilando em intervalos de $1^{\circ} \mathrm{C}$ da temperatura verificada no ítem anterior como a principal responsável pela ventilação. A partir disso, foi feita uma regressão linear para verificar se o aumento dessa temperatura causa um aumento na média do número de abelhas ventilando.

Para verificar se a umidade relativa diminui em condições de altas taxas de ventilação, para que o resfriamento evaporativo seja mais eficiente a UR $U_{C R I A} e$ UR $_{\text {POTES }}$ foram correlacionadas (Spearman) com o número de abelhas ventilando. Uma correlação negativa indica que o maior número de abelhas ventilando tenderia a diminuir a umidade relativa, facilitando a evaporação e, consequentemente, a dissipação do calor. A UR $\mathrm{R}_{\text {CONTR }}$ e UR $\mathrm{UMMB}_{\mathrm{A} B}$ não foram utilizadas pelo mesmo motivo que não foram utilizadas as $\mathrm{T}_{\mathrm{AMB}}$ e $\mathrm{T}_{\mathrm{CONTR}}$, como explicado anteriormente.

\section{RESULTADOS}

\section{Coleta de água}

Cerca de $20 \%$ das forrageiras coletadas (47, num total de 231) nas duas colônias traziam água para o ninho. A coleta de água aconteceu entre às 10:00 e às 15:00 h. Nos intervalos que ocorreram a coleta de água, a $\mathrm{T}_{\mathrm{CRIA}}$ média foi 35,7 $( \pm$ $2,0)$ e $35,2( \pm 2,3)^{\circ} \mathrm{C}$ nas colônias $\mathrm{C} 1$ e C2, respectivamente (Tabela 1$)$.

Tabela 1. Temperaturas média ( \pm desvio-padrão), mínima e máxima medidas nas regiões dos favos de cria $\left(T_{\text {CRIA }}\right)$ e potes de alimento ( $\left.T_{\text {POTES }}\right)$, no ambiente $\left(T_{A M B}\right)$ e na caixa-controle ( $\left.T_{\text {CONTR }}\right)$ para duas colônias (C1 e C2) de Scaptotrigona aff. depilis. As medidas foram realizadas durante o período de coleta de água por forrageiras, entre 10:00h e 15:00h, durante $X$ dias.

\begin{tabular}{|c|c|c|c|c|c|c|c|c|}
\hline & \multicolumn{8}{|c|}{ Temperatura $\left({ }^{\circ} \mathrm{C}\right)$} \\
\hline & \multicolumn{4}{|c|}{$\mathrm{C} 1$} & \multicolumn{4}{|c|}{$\mathrm{C2}$} \\
\hline & $\mathrm{T}_{\mathrm{CRIA}}$ & $\mathrm{T}_{\text {POTES }}$ & $\mathrm{T}_{\mathrm{AMB}}$ & $T_{\text {CONTR }}$ & $\mathrm{T}_{\mathrm{CRIA}}$ & $\mathrm{T}_{\text {POTES }}$ & $\mathrm{T}_{\mathrm{AMB}}$ & $\mathrm{T}_{\text {CONTR }}$ \\
\hline $\begin{array}{l}\text { Média } \\
( \pm \text { d.p. })\end{array}$ & $\begin{array}{c}35,7 \\
( \pm 2,0)\end{array}$ & $\begin{array}{c}35,5 \\
( \pm 2,0)\end{array}$ & $\begin{array}{c}33,3 \\
( \pm 3,4)\end{array}$ & $\begin{array}{c}37,9 \\
( \pm 3,6)\end{array}$ & $\begin{array}{c}35,2 \\
( \pm 2,3)\end{array}$ & $\begin{array}{c}34,6 \\
( \pm 2,3)\end{array}$ & $\begin{array}{c}33,0 \\
( \pm 3,3)\end{array}$ & $\begin{array}{c}36,8 \\
( \pm 4,6)\end{array}$ \\
\hline Mínima & 33,0 & 32,2 & 28,5 & 32,6 & 29,1 & 28,2 & 27,7 & 26,6 \\
\hline Máxima & 39,6 & 39,0 & 41,1 & 44,3 & 39,0 & 38,5 & 40,7 & 44,3 \\
\hline
\end{tabular}


As amostragens foram separadas de acordo com a temperatura da cria ( $\left.\mathrm{T}_{\mathrm{CRIA}}\right)$ no momento em que foram coletadas (dentro de intervalos de $1^{\circ} \mathrm{C}$, de 24 a $39^{\circ} \mathrm{C}$ ). Em cada intervalo de temperatura as amostras foram separadas em amostras de água e amostras totais (água e néctar). A frequência relativa de coleta de água foi calculada através do número forrageiras que coletaram água pelo número total de forrageiras amostradas na mesma faixa de temperatura da cria no momento em que a coleta foi feita (Tabela 2).

Tabela 2. Frequência de forrageiras que coletam água em relação à temperatura na região dos favos de cria medida em duas colônias de Scaptotrigona aff. depilis. A frequência relativa de forrageiras com água se refere ao número de coletas de água em uma determinada faixa de temperatura, em relação ao número total de amostras (tanto de água como de néctar) nesta mesma faixa de temperatura.

\begin{tabular}{cccc}
\hline $\begin{array}{c}\text { Classes de } \\
\text { temperaturas }\left({ }^{\circ} \mathbf{C}\right)\end{array}$ & \begin{tabular}{c} 
Frequência absoluta de forrageiras \\
\cline { 2 - 3 }
\end{tabular} & total & $\begin{array}{c}\text { Frequência relativa de } \\
\text { forrageiras com água }(\%)\end{array}$ \\
\hline $24,0-24,9$ & 1 & 0 & 0 \\
$25,0-25,9$ & 6 & 0 & 0 \\
$26,0-26,9$ & 9 & 0 & 0 \\
$27,0-27,9$ & 9 & 0 & 0 \\
$28,0-28,9$ & 15 & 0 & 0 \\
$29,0-29,9$ & 19 & 1 & 5 \\
$30,0-30,9$ & 8 & 0 & 0 \\
$31,0-31,9$ & 20 & 1 & 5 \\
$32,0-32,9$ & 15 & 1 & 7 \\
$33,0-33,9$ & 23 & 5 & 22 \\
$34,0-34,9$ & 49 & 10 & 20 \\
$35,0-35,9$ & 30 & 13 & 43 \\
$36,0-36,9$ & 11 & 5 & 45 \\
$37,0-37,9$ & 6 & 3 & 50 \\
$38,0-38,9$ & 6 & 4 & 67 \\
$39,0-39,9$ & 4 & 4 & 100 \\
\hline
\end{tabular}

Considerando a faixa de temperatura entre 27 e $39^{\circ} \mathrm{C}$, a regressão linear entre a frequência relativa de coleta de água com a respectiva faixa de $T_{\text {CRIA }}$ foi significativamente positiva ( $n=13 ; R^{2}=0,84 ; P<0,001$; Fig. 3). Provavelmente, esse resultado indica que a coleta de água é influenciada pelo aumento na temperatura nos favos de cria. 


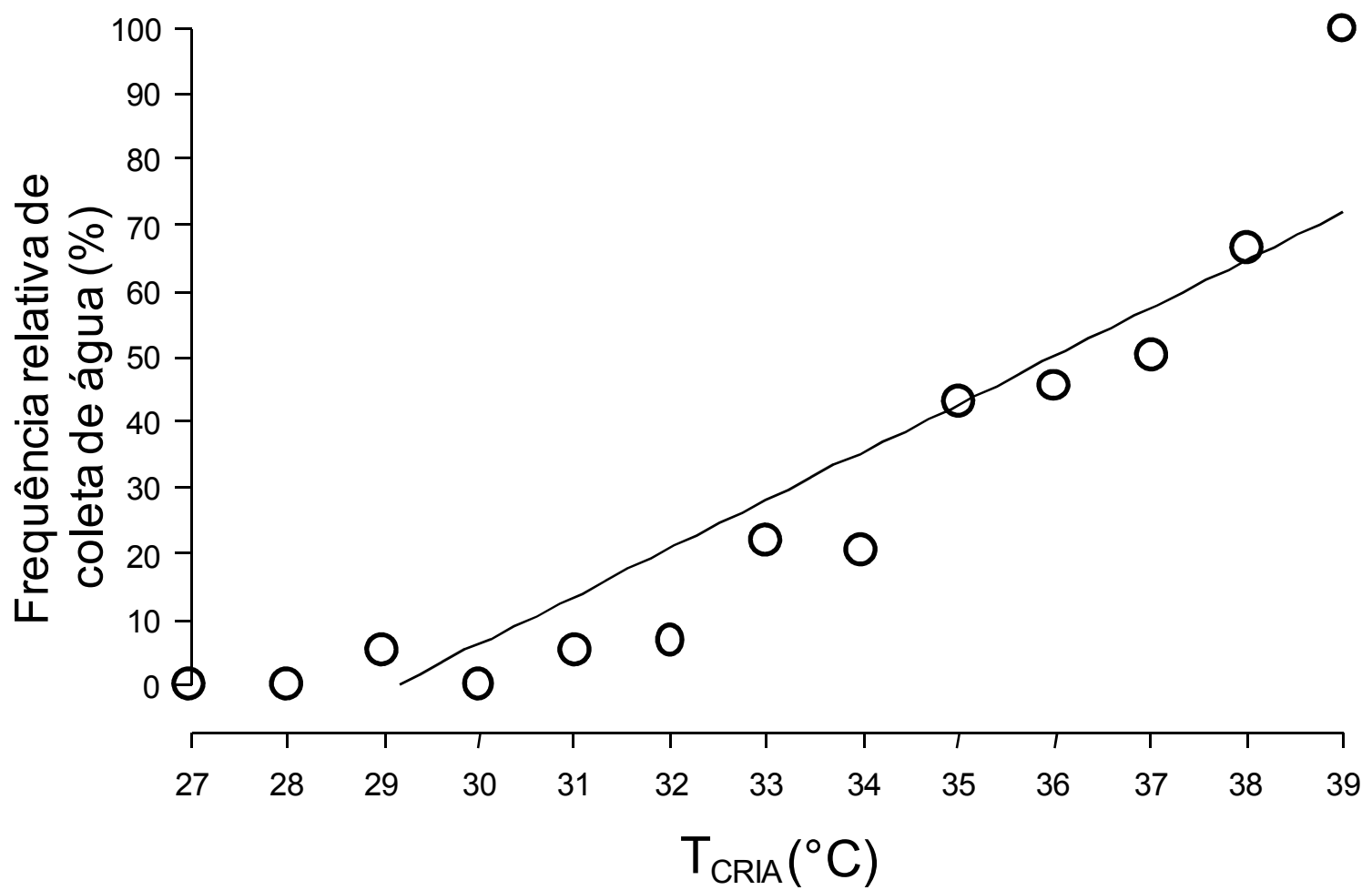

Fig. 3. Frequência de forrageiras que trazem água para o ninho da coleta de água em relação a temperatura dos favos de cria $\left(T_{C R I A}\right)$. A linha corresponde à equação da regressão linear $\left(R^{2}=0,84\right.$; $\left.\mathrm{P}<0,001 ; \mathrm{F}_{\text {relat }}=-214.7+7.3 \times \mathrm{T}_{\text {CRIA }}\right)$

A regressão não significativa $\left(R^{2}=0,08 ; P=0,273\right)$ entre a temperatura da cria e a concentração de açúcares no néctar (com maiores que $2 \%$ de solutos) indicou que a concentração do néctar não é utilizada como mecanismo para o resfriamento do ninho. (Fig. 4). 


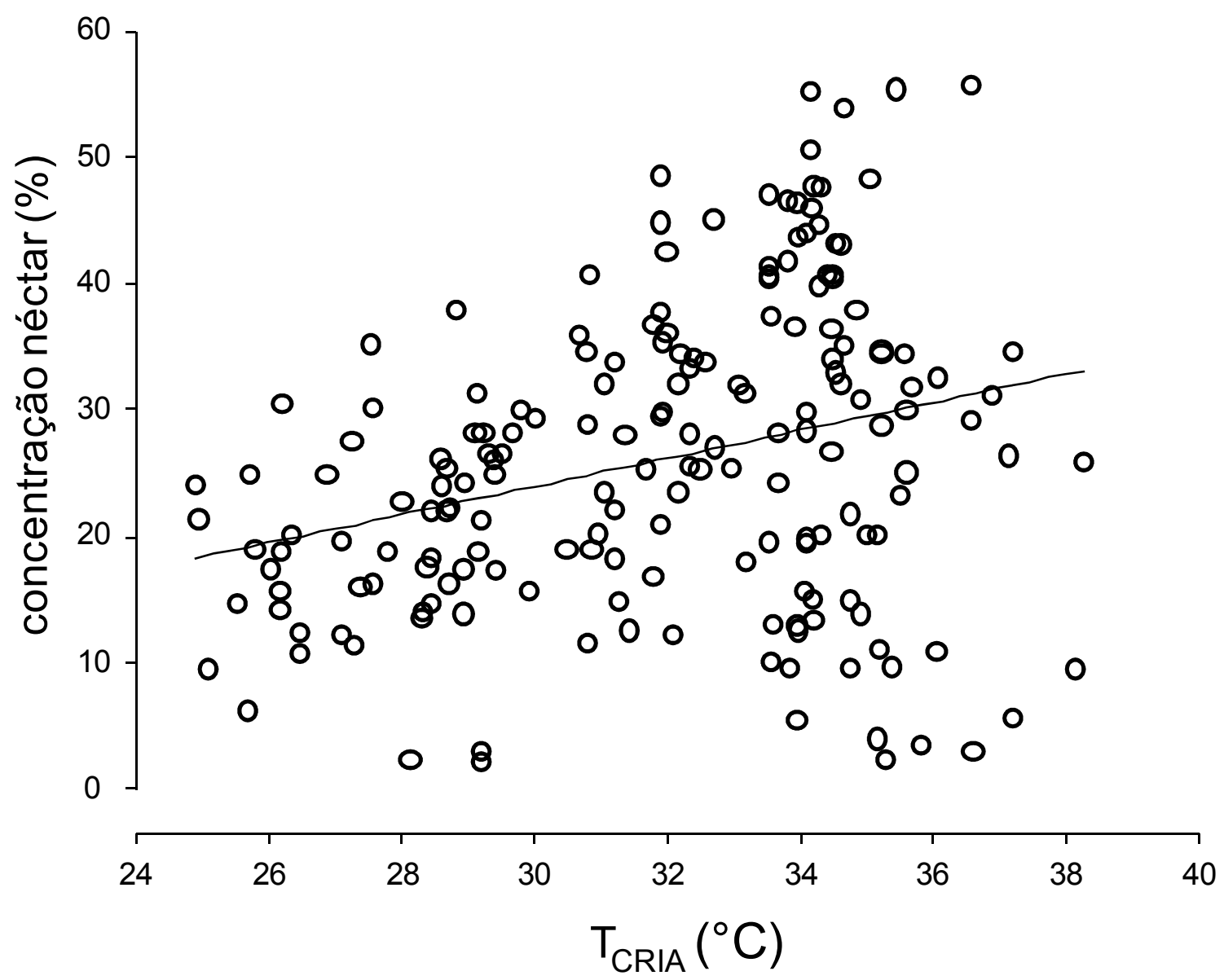

Fig. 4. Concentração de açúcares no néctar coletado por forrageiras de duas colônias de Sd em todas as amostras coletadas nas duas colônias. Concentrações inferiores a $2 \%$ de açúcares no néctar (água) foram excluídas da análise. $A$ linha corresponde à equação da regressão linear $\left(R^{2}=\right.$ 0,$\left.08 ; \mathrm{P}=0,273 ; \mathrm{C}_{\text {néctar }}=-9,5+1,11 \times \mathrm{T}_{\text {CRIA }}\right)$

A UR $R_{\text {CRIA }}$ apresentou um coeficiente de correlação negativo e estatisticamente significantivo $(r=-0,58 ; P=0,000)$ com a $T_{\text {CRIA }}$ durante as amostras de coleta de água $(n=47)$, indicando que existe uma relação inversamente proporcional entre estas variáveis durante a coleta de água (Fig. 5). 


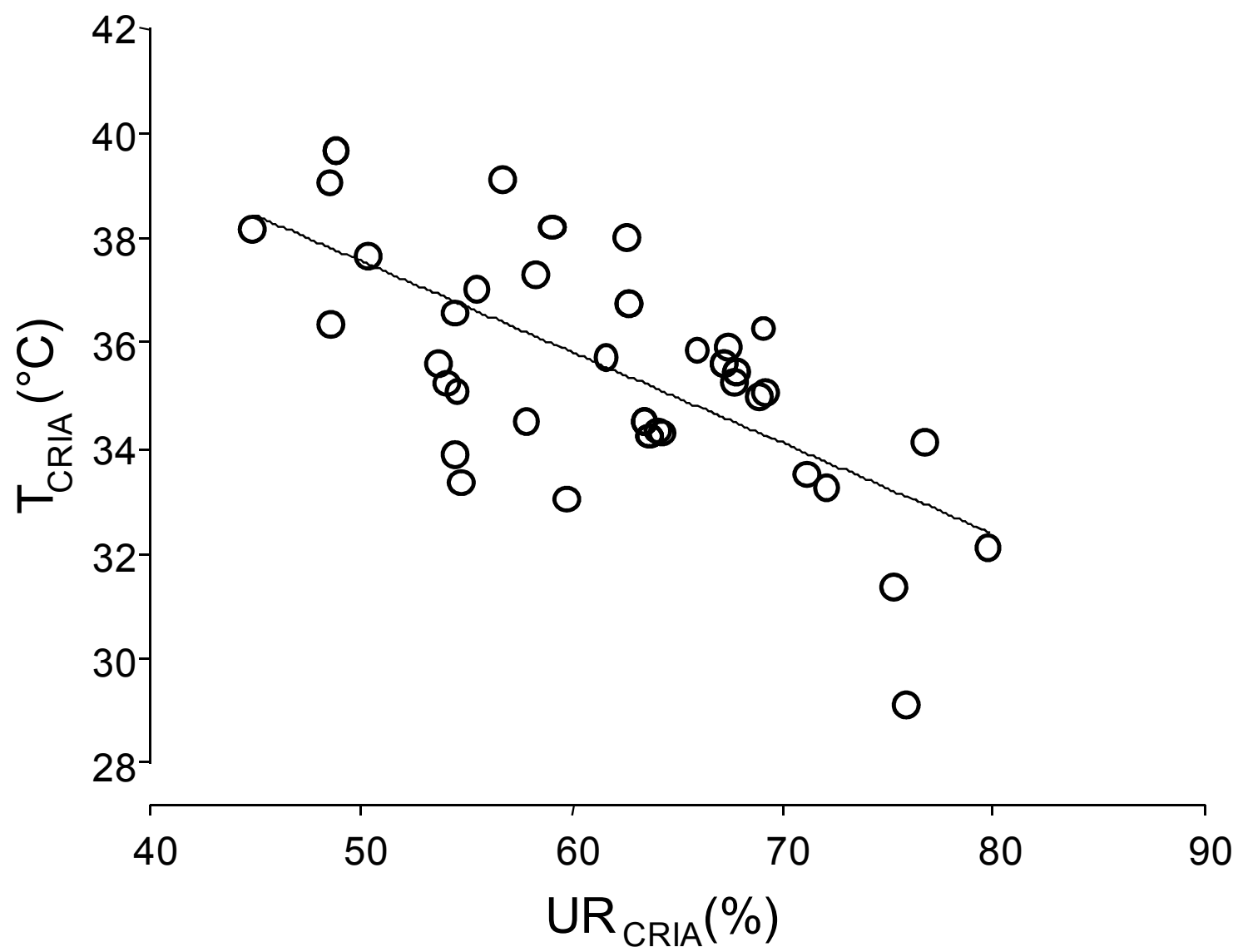

Fig. 5. Relação entre a temperatura e umidade relativa na região dos favos de cria durante os períodos de coleta de água pelas forageiras de duas colônias de Scaptotrigona depilis $\left(R^{2}=0,44 ; P<\right.$ 0,$001 ; \mathrm{T}_{\mathrm{CRIA}}=151.952-2.534 \times \mathrm{UR}_{\mathrm{CRIA}} ;$ )

\section{Ventilação do ninho}

O número de operárias ventilando foi altamente relacionado com a temperatura na região dos favos de cria $\left(R^{2}=0,47 ; P=0\right)$. Essa relação foi consideravelmente maior que a temperatura dos potes de alimento (Fig. 6). 

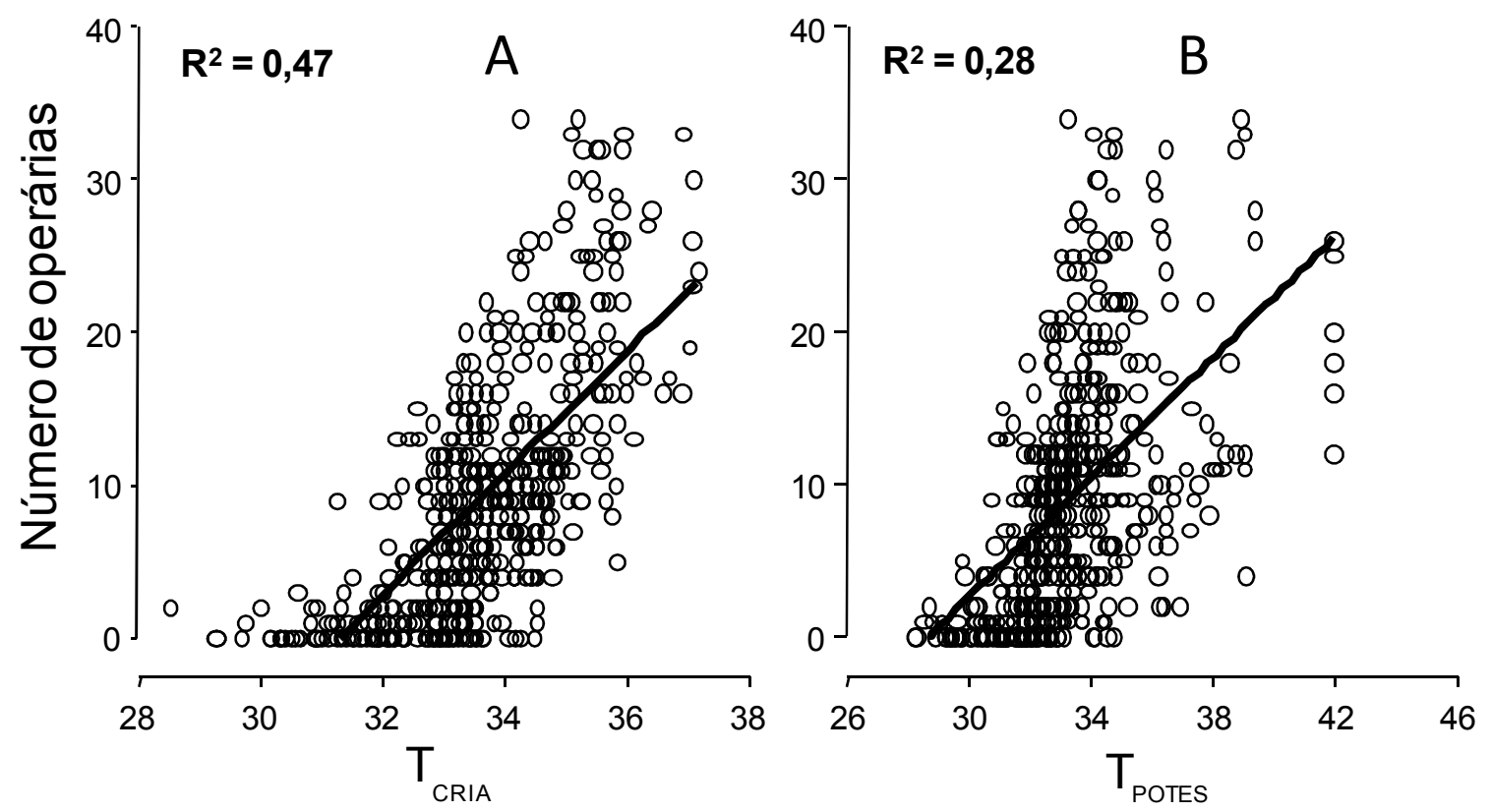

Fig. 6. Relação entre o número de operárias de $S$. depilis ventilando e a temperatura: A) favos de cria; B) potes de alimento

A temperatura da cria ( $T_{\text {CRIA }}$ ) foi, então, separada em intervalos de $1^{\circ} \mathrm{C}$ (de 29 a $\left.37{ }^{\circ} \mathrm{C}\right)$. A média do número de abelhas ventilando em cada intervalo de temperatura foi calculada e relacionada com seu respectivo intervalo (Fig. 7). Uma regressão linear da média do número de abelhas ventilando pelos intervalos de temperatura mostrou forte influência da $T_{\text {CRIA }}$ no número médio de abelhas ventilando $\left(R^{2}=0,93 ; P<0,001\right)$, ficando claro que o número médio de abelhas ventilando tende a crescer conforme a $\mathrm{T}_{\mathrm{CRIA}}$ aumenta. 


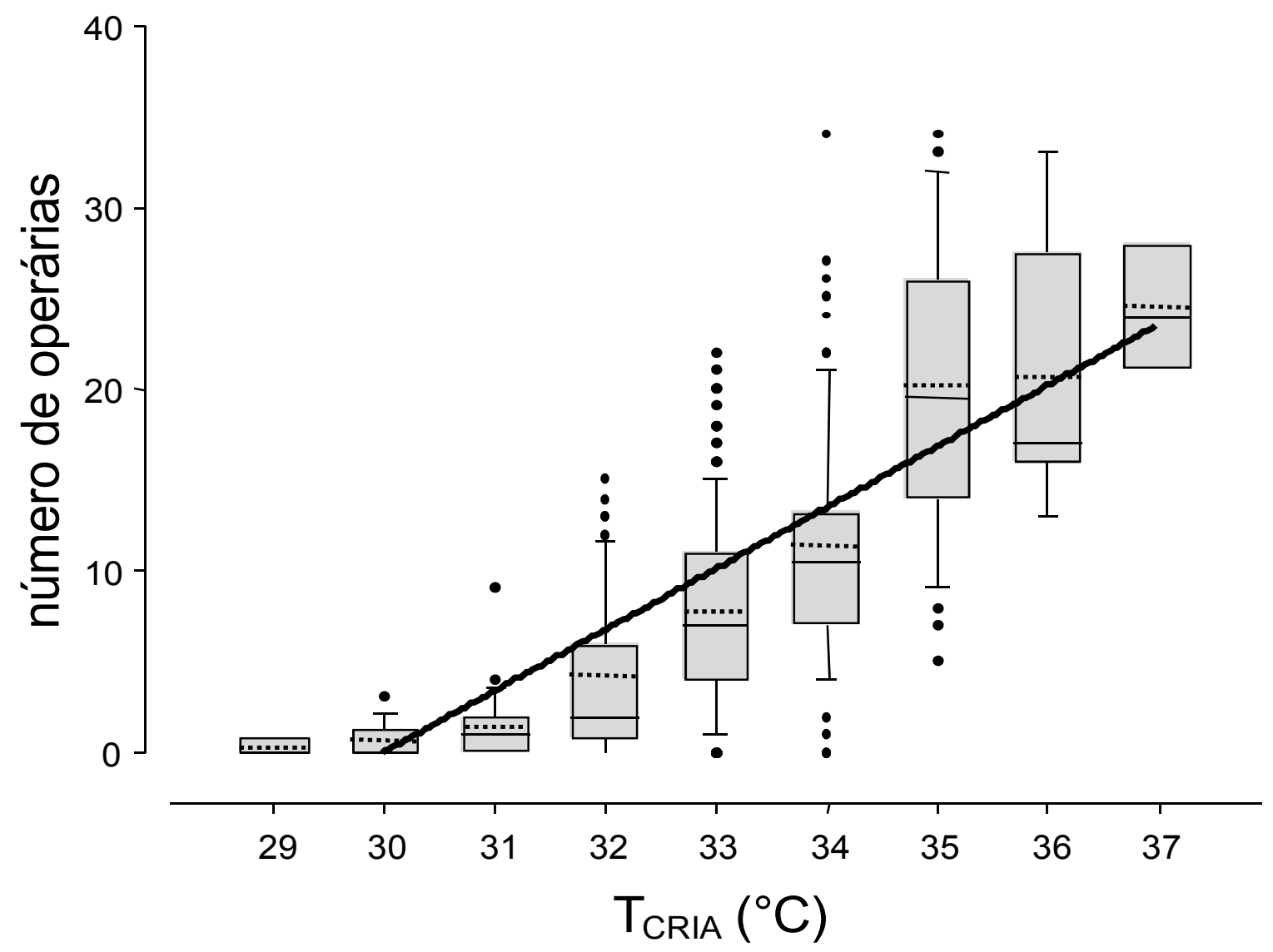

Fig. 7. Número de abelhas ventilando em intervalos de $1{ }^{\circ} \mathrm{C}$ da $T_{\text {CRIA. }}$. Boxplot: a linha inteira dentro das caixas indica a mediana, enquanto que a pontilhada indica a média. Os limites inferiores e superior das caixas indicam o quartil inferior e superior, respectivamente. As hastes delimitam a distribuição de $95 \%$ dos dados. Os valores fora dos limites de 95\% estão representados individualmente (outliers). A linha corresponde à equação da regressão linear $\left(R^{2}=0,93 ; P<0,001\right.$; Núm op $=-100,6+3.35 \times \mathrm{T}_{\text {CRIA }}$ )

Foram encontrados coeficientes de correlação de Spearman negativos e muito parecido para a URR $R_{\text {CRIA }}$ e U $R_{\text {POTES }}\left(\rho_{\text {cria }}=-0,46 ; p=0\right.$ e $\rho_{\text {potes }}=-0,48 ; p=0$, repectivamente), o que mostra que conforme o número de abelhas ventilando aumenta a UR $\mathrm{R}_{\mathrm{CR} A \mathrm{~A}}$ e a UR $\mathrm{UOTES}$ diminuem (Fig 8). 

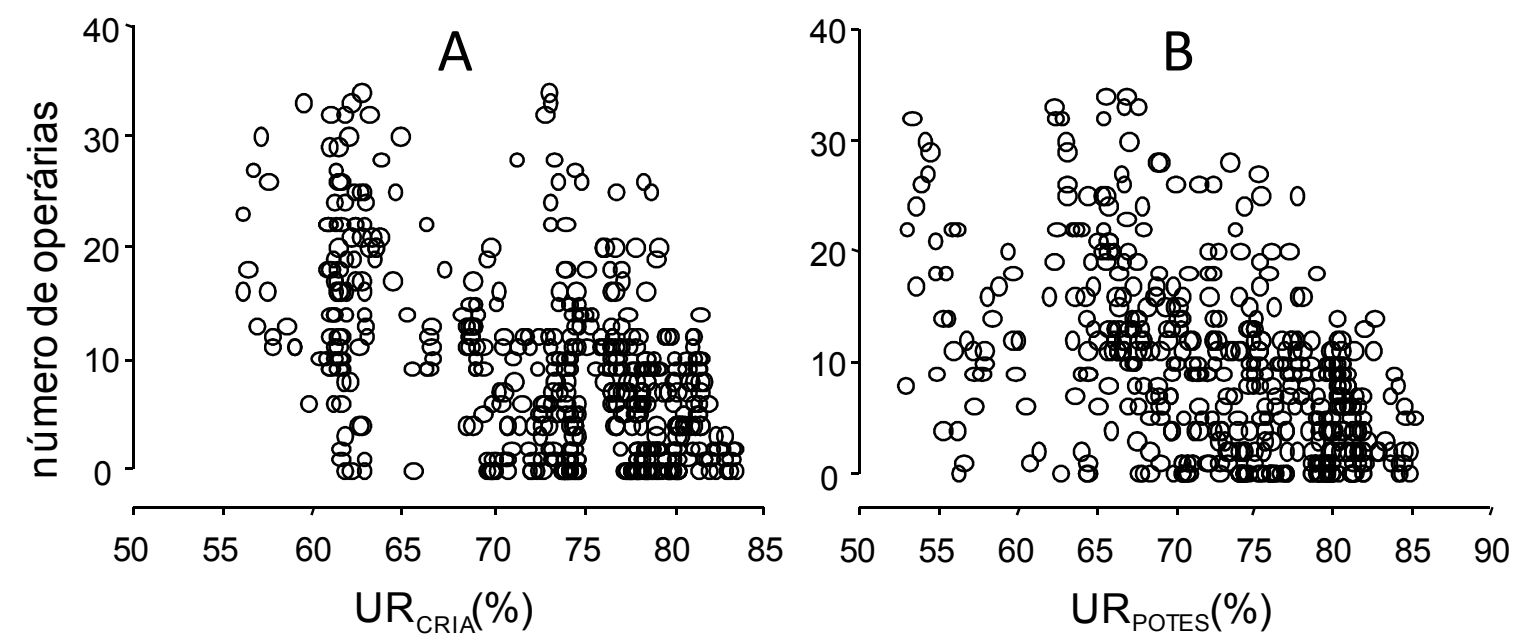

Fig. 8. Relação entre o número de abelhas ventilando e a umidade relativa: A) favos de cria; B) potes de alimento.

\section{DISCUSSÃO}

\section{Coleta de água}

O comportamento de coleta de água para resfriamento evaporativo do ninho é bem conhecido em Apis mellifera e em algumas espécies de vespas sociais (Jones e Oldroyd, 2007). Esse comportamento das operárias é caracterizado pela distribuição de pequenas quantidades de água pelo ninho, depositando as gotículas em pequenas cavidades formadas entre as células de cria operculadas. Em $A$. mellifera também ocorre a deposição nas margens das células abertas, além da exposição das gotículas através de suas glossas, em um comportamento conhecido como "tongue-lashing" - também utilizado para desidratação do néctar (Winston, 1987). Assim como nos Bombini, a coleta e depósito de água sobre a cria ou o "tongue-lashing" nunca foi observado em Meliponini (Jones e Oldroyd, 2007).

Aqui apresentamos a primeira evidência de coleta ativa de água em um nível colonial, para fins de resfriamento do ninho em abelhas sem ferrão, usando como organismo de estudo a $S$. depilis. Não observamos forrageiras com água quando a temperatura da região dos favos de cria era inferior a $29^{\circ} \mathrm{C}$. Contudo, acima desse valor, $5 \%$ das forrageiras traziam esse recurso para o ninho. Conforme a temperatura aumentava, o número de forrageiras com água também aumentou, evidenciado pelo alto coeficiente de determinação $\left(R^{2}=0,84 ; P<0,001\right)$. A $33^{\circ} \mathrm{C}$, cerca de $20 \%$ das forrageiras traziam água para o ninho. 
Macías-Macías et al. (2011) encontraram os primeiros indícios de que operárias de uma espécie de abelha sem ferrão (Melipona colimana) poderiam utilizar água para resfriamento do ninho, quando observaram que operárias em situações artificiais de confinamento a $40^{\circ} \mathrm{C}$ coletavam água e espalhavam em pequenas gotículas pela caixa onde estavam, porém atentaram para a necessidade de verificação deste comportamento em situações naturais a nível colonial. Nogueira-Neto (1997) já havia relatado sobre a coleta de água em poças e roupas secando por operárias de S. postica e Frieseomelitta varia, sem apresentar nenhuma evidência de que esse recurso fosse utilizado para o resfriamento do ninho. Engels et al. (1995) superaqueceram ninhos de S. postica (até cerca de $44^{\circ} \mathrm{C}$ na região da cria), porém não observaram nenhum comportamento de depósito de água sobre a cria ou o tongue-lashing.

Roubik (2006) sugere que a água coletada pelas operárias em abelhas sem ferrão seja utilizada para diluição do mel, apesar de não tenha apresentado nenhuma evidencia para tal. Nicolson (2009) alerta que a alimentação larval em $A$. mellifera demanda uma grande quantidade de água pelas operárias nutridoras e que, em alguns casos, o néctar não e a única fonte desse recurso. $O$ mesmo poderia acontecer para algumas espécies de abelhas sem ferrão.

Embora nós não tenhamos observado, até porque esse não era o objetivo deste estudo, se o comportamento de depósito de gotículas de água ou o de tonguelashing aconteceu ou aumentou, existem evidências fortes de que ele deve acontecer (Macías-Macías et al., 2011). Além disso, nós supomos que ele ocorra principalmente sobre as células de cria, que deve ser a região mais crítica sob condições de temperaturas extremas (veja Capítulo 3). Essa hipótese se baseia no fato de que a água está em contato com a estrutura a ser resfriada, durante a evaporação. Neste processo, a passagem do estado líquido para o gasoso requer a absorção de calor que provém de todo o meio em que a água está em contato inclusive do ar - diminuindo, consequentemente, a temperatura da matéria ao redor (Prange, 1996). Se realmente a água estiver em contato direto com a cria, sua temperatura diminuirá. A evaporação do néctar através do tongue-lashing e nos potes de alimento também reduzem a temperatura, porém não diretamente da cria, mas das operárias adultas que realizam o tongue-lashing e do mel nos potes de alimento, respectivamente. Este processo de evaporação do néctar também 
contribui com a diminuição da temperatura do ninho (inclusive da cria), porém de maneira menos eficiente. Além disso, espalhar a água pode aumentar a superfície de contato com o ar e com o substrato a ser resfriado, aumentando a taxa de evaporação e aumentando a perda de calor (Varejão-Silva, 2005), ao contrário do comportamento de tongue-lashing, que promove uma área muito pequena para a evaporação. Talvez isto ajude a esclarecer a ausência de associação entre a concentração de açucares do néctar coletado e a temperatura $\left(R^{2}=0,08 ; P=\right.$ 0,273), o que indica que as operárias não coletam néctar menos concentrado como mecanismo de resfriamento do ninho. Teoricamente, soluções açucaradas não são interessantes para serem depositadas sobre os favos de cria, uma vez que soluções com solutos dissolvidos apresentarem menor taxa de evaporação (Young, 1967). Colônias superaquecidas de $A$. mellifera e desprovidas de fontes de água preferem néctar mais diluído em relação ao concentrado (Simpson, 1961), porém isto pode estar relacionado com o balaço hídrico individual (Nicolson, 2009).

Nossos resultados mostram que a coleta de água aconteceu quando a temperatura dos favos de cria atingiu $29^{\circ} \mathrm{C}$. Contudo, ela é menor do que a média de temperatura mantida durante o dia inteiro nesta mesma região $\left(30,5^{\circ} \mathrm{C}\right.$ em $S$. depilis (Capítulo 1); $30^{\circ} \mathrm{C}$ em S. postica (Engels et al., 1995) e bem menor do que a média durante os períodos mais quentes $\left(34^{\circ} \mathrm{C}\right.$; Capítulo 1$)$, além de ser consideravelmente menor que a temperatura "ideal" para que o desenvolvimento larval seja mais rápido e com maior índice de sobrevivência (34 ${ }^{\circ} \mathrm{C}$, Capítulo 3 ). Aparentemente a coleta de água a partir dos $29^{\circ} \mathrm{C}$ em S. depilis não foi induzida pelo aumento da temperatura, o que sugere que apenas a água contida no néctar não supre as necessidades fisiológicas individuais seja necessária, assim como ocorre em A. mellifera (Kuhnholz e Seeley, 1997; Nicolson, 2009).

Portanto, provavelmente a coleta de água não é iniciada para o resfriamento evaporativo. Porém, ficou claro que o aumento da temperatura interna ( $\left.T_{\text {CRIA }}\right)$ aumentou significativamente $\left(R^{2}=0,84 ; P<0,001\right)$ o número de operárias que coletam água. Em $A$. mellifera, o mecanismo que controla e permite o rápido aumento nos esforços para coleta de água foram praticamente elucidados. Lindauer (1954) e posteriormente Kühnholz e Seeley (1997) mostraram que as operárias que coletam água adquirem informações sobre a as necessidades da colônia por mais água, ao observarem o grau de "facilidade" com que elas entregam a água coletada para 
outras operárias, chamadas de receptoras de água. A "facilidade" foi medida pelo tempo que as operárias doadoras demoram para achar as receptoras e, principalmente, dependendo do número de rejeições de recebimento da água. Conforme o número de receptoras aumenta (através da demanda de água por conta do aumento da temperatura), novas operárias são recrutadas para coletarem água. De acordo com a diminuição do número de receptoras, e da diminuição da temperatura, as coletoras de água desistem de coletar água por causa da dificuldade em transferir a água coletada para receptoras. Mesmo que em frequência baixa, operárias de $S$. depilis coletam água independente da temperatura. Conforme a temperatura aumenta, há um incremento considerável dos esforços de coleta, podendo apresentar um mecanismo de regulação semelhante ao de $A$. mellifera.

\section{Ventilação do ninho}

O comportamento de bater as asas para criar correntes de ar ocorre em todos os grandes grupos de insetos sociais alados (Jones e Oldroyd, 2007). Este comportamento pode ser utilizado para controle de três variáveis climáticas internas do ninhos: (1) a umidade relativa, a (2) temperatura e (3) a concentração de gases respiratórios (Simpson, 1961; Southwick e Moritz, 1987). Nossos resultados mostraram, pela primeira vez em abelha sem ferrão, que a ventilação em $S$. depilis aumenta linearmente com o aumento das temperaturas internas do ninho ( $T_{\text {CRIA }}$ ). Nossos dados corroboram com a teoria do limiar de resposta, que assume que as operárias variam suas respostas de acordo com os níveis de estímulo. O mesmo foi verificado para algumas espécies de Bombus, em que as operárias possuem diferentes limiares de reposta para iniciar a ventilação (O'donnell e Foster, 2001; Weidenmuller, 2004; Duong e Dornhaus, 2011).

Ao contrário do que ocorre em A. mellifera (Southwick e Moritz, 1987), as operárias de $S$. depilis realizam o comportamento de ventilação com as faces voltadas para fora (Nogueira-Neto, 1948; observação pessoal). Consequentemente um fluxo ativo de ar deve ser formado de fora para dentro. Southwick e Moritz (1987) sugerem que em $A$. mellifera, a ventilação é bidirecional, i.e., o ar sai e entra através do mesmo orifício de entrada da cavidade de nidificação. O mesmo foi verificado por nós em S. depilis. Porém como sugerido por Nogueira-Neto (1948), existem outras frestas na cavidade onde o ninho de $S$. depilis está alojado e a presença do batume 
crivado construídos pelas operárias permite uma ventilação unidirecional, que pode ser mais eficiente para atingir determinadas regiões do ninho. Como isto depende da presença de frestas no local de nidificação, é provável que a ventilação bidirecional seja a mais importante para assegurar o mínimo de ventilação.

Diversos trabalhos mostram claramente que nos Apini e Bombini a ventilação é utilizada como resposta às altas temperaturas, i.e. para resfriamento do ninho (revisão detalhada em Jones e Oldroyd, 2007). Em abelhas sem ferrão, já em 1948, Nogueira-Neto observou a ocorrência da ventilação para resfriamento do ninho, uma vez que este comportamento foi observado em colônias expostas ao sol. MacíasMacías et al. (2011) também encontraram certa evidência de que altas temperaturas podem desencadear o comportamento de ventilação, observando o comportamento de Melipona colimana em condições artificiais de confinamento a $40^{\circ} \mathrm{C}$, onde agumas operárias apresentaram o comportamento de ventilação.

Nogueira-Neto (1948) também relatou este comportamento em condições de baixas temperaturas $\left(16^{\circ} \mathrm{C}\right)$ e sugeriu que, neste caso, a ventilação teria como função facilitar a desidratação do mel e a prevenção de desenvolvimento de fungos no interior do ninho. Ellis et al. (2008) comprovaram que o comportamento de ventilação em operárias de $A$. mellifera também é desencadeado por umidades relativas muito altas, sugerindo que um dos propósitos seja a regulação da umidade relativa e a desidratação do mel. Altos níveis de umidade relativa não desencadeia a ventilação em Bombini (Weidenmuller et al., 2002), condizendo com a hipótese de que a ventilação tem como uma de suas funções a desidratação do mel, uma vez que neste grupo as operárias não desidratam o néctar, armazenando-o com altas concentrações de água (Michener, 1974; Goulson, 2003), provavelmente fazendo com que não exista a necessidade de diminuição da umidade relativa, ou ao menos seja menor que nos grupos que desidratam o néctar.

Além disso, a ventilação pode ser utilizada para controlar a concentração de gases respiratórios. Altos níveis de gás carbônico $\left(\mathrm{CO}_{2}\right)$ pode causar inibição de enzimas da respiração celular (ciclo de Krebs) e podem causar problemas na manutenção do pH e retenção de água na hemolinfa (Seeley, 1974). Fletcher \& Crewe (1981) verificaram ciclos de ventilação em Trigona denotii, uma espécie que nidifica em cavidades no solo, e calcularam uma troca completa do ar da cavidade do ninho a cada sete horas, com picos de ventilação durante a noite. Os autores 
sugeriram que a ventilação é utilizada principalmente para troca dos gases respiratórios, uma vez que as temperaturas ambiente são muito altas durante o dia (cerca de $60^{\circ} \mathrm{C}$ na superfície do solo), o que explicaria a ausência de ventilação nesse período, para evitar o superaquecimento por conta da entrada de ar quente. Seeley (1974) verificou que $A$. mellifera controla precisamente a concentração de $\mathrm{CO}_{2}$ no ninho, mantendo os níveis entre $0,10-4,25 \%$, sendo que o único mecanismo proposto para isto seria a ventilação. Em B. terrestris, a concentração de $\mathrm{CO}_{2}$ em um ninho natural nunca passou de $1,6 \%$, sendo que perto deste limite a ventilação foi desencadeada (Weidenmuller et al., 2002). Portanto, é possível concluir que a concentração de $\mathrm{CO}_{2}$ é uma variável de grande importância para 0 controle em espécies que nidificam em cavidades, sendo que a ventilação é o único mecanismo que permite controlar esta variável. O aumento do metabolismo em condições de altas temperaturas poderia aumentar, consequentemente a concentração de $\mathrm{CO}_{2}$ no ninho (Proni e Hebling, 1996), durante os episódios de superaquecimento, o que levaria a conclusões precipitadas quanto ao desencadeamento da ventilação em relação às altas temperaturas, com a possibilidade do propósito da ventilação ser o controle de $\mathrm{CO}_{2}$, ao invés de diminuir a temperatura. Estudos posteriores são necessários para compreender esta questão.

Fletcher e Crewe (1981) levantaram uma questão importante e raramente discutida sobre os efeitos da ventilação no resfriamento do ninho. A ventilação só pode diminuir a temperatura por si só apenas se a temperatura do ar externo ao ninho estiver mais frio (Southwick e Moritz, 1987). Isso não é comum de acontecer, visto que os organismos que estão sob condições de altas temperaturas assim o estão por conta das altas temperaturas do ambiente, incluindo a temperatura do ar, como no caso de $T$. denotii (Fletcher e Crewe, 1981). O que acontece, então, é que no processo de ventilação, apesar de na maioria das vezes ocorrer a entrada de ar ligeiramente mais quente que o ninho, a umidade relativa é diminuída, ocorrendo uma troca do ar saturado de água de dentro do ninho por um ar mais seco do ambiente, o que estimula a evaporação dentro do ninho e, consequentemente, o resfriamento (Prange, 1996). O resfriamento evaporativo é a única maneira de um organismo diminuir sua temperatura em um ambiente mais quente do que o próprio organismo (Prange, 1996). Portanto, a ventilação atua em conjunto com o 
resfriamento evaporativo dentro do ninho, expelindo o ar úmido e introduzindo ar mais seco no ninho.

\section{Considerações finais}

Nossos resultados mostraram de maneira consistente que $S$. depilis possui pelo menos dois mecanismos ativos de resfriamento do ninho: a (1) coleta de água e a (2) ventilação. Ambos os mecanismos são desencadeados pelo aumento das temperaturas internas do ninho, e sua intensidade aumenta conforme a temperatura aumenta. Apesar de normalmente abordados de maneira independente pelos autores, a ventilação e a coleta de água parecem ser comportamentos associados, sendo que a eficiência de um mecanismo depende diretamente da eficiência do outro.

De forma análoga aos mamíferos, os animais com os mecanismos de termorregulação mais precisos, o principal mecanismo de resfriamento das abelhas sociais parece ser muito semelhante à sudorese, através da evaporação de água para liberação de calor. A principal diferença é que nos mamíferos a água é proveniente do metabolismo dos animais, enquanto nas abelhas é proveniente da coleta ativa pelas operárias forrageiras. 


\section{REFERÊNCIAS BIBLIOGRÁFICAS}

DUONG, N.; DORNHAUS, A. Ventilation response thresholds do not change with age or selfreinforcement in workers of the bumble bee Bombus impatiens. Insectes Sociaux, p. 1-8, 2011.

ELLIS, M. B. et al. Hygropreference and brood care in the honeybee (Apis mellifera). Journal of Insect Physiology, v. 54, n. 12, p. 1516-1521, 2008.

ENGELS, W.; ROSENKRANZ, P.; ENGELS, E. Thermoregulation in the nest of the neotropical stingless bee Scaptotrigona postica and a hypothesis on the evolution of temperature homeostasis in highly eusocial bees. Studies on Neotropical Fauna and Environment, v. 30, n. 4, p. 193-205, 1995.

FLETCHER, D.; CREWE, R. Nest Structure and Thermoregulation in the Stingless Bee Trigona (Plebeina) denoiti Vachal (Hymenoptera: Apidae). Journal of the Entomological Society of Southern Africa, v. 44, n. 2, p. 183-196, 1981.

GOULSON, D. Bumblebees - Behaviour and Ecology. Oxford: Oxford University Press, 2003. 235p.

GRAY, D. E.; WISE, H. American Institute of Physics Handbook. New York: McGraw-Hill 1957. 2364

HEINRICH, B. The hot-blooded insects: strategies and mechanisms of thermoregulation. Harvard Univ Pr, 1993.

JONES, J. C.; OLDROYD, B. P. Nest thermoregulation in social insects. Advances in Insect Physiology, v. 33, p. 153-191, 2007.

KLEINHENZ, M. et al. Hot bees in empty broodnest cells: heating from within. Journal of Experimental Biology, v. 206, n. 23, p. 4217-4231, 2003.

KUHNHOLZ, S.; SEELEY, T. D. The control of water collection in honey bee colonies. Behavioral Ecology and Sociobiology, v. 41, n. 6, p. 407-422, 1997.

LEONHARDT, S. et al. Foraging loads of stingless bees and utilisation of stored nectar for pollen harvesting. Apidologie, v. 38, n. 2, p. 125-135, 2007.

LINDAUER, M. Temperaturregulierung und Wasserhaushalt im Bienenstaat. Journal of Comparative Physiology A: Neuroethology, Sensory, Neural, and Behavioral Physiology, v. 36, n. 4, p. 391432, 1954.

MACÍAS-MACÍAS, J. O. et al. Comparative temperature tolerance in stingless bee species from tropical highlands and lowlands of Mexico and implications for their conservation (Hymenoptera: Apidae: Meliponini). Apidologie, p. 1-11, 2011.

MARDAN, M.; KEVAN, P. G. Critical temperatures for survival of brood and adult workers of the giant honeybee, Apis dorsata (Hymenoptera: Apidae). Apidologie, v. 33, n. 3, p. 295-302, 2002.

MICHENER, C. D. The Social Behavior of the Bees. Massachusetts: Harvard University Press, 1974.

MORITZ, R. F. A.; CREWE, R. M. Air Ventilation in Nests of Two African Stingless Bees Trigona denoiti and Trigona gribodoi. Experientia Basel, v. 44, n. 11-12, p. 1024-1027, 1988.

NICOLSON, S. W. Water homeostasis in bees, with the emphasis on sociality. Journal of Experimental Biology, v. 212, n. 3, p. 429-434, 2009. 
NOGUEIRA-NETO, P. Notas bionomicas sobre meliponineos. I. Sobre ventilação dos ninhos e as constucões com ela relationadas. Rev. Bras. Biol, v. 8, p. 465-488, 1948.

Vida e criação de abelhas indígenas sem ferrão. São Paulo: Editora Nogueirapis, 1997. 445 ISBN 85-86525-01-4.

O'DONNELL, S.; FOSTER, R. L. Thresholds of response in nest thermoregulation by worker bumble bees, Bombus bifarius nearcticus (Hymenoptera : Apidae). Ethology, v. 107, n. 5, p. 387-399, 2001.

PRANGE, H. D. Evaporative cooling in insects. Journal of Insect Physiology, v. 42, n. 5, p. 493-499, 1996.

PRONI, E. A.; HEBLING, M. J. A. Thermoregulation and respiratory metabolism in two Brazilian stingless bee subspecies of different climatic distribution, Tetragonisca angustula fiebrigi and $T$. a. angustula (Hymenoptera: Apidae: Meliponinae). Entomologia Generalis, v. 20, n. 4, p. 281-289, 1996.

ROUBIK, D. W. Stingless bee nesting biology. Apidologie, v. 37, n. 2, p. 124-143, Mar-Apr 2006.

ROUBIK, D. W.; PERALTA, F. J. A. Thermodynamics in Nests of 2 Melipona-spp in Brazil. Acta Amazonica, v. 13, n. 2, p. 453-466, 1983 (recd. 1984) 1983.

SEELEY, T. D. Atmospheric carbon-dioxide regulation in honeybee (Apis mellifera) colonies. Journal of Insect Physiology, v. 20, n. 11, p. 2301-2305, 1974.

SIMPSON, J. Nest Climate Regulation in Honey Bee Colonie. Science, v. 133, n. 3461, p. 1327, 1961.

SOUTHWICK, E. E.; MORITZ, R. F. A. Social-Control of Air Ventilation in Colonies of Honey-Bees, Apis mellifera. Journal of Insect Physiology, v. 33, n. 9, p. 623-626, 1987.

VAREJÃO-SILVA, M. A. Meteorologia e climatologia: versão digital. Recife: INMET, 2005. 133

WEIDENMULLER, A. The control of nest climate in bumblebee (Bombus terrestris) colonies: interindividual variability and self reinforcement in fanning response. Behavioral Ecology, v. 15, n. 1, p. 120-128, 2004.

WEIDENMULLER, A.; KLEINEIDAM, C.; TAUTZ, J. Collective control of nest climate parameters in bumblebee colonies. Animal Behaviour, v. 63, p. 1065-1071, 2002.

WINSTON, M. L. The Biology of the Honey Bee. Cambridge, Massachusetts: Harvard University Press, 1987.

YOUNG, J. Humidity control in the laboratory using salt solutions - a review. Journal of Applied Chemistry, v. 17, n. 9, p. 241-245, 1967. 


\section{CAPÍTULO 3. A sensibilidade térmica em Scaptotrigona depilis (Apidae, Meliponini): efeitos da variação da temperatura sobre a produção de células de cria e desenvolvimento dos imaturos}

\section{RESUMO}

O desempenho de todo processo fisiológico ou atividade comportamental é influenciado pela temperatura do organismo. A sensibilidade térmica de Scaptotrigona depilis exerce um papel importante nas adaptações térmicas desta espécie, que não possui um controle da temperatura do ninho tão eficiente quanto Apis mellifera. Adicionalmente, conhecer como a fisiologia e o comportamento dos organismos reagem às variações de temperatura contribui com a previsão de como esses organismos podem reagir frente às mudanças climáticas, associada às suas capacidades de controle de temperatura. Nosso objetivo foi investigar como o desempenho do desenvolvimento do estágio pupal e da produção de células de cria são influenciados pela temperatura. Verificamos que o tempo de desenvolvimento pupal até a fase adulta diminui consideravelmente conforme a temperatura aumenta. A mortalidade também segue este padrão, porém somente até atingir uma temperatura limite e, após esse limiar, aumenta de forma drástica. Também, o tempo de desenvolvimento do estágio pupal até o adulto em $S$. depilis ocorre em uma faixa de temperatura mais ampla, quando comparamos com $A$. mellifera. Estes resultados suportam nossa hipótese de que por possuir uma capacidade termorregulatória menor, a cria de $S$. depilis deve suportar uma amplitude maior de temperaturas, porém com um tempo desenvolvimento ótimo menor. Apesar de sutil, a produção de células de cria mostrou sofrer mais influência da temperatura ambiente do que da temperatura interna do ninho. Para explicar essa aparente contradição, sugerimos que as operárias deixam de trabalhar nos processos de produção de células de cria em temperaturas altas e passam a investir seus esforços no resfriamento do ninho. Assim há a diminuição da produção de cria nestas condições, de forma a evitar que a temperatura aumente demais e ameace a viabilidade da cria e dos adultos. 


\section{INTRODUÇÃO}

A temperatura é uma variável física que afeta diretamente qualquer reação química, portanto toda reação bioquímica. A fisiologia de qualquer ser vivo está intimamente relacionada a processos metabólicos subjacentes que, ao nível molecular sofrem influência direta da temperatura. Por isso, essa variável influencia o comportamento e a performance (desempenho) dos organismos nas mais variadas atividades.

Especialmente em ectotérmicos, em que a temperatura corporal acompanha consideravelmente as variações na temperatura ambiente, o desempenho da grande maioria das atividades é amplamente afetada pela temperatura. Geralmente, a performance de uma atividade qualquer em ectotermos aumenta com a elevação da temperatura até estabilizar-se em uma temperatura ótima de desempenho, passando então a diminuir até a temperatura letal, definindo a sensbilidade térmica do organismo em questão (Huey e Kingsolver, 1989; Angilletta, 2002; Angilletta Jr et al., 2006).

Dessa maneira a temperatura acaba afetando os padrões de distribuição das espécies. Análises recentes mostraram que as espécies ectotérmicas tropicais possuem maiores riscos de extinção por conta das mudanças climáticas, como um resultado de sua baixa tolerância ao aquecimento (Deutsch et al., 2008). Portanto, investigar os efeitos da temperatura nos organismos vivos e como estes reagem em todos os níves (desde a fisiologia até o comportamento) pode oferecer indicações sobre como as mudanças futuras previstas na temperatura global podem impactar a distribuição e o status fisiológico dos organismos (Hochachka e Somero, 2002).

Neste capítulo abordamos como o desempenho do desenvolvimento dos imaturos (em relação à mortalidade e tempo de desenvolvimento) e da capacidade de produção de células de cria de $S$. depilis se comportam em relação à variação da temperatura, mais precisamente em condições de altas temperaturas.

\section{Desenvolvimento dos imaturos}

Em geral, o desenvolvimento dos organismos ectotérmicos sofre influência da temperatura em dois aspectos distintos: no tamanho e no tempo de desenvolvimento. Com poucas exceções, quanto maior a temperatura, menor é o 
tempo de desenvolvimento (Savage et al., 2004; Angilletta Jr et al., 2010), assim como o tamanho corpóreo do adulto é menor (Atkinson, 1994; Atkinson e Sibly, 1997; Frazier et al., 2006; Kingsolver e Huey, 2008).

Nas abelhas não é diferente. Assim como esperado, em baixas temperaturas o desenvolvimento da cria de abelhas solitárias do gênero Osmia é mais lento, (Kemp e Bosch, 2005) assim como os adultos são maiores nessa condição (Radmacher e Strohm, 2010). Radmacher e Strohm (2010) verificaram que a mortalidade aumenta significativamente em altas temperaturas $\left(30{ }^{\circ} \mathrm{C}\right)$. Como as abelhas solitárias não possuem nenhum mecanismo ativo de controle de temperatura, elas dependem exclusivamente do isolamento térmico do seu local de nidificação para a manutenção de estabilidade de temperatura para o desenvolvimento adequado da cria (Couto e Camillo, 2007).

Em Apis mellifera, abelhas altamente eussociais que controlam precisamente a temperatura de incubação da cria, diversos estudos mostram que pequenas variações acima ou abaixo da faixa ótima da temperatura de incubação afetam consideravelmente o desenvolvimento e a emergência da cria. Pupas mantidas em temperaturas menores que $32^{\circ} \mathrm{C}$ se desenvolvem em adultos e emergem, porém apresentam retardamento no desenvolvimento (Himmer, 1927; Michener, 1974). Já as mantidas abaixo de $28^{\circ} \mathrm{C}$, morrem. Se a temperatura de incubação é aumentada 1 ou $2^{\circ} \mathrm{C}$ acima de $36^{\circ} \mathrm{C}$, as operárias nascem com deformidades e a mortalidade aumenta consideravelmente. A $38^{\circ} \mathrm{C}$ ou acima disso a taxa de mortalidade é total (Himmer, 1927; Mardan e Kevan, 2002)

Além do tempo de emergência e da mortalidade, a incubação da cria fora da faixa ideal aumenta a susceptibilidade a parasitas (e.g. "ácaro traqueal" (Acarapis woodi) Mcmullan e Brown, 2005) e influencia o desempenho comportamental dos adultos em diversas atividade, como a capacidade de aprendizado, a memória e a divisão de trabalho (Kleinhenz et al., 2003; Tautz et al., 2003; Jones et al., 2005; Becher et al., 2009).

O único estudo, até o momento, que avaliou a sensibilidade térmica em abelhas sem ferrão verificou a temperatura letal em episódios de incubação de pupas sob temperaturas constantes por intervalos de 24 horas em Melipona beecheii, M. colimana e Scaptotrigona hellwegeri. Os autores verificaram que a mortalidae de $50 \%$ das pupas ocorreu quando foram submetidas a temperaturas 
mínina de $5^{\circ} \mathrm{C}$, e entre 33 e $39^{\circ} \mathrm{C}$ para as máximas, porém não foram testadas temperaturas ligeiramente maiores que $5^{\circ} \mathrm{C}$ (Macías-Macías et al., 2011).

Portanto, ainda temos pouca informação sobre a sensibilidade térmica do desenvolvimento da cria em abelhas sem ferrão. Nós não conhecemos a influência da temperatura durante todo o tempo de incubação na mortalidade da cria e tempo de desenvolvimento. Essas informações, combinadas com a capacidade termorregulatória, podem ajudar na previsão dos efeitos das mudanças climáticas sobre a distribuição de espécies desse grupo.

Além disso, as informações sobre a sensibilidade térmica de $S$. depilis podem contribuir para a maior compreeensão de como as abelhas sociais (em especial, as abelhas sem ferrão) lidam com a heterogeneidade térmica ambiental. Dado o fato de que as abelhas sem ferrão possuem uma capacidade termorregulatória menor quando comparadas à $A$. mellifera (Zucchi et al., 1972; Jones e Oldroyd, 2007), esperamos que os imaturos de $S$. depilis possuam menor sensibilidade térmica, suportando temperatura mais extremas.(já que no interior do ninho há uma ampla variação de temperatura). Assim, nossa previsão é que o desenvolvimento dos imaturos de $S$. depilis seja regular em uma faixa de temperatura mais ampla que em A. mellifera, porém com um desempenho ótimo menor, em termos de tempo de desenvolvimento.

\section{Produção de células de cria}

Ao contrário das abelhas melíferas, em que as larvas são alimentadas progressivamente pelas operárias nutridoras e há reutilização das células de crias das quais as abelhas emergiram, nas abelhas sem ferrão as larvas recebem todo o alimento uma única vez (as operárias regurgitam todo o alimento larval na célula de cria vazia antes da rainha ovipostiar durante o processo de aprovisionamento e postura (POP) e as células de cria são utilizadas uma só vez (Sakagami, 1982), O POP tem importância fundamental na dinâmica e manutenção da população da colônia (Michener, 2000). O número de células construídas por dia pode variar de cerca de algumas unidades até centenas, dependendo da espécie e das condições da colônia (Sakagami, 1982; Cepeda, 2006).

A temperatura parece ter fundamental importância na produção de cria dos meliponineos, porém os estudos realizados até o momento focam nos efeitos das 
baixas temperaturas sobre a cria. Velthuis et al. (1999) observaram uma diminuição do número de células construídas durante períodos frios, em comparação com períodos mais quentes, em uma colônia de Melipona bicolor bicolor. O mesmo foi encontrado por Borges \& Blochtein (2006) em M. bicolor schencki. Em algumas espécies que vivem nas regiões subtropicais, como as do gênero Plebeia, ocorre a interrupção total da construção de células de cria pelas operárias e de postura por parte da rainha durante o outono e inverno (Van Benthem, Imperatriz-Fonseca et al., 1995;. Ribeiro, Imperatriz-Fonseca et al., 2003). Contudo, esse fenômeno, conhecido como diapausa reprodutiva, parece não ser desencadeado pela temperatura e sim pela diminuição do comprimento do dia (Van Benthem et al., 1995; Ribeiro et al., 2003). Vollet-Neto et al. (2011) verificaram que, em sete colônias de Nannotrigona testaceicornis, em média, 4,4 vezes mais células de cria foram produzidas quando as colônias recebiam aquecimento artificial durante períodos de baixas temperaturas ambientais.

Assim como nas abelhas sem ferrão, os estudos com Bombus mostram os efeitos apenas das baixas temperaturas sobre a produção de cria. Vogt (1986) demonstrou que, sob baixas temperaturas, as operárias de Bombus terrestris gastam mais energia e, principalmente, mais tempo com a termorregulação da cria do que construindo células e/ou alimentando as larvas, resultando em menor produção de cria. Esses dados serviram como premissa para as hipóteses formuladas para explicar a diminuição de células de cria nos Meliponini (Engels et al., 1995). Ou seja, de maneira similar a Bombus, as operárias dos Meliponini poderiam gastar mais energia e tempo aquecendo a cria, atraés da termorregulação, ao invés de realizar tarefas relacionadas com a produção de mais cria. Embora nenhum estudo comprove esta hipótese, Velthuis et al. (1999) sugerem que a sensibilidade ao frio poderia ser por parte da rainha, mas também não evidenciam de tal especulação.

Até o momento, nenhum trabalho teve como objetivo verificar, diretamente, do efeito de altas temperaturas sobre a produção de células de cria em abelhas sociais. O pouco que se sabe sobre o efeito das altas temperaturas no POP foi descrito por Engels et al. (1995), que relatam que, sob condições de superaquecimento, as operárias de Scaptotrigona postica ficam muito agitadas, aparentemente desistindo das tarefas necessárias ao POP (como construir células de cria ou aprovisioná-las 
com alimento larval) e, posteriormente, em temperaturas extremas,as operárias desoperculam as células recém-construídas e retiram o alimento larval.

Portanto, o superaquecimento do ninho pode alterar o POP e, consequentemente, diminuir o número de células que seriam produzidas. Dentro deste contexto, nossa hipótese é de que temperaturas extremamente altas possam alterar o comportamento das operárias durante o processo de POP, de maneira a diminuir o número de células produzidas por unidade de tempo.

\section{Objetivos}

Nosso objetivo neste capítulo foi de investigar a influência de altas temperaturas no desempenho duas atividades em S. depilis: (1) o desenvolvimento dos imaturos e (2) a produção de células de cria.

Especificamente verificaremos a mortalidade e o tempo de desenvolvimento das pupas de $S$. depilis incubadas em quatro diferentes temperaturas $(26,30,34$ e $38^{\circ} \mathrm{C}$ ). Também analisaremos a influência das temperaturas ambientais e internas do ninho sobre a produção de células de cria, durante os períodos de altas temperaturas.

\section{MATERIAIS E MÉTODOS}

\section{Desenvolvimento dos imaturos}

Para investigar os efeitos da temperatura sobre o desenvolvimento das pupas, os imaturos de Scaptotrigona aff. depilis foram mantidos em estufa B.O.D. em quatro temperaturas diferentes: $26,30,34$ e $38^{\circ} \mathrm{C}$. Em cada temperatura foram utilizados cinco favos de colônias diferentes, sendo que em cada um deles foi acompanhado o desenvolvimento de 50 imaturos, totalizando 250 imaturos para cada temperatura.

Para padronizar as idades dos imaturos que acabaram de entrar na fase de pupa, os favos foram selecionados favos de cria contendo pré-pupas e pupas. As células foram desoperculadas com ajuda de uma pinça, de maneira a permitir a identificação dos estágios de desenvolvimento da cria (Fig. 1). Devido ao modo de contrução das células de cria, onde as mais centrais são as primeiras a comporem o disco horizontal do favo e, portanto são as mais antigas, as pupas são encontradas 
mais internamente, enquanto que os estágios menos avançados de desenvolvimento se encontram nas bordas do favo. Foi possível então, identificar uma "fronteira" entre as pupas e as pré-pupas, de maneira que cerca de 70 prépupas mais próximas das pupas foram selecionadas. No dia seguinte, elas puderam ser utilizadas, já que tinham se metamorfoseado em pupas, (Fig. 1). Este favo foi colocado sobre um apoio que impedia que ele ficasse em contato direto com o fundo da placa de Petri. No fundo foi colocado água com cloreto de sódio $(\mathrm{NaCl})$, para que a umidade relativa fosse mantida em ca. 75\% (Young, 1967), impedindo a proliferação de fungos e ao mesmo tempo evitando que as pupas desidratassem. $O$ favo fora mantido em estufa a $30{ }^{\circ} \mathrm{C}$ por 24 horas, quando 55 (5 a mais para descontar o possível aparecimento de machos) pré-pupas que se metamorfosearam em pupas fossem selecionadas (já que descartamos os demais indivíduos que não tiveram metamorfose adequada ou danificaram-se no processo de abertura das células). 


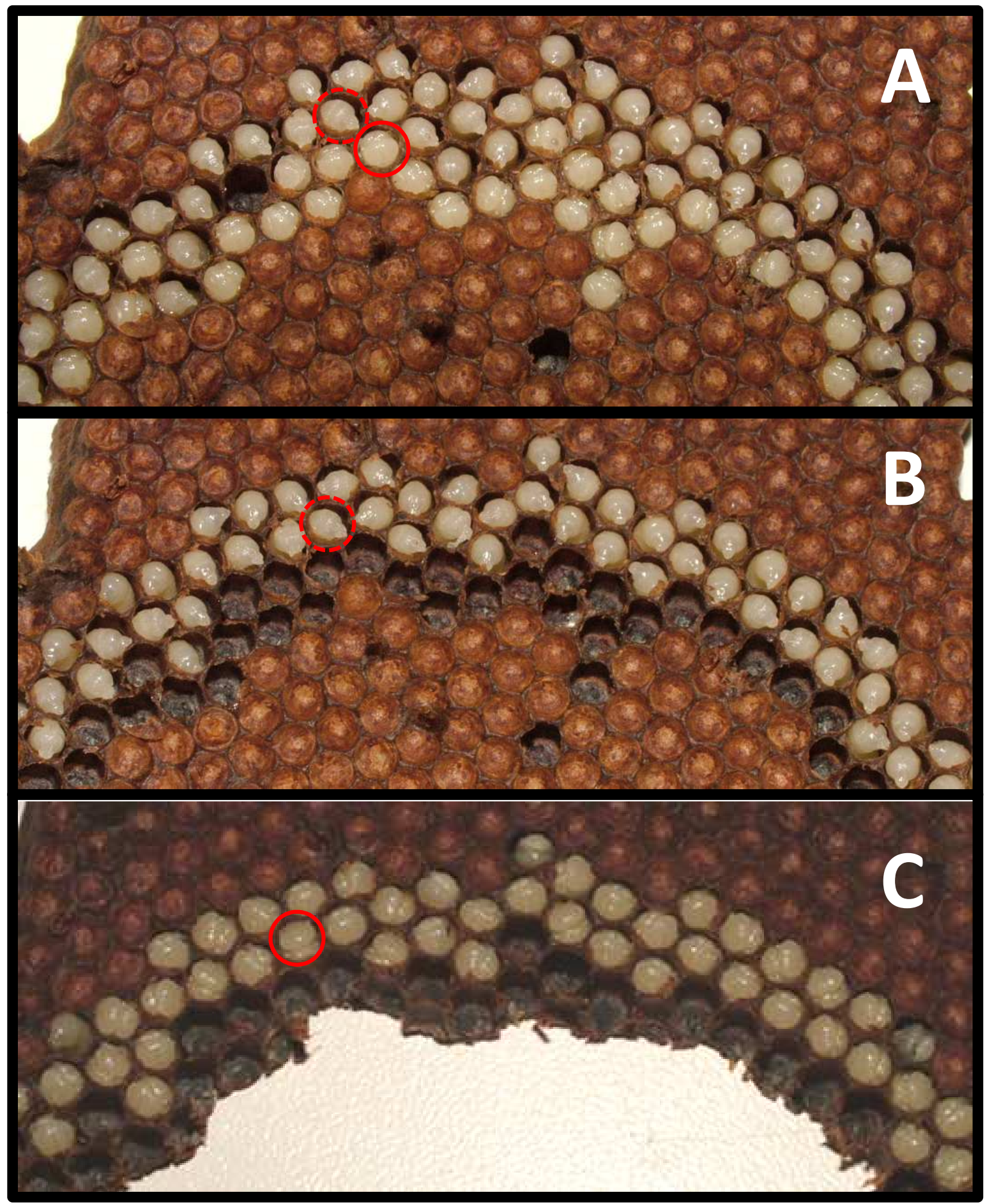

Fig. 1. Padronização da idade dos imaturos em favo Scaptotrigona depilis: (A) identificação da presença de pupas (círculos inteiros) e pré-pupas (círculos pontilhados) no mesmo favo; (B) seleção das duas fileiras de células contendo pré-pupas mais próximas das pupas através da remoção das últimas; e (C) imaturos recém empupados após incubação de 24 horas a $28{ }^{\circ} \mathrm{C}$. 


\section{Bioensaio}

Os favos foram colocados em estufa B.O.D. para que os indivíduos desenvolvessem a temperaturas de $26,30,34$ e $38^{\circ} \mathrm{C}$. Conforme o desenvolvmento das pupas avançava, os olhos inciavam a pigmentação, permitindo a identificação de machos. Caso aparecesse algum, seria retirado da amostragem. O número de pupas se desenvolvendo em operárias foi estabelecido em 50.

A emergência das operárias foi considerada no momento em que as operárias emergiam das células de cria. A mortalidade foi determinada subtraíndo-se de 50 o número de operárias adultas que emergirem. O tempo de desenvolvimento foi determinado através de vistorias diárias.

\section{Análise estatística}

Foi verificada a taxa de sobrevivência e mortalidade (\%) para cada tratamento (26, 3034 e $\left.38^{\circ} \mathrm{C}\right)$. Foi aplicado um teste de ANOVA entre as taxas de mortalidade de cada favo para verificar se existia diferenças entre as taxas de mortalidade e sobrevivência para cada tratamento.

Foi verificado a média do tempo de desenvolvimento das pupas até a emergência, bem como o desvio padrão e a variância. Para verificar se o tempo de desenvolvimento muda de acordo com a temperatura de incubação, foi feito um teste de Kruskal-Wallis One Way ANOVA on Ranks entre o tempo de emergência de cada operária que sobreviveu dos quatro tratamentos $\left(26,30,34\right.$ e $\left.38^{\circ} \mathrm{C}\right)$.

\section{Produção de células de cria}

Foram utilizadas nove colônias de $S$. depilis mantidas em caixas de madeira (medidas externas $16 \times 16 \times 23 \mathrm{~cm}$, com $2 \mathrm{~cm}$ de espessura), estabelecidas cerca de 18 meses antes dos experimentos. As colônias foram mantidas em ambiente aberto. Furos nas laterais das caixas permitiram a entrada dos sensores conforme descrito no Capítulo 1, posicionados nas laterais dos favos de cria em construção. Portanto, os sensores monitoraram, a cada $5 \mathrm{~min}$, a temperatura e umidade relativa da região dos favos de cria indicados por $T_{C R I A}$ e $U R_{C R I A}$, respectivamente. Outros dois sensores monitoraram as temperatura ambiente $\left(T_{A M B}\right)$ (em local sombreado ao lado 
das colônias) e a da caixa controle (T conTR) (em uma caixa vazia de mesma dimensões). A exposição das colônias ao sol determinou o superaquecimento das mesmas. As temperaturas ambientais máximas foram superiores a $34^{\circ} \mathrm{C}$.

Determinação do número de células produzidas por dia ( $\left.N_{C E L}\right)$

Diariamente às 18:00h, fotografias eram tiradas para determinar o número de células de cria produzidas por dia ( $\mathrm{N}_{\mathrm{CEL}}$ ) (Fig. 2). A comparação de fotos diárias permitiu determinar o número de células construídas durante o período de 24 horas. Durante 10 dias, as fotos foram registradas, bem como o monitoramento da $T_{\text {CRIA. }}$.

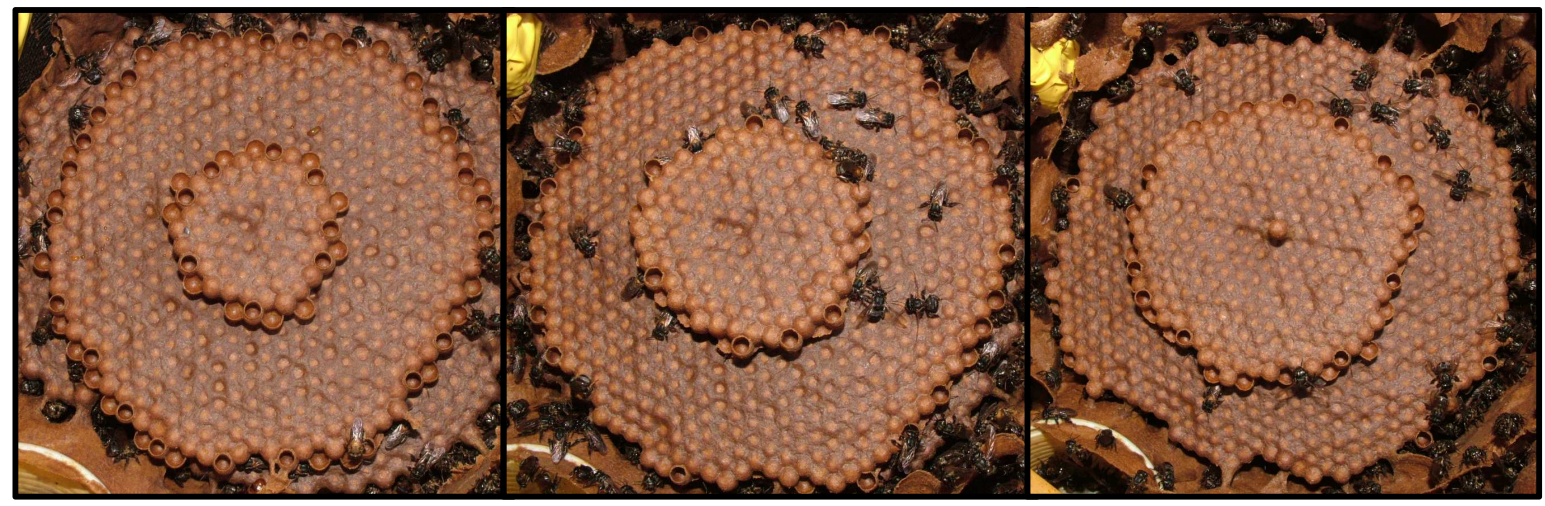

Fig. 2. Fotografias tiradas em três dias consecutivos em intervalos de 24 horas, da região do favo de cria de uma das colônias de Scaptotrigona depilis utilizadas no experimento, a fim de acompanhar a taxa de construção de células de cria.

\section{Análise estatística}

Para cada medição do $\mathrm{N}_{\mathrm{CEL}}$ foi calculado uma média da temperatura nas três regiões amostradas das 18 às 18 horas, representando o intervalo de 24 horas em que o $\mathrm{N}_{\mathrm{CEL}}$ foi amostrado.

Para realizar as análises, foi necessário verificar se houve diferença no $\mathrm{N}_{\mathrm{CEL}}$ entre as colônias. Para isto foi aplicado um teste de análise de variância One Way ANOVA (Kruskal-Wallys) entre o $\mathrm{N}_{\mathrm{CEL}}$ de cada colônia durante os nove dias amostrados.

Como houve uma diferença estatística (ver Resultados) no $\mathrm{N}_{\mathrm{CEL}}$ entre as colônias, provavelmente devido a diferenças inerentes a cada uma delas (e.g. no tamanho da população), foi necessário fazer uma correção nos dados para poder compará-los. Para isto, foi calculado o $\mathrm{N}_{\mathrm{CEL}}$ relativo ao total de células produzidas por determinada colônia, conforme a fórmula 


$$
N_{C E L} \text { relativo }=\frac{N_{C E L} C x}{\text { número total de células construídas de Cx}}
$$

onde $C x$ representa determinada colônia $(\mathrm{C} 1, \mathrm{C} 2, \mathrm{C} 3 \ldots), \mathrm{N}_{\mathrm{CEL}}$ relativo representa então a porcentagem de células de cria construídas em determinado dia em uma colônia, em relação ao total de células construídas por esta colônia durante o período experimental.

Nas análises para investigar a influência da temperatura do ambiente na produção de células de cria, a T CONTR é que foi considerada, pois reflete com maior precisão a temperatura na qual as colônias estão sendo submetidas, ao contrário da $\mathrm{T}_{\mathrm{AMB}}$, que se refere à temperatura do ar fora das caixas. Para verificar se altas TCONTR causam uma diminuição do número de células de cria produzidas, foi feita uma correlação de Pearson entre a $T_{\text {CONTR }}$ e o $\mathrm{N}_{\text {CEL }}$.

Para verificar qual a relação da temperatura interna do ninho com a produção de células de cria, o $\mathrm{N}_{\mathrm{CEL}}$ relativo de todas as amostragens nas nove colônias foi correlacionado com a média da TCRIA correspondente a cada amostragem.

\section{RESULTADOS}

\section{Desenvolvimento dos imaturos}

A taxa de mortalidade atingiu os menores níveis na temperatura de desenvolvimento de $34{ }^{\circ} \mathrm{C}(1,2 \%)$, e os maiores na de $38{ }^{\circ} \mathrm{C}(95,6 \%$; Tabela 1 , Fig. 3). Não houve diferença estatística significativa entre os grupos dos tratamentos de 26, 30 e $34^{\circ} \mathrm{C}$, apenas o de $38^{\circ} \mathrm{C}$ foi estatisticamente diferente (One Way ANOVA: F = 519,43; $\mathrm{P}<0,001-$ Holm-Sidak: $\mathrm{P}<0,05)$. 


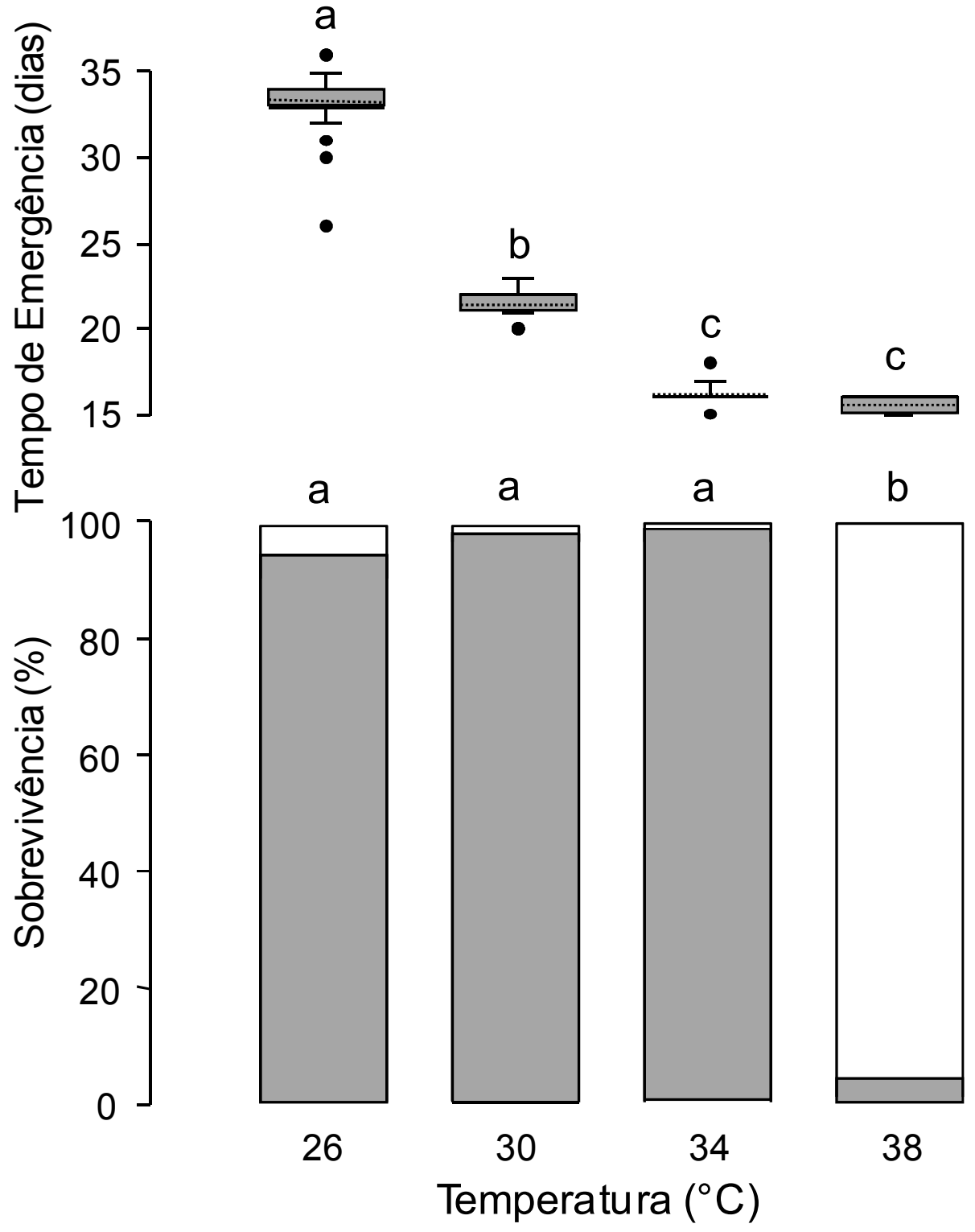

Fig. 3. Barras: porcentagem de sobrevivência (barras cinza) das pupas de Scaptotrigona depilis desenvolvidas em diferentes temperaturas ( $n=250$ pupas para cada tratamento). As letras sobrescritas diferentes $(a-b)$ indicam grupos de dados estatisticamente diferentes: Holm-Sidak, $\mathrm{P}<$ $0,05)$. Boxplot: tempo de emergência (dias) para cada temperatura de desenvolvimento $(n=250$ pupas para cada tratamento). A linha pontilhada dentro das caixas dos boxplots indica a média. Os limites inferiores e superior das caixas indicam o quartil inferior e superior, respectivamente. As hastes delimitam a distribuição de $95 \%$ dos dados. Os valores fora dos limites de $95 \%$ estão representados individualmente (outliers). As letras sobrescritas diferentes $(a-c)$ indicam grupos de dados estatisticamente diferentes: Dunn's test, $\mathrm{P}<0,05$ ). 
O tempo de desenvolvimento variou significativamente entre os tratamentos $(H=675,1 ; P<0,001)$, sendo que não houve diferença apenas entre o tratamento de 34 e o de $38^{\circ} \mathrm{C}$ (Dunn's test: $\left.\mathrm{P}<0,05\right)$ (Tabela 1).

Tabela 1. Duração média (e respectivo desvio-padrão) para o desenvolvimento e emergência de operárias de $S$. depilis mantidas sob quatro temperaturas diferentes: $26,30,34$ e $38{ }^{\circ} \mathrm{C}(\mathrm{n}=250$ pupas para cada temperatura). As letras sobrescritas diferentes $(a-c)$ indicam grupos de dados estatisticamente diferentes: Dunn's test, $P<0,05)$.

\begin{tabular}{lcccc}
\hline & \multicolumn{4}{c}{ Temperatura de desenvolvimento $\left({ }^{\circ} \mathbf{C}\right)$} \\
\cline { 2 - 5 } & $\mathbf{2 6}$ & $\mathbf{3 0}$ & $\mathbf{3 4}$ & $\mathbf{3 8}$ \\
\hline Duração média \pm d.p. (dias) & $33,3^{\mathrm{a}} \pm 1,05$ & $21,6^{\mathrm{b}} \pm 0,76$ & $16,2^{\mathrm{c}} \pm 0,46$ & $15,7^{\mathrm{c}} \pm 0,47$ \\
Taxa de mortalidade (\%) & $5,6^{\mathrm{a}}$ & $2,0^{\mathrm{a}}$ & $1,2^{\mathrm{a}}$ & $95,6^{\mathrm{b}}$ \\
\hline
\end{tabular}

O tempo médio para emergência diminuiu consideravelmente conforme a temperatura de desenvolvimento aumentou (Fig. 3). Comparando-se o tratamento de $26{ }^{\circ} \mathrm{C}$ com o de $34{ }^{\circ} \mathrm{C}$, a duração de desenvolvimento diminuiu pela metade (Tabela 1; Fig. 3). O mesmo aconteceu com o desvio padrão para cada tratamento, conforme a temperatura de desenvolvimento aumentou, as emergências aconteceram em intervalos de tempo menores.

\section{Produção de células de cria}

Devido a problemas relacionados com a amostragem do $\mathrm{N}_{\mathrm{CEL}}$ e com a aquisição automática de temperatura, 4 das 81 amostras (considerando 9 colônias em 9 dias) foram perdidas, totalizando um número amostral de 77. O $\mathrm{N}_{\mathrm{CEL}}$ variou entre cada colônia, mostrado pela diferença estatisticamente significativa entre elas $(\mathrm{H}=57,699 ; \mathrm{P}<0,001)$ (Fig. 4A).

Devido à grande variação no $\mathrm{N}_{\mathrm{CEL}}$ de cada colônia, foi feita uma correção dos dados, de forma a transformar cada amostra de $\mathrm{N}_{\mathrm{CEL}}$ em uma porcentagem do número total de células produzidas por determinada colônia (ver Materiais e Métodos), o $\mathrm{N}_{\mathrm{CEL}}$ relativo. Assim, as médias de cada colônia se concentraram em um único valor $\left(\mathrm{N}_{\mathrm{CEL}}\right.$ relativo médio $\left.=11,11\right)$, porém os valores relativos variam dentro de cada colônia (Fig. 4B). Não houve diferença estatística do $\mathrm{N}_{\mathrm{CEL}}$ relativo entre as colônias (Kruskal-Wallis One Way ANOVA on Ranks, $P=1,00 ; H=0,24$ ). 

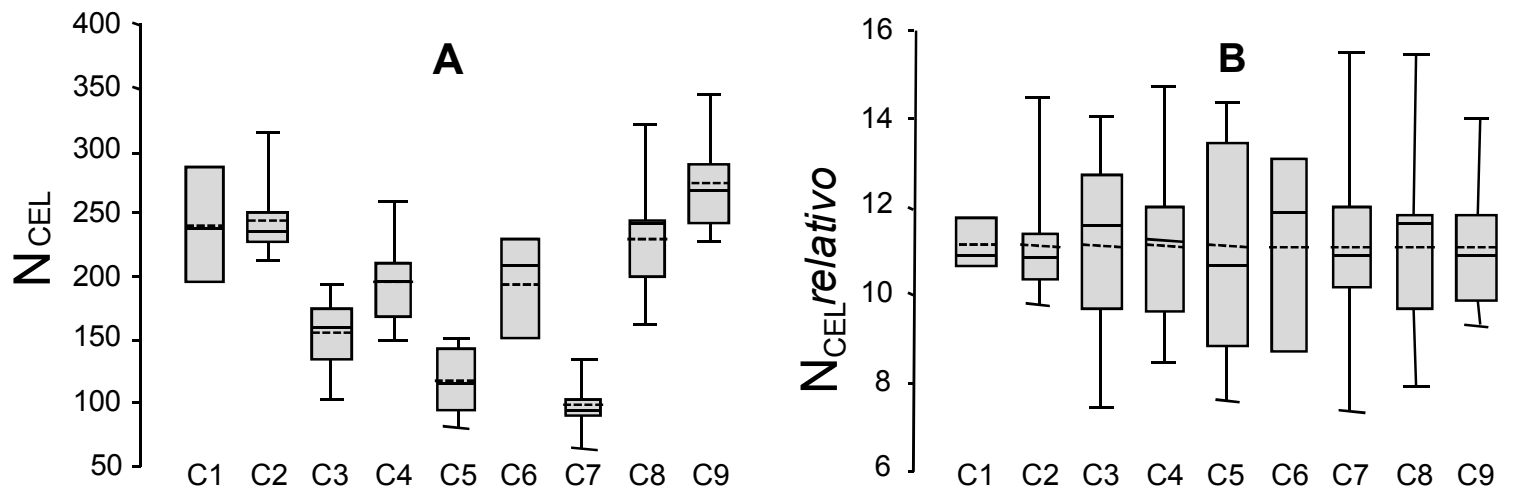

Fig. 4. A) número de células totais produzidas por cada colônia; B) número de células relativo ao total produzido por cada colônia. Boxplot: A linha inteira dentro das caixas dos boxplots indica a mediana, enquanto que a pontilhada indica a média. Os limites inferiores e superior das caixas indicam o quartil inferior e superior, respectivamente. As hastes delimitam a distribuição de $95 \%$ dos dados.

A $T_{\text {CONTR }}$ e a $T_{A M B}$ diárias (das 18 às 18 horas) apresentaram diferenças significativas entre cada dia, durante os nove dias de experimento $(H=583,32, P<$ 0,001 e $H=579,04, P<0,001$, respectivamente). Para verificar a influência da $\mathrm{T}_{\text {CONTR }}$ na produção de células de cria, o $\mathrm{N}_{\mathrm{CEL}}$ relativo foi correlacionado com a respectiva $T_{\text {CONTR }}$ média do dia (Fig. 5). O valor de coeficiente de correlação mostrou que, apesar de fraca, existe uma correlação negativa e significativa entre as variáveis $(\rho=-0,29 ; P=0,008)$.

A

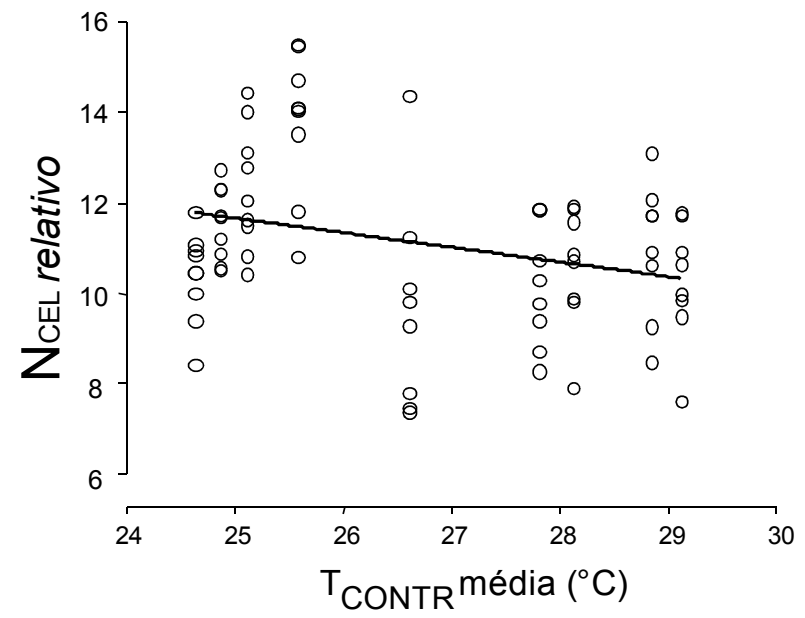

B

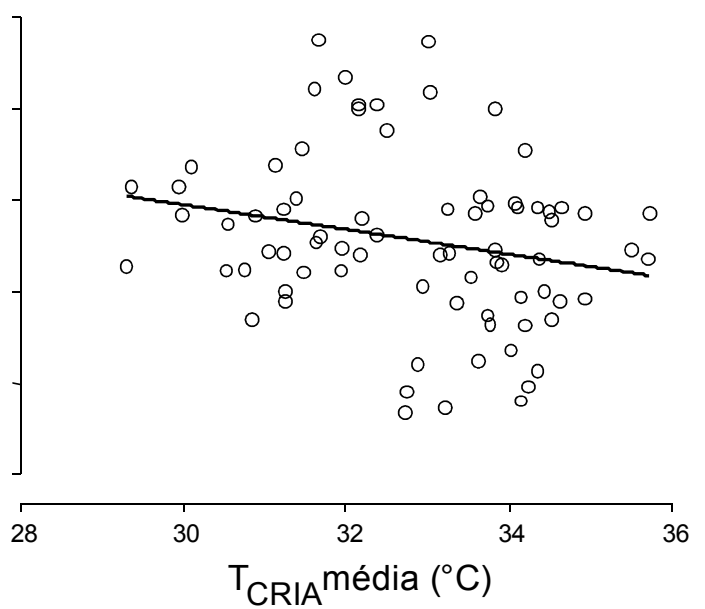

Fig. 5. $N_{C E L}$ relativo em função da (A) $T_{\text {CONTR }}$ média (das 18 às 18$)$ de cada dia $(n=9)$ e da (B) $T_{\text {CRIA }}$ média das 18 às 18 horas $(n=77)$. Cada ponto representa o número de células produzidas em um dia (relativo ao total produzido no experimento inteiro) por uma colônia, em relação à temperatura média da caixa controle ( $\left.T_{\text {CONTR }}\right)$ e à temperatura média interna do ninho ( $\left.T_{\text {CRIA }}\right)$ no dia amostrado. As 
linha correspondem à equação da regressão linear $\left(T_{\text {CONTR }}-R^{2}=0,084 ; N_{C E L}\right.$ relativo $=0,19-0,003 x$ $\mathrm{T}_{\text {CONTR }} ; \mathrm{T}_{\text {CRIA }}-\mathrm{R}^{2}=0,028 ; \mathrm{N}_{\text {CEL }}$ relativo $\left.=0,17-0,002 \times \mathrm{T}_{\text {CRIA }}\right)$.

O teste de correlação de Pearson mostrou que não há relação entre o $\mathrm{N}_{\mathrm{CEL}}$ relativo de cada colônia e sua respectiva $T_{\text {CRIA }}$ média no dia da amostragem ( $\rho=-$ $0,17 ; P=0,126 ;$ Fig. $w)$, indicando que a temperatura interna dos ninho não influencia a produção de células de cria.

\section{DISCUSSÃO}

\section{Desenvolvimento imaturos}

A temperatura de $34^{\circ} \mathrm{C}$ mostrou ser, considerando os parâmetros analisados, a ideal para o desenvolvimento das pupas, em que foi observado o menor tempo necessário para o desenvolvimento (cerca de 16 dias), assim como a menor taxa de mortalidade (1,2\%). Coincidentemente a temperatura média da $\mathrm{T}_{\mathrm{CRIA}}$ durante os períodos de termorregulação foi $34,0 \pm 1,4{ }^{\circ} \mathrm{C}$; ver Capítulo 1). Apesar disso a temperatura média durante o dia inteiro foi de $30,5 \pm 2,9^{\circ} \mathrm{C}$ para todas as colônias, o que poderia mostrar que $S$. depilis não controla precisamente a temperatura, mantendo-a abaixo dos níveis ótimos, considerando os nossos parâmetros. É preciso deixar claro que estes parâmetros analisados (tempo de desenvolvimento e mortalidade) não são os únicos a serem considerados para avaliação de uma temperatura ideal. Outras várias atividades e características biológicas que influenciam o desempenho da operária adulta (e consequentemente o fitness da colônia), como presença de deformações, o tamanho, a capacidade cognitiva, a longevidade, entre outros, não foram medidos e podem variar em relação às suas respectivas temperaturas ótimas (ideais).

A T CRIA máxima nunca passou os $36{ }^{\circ} \mathrm{C}$ em nenhuma das colônias, permanecendo em torno dos $35^{\circ} \mathrm{C}$ para todas as colônias (ver Capítulo 1). Isto pode indicar que a capacidade de resfriamento do ninho é suficiente para manter a temperatura longe dos $38^{\circ} \mathrm{C}$, que são maléficos para a cria. Nossos resultados mostraram que uma mortalidade maior que 95\% quando a temperatura é igual a 38 ${ }^{\circ} \mathrm{C}$. Porém, será necessário aprofundar a precisão das análises e dos experimentos, a fim de verificar como os imaturos reagem à incubação a $36^{\circ} \mathrm{C}$ (temperatura que foi atingida na região dos favos de cria de algumas colônias) e, principalmente, como 
reagem a episódios curtos de temperaturas extremas $\left(36\right.$ e $\left.38^{\circ} \mathrm{C}\right)$, uma vez que estas temperaturas são experimentadas ocasionalmente e apenas durante períodos curtos, quando as temperaturas ambientais são extremas. Apenas uma hora de exposição das pupas ou pré-pupas de uma espécie de abelha Megachile rotundata (Megachilidae) a temperaturas de $50{ }^{\circ} \mathrm{C}$ causou uma mortalidade de $100 \%$, enquanto o mesmo tempo de exposição a $45^{\circ} \mathrm{C}$ não aumentou signifcativamente a mortalidade quando comparada com o grupo controle (Undurraga e Stephen, 1980), o que pode indicar que devem existir temperaturas extremas que provavelmente inviabilizam componentes importantes do metabolismo (desnaturação de proteínas, permeabilidade de membanas), causando mudanças irreversíveis na fisiologia, levando a deficiências ou até mesmo à morte.

O tempo de desenvolvimento diminuiu consideravelmente conforme a temperatura de incubação aumentou. $\mathrm{A} 26^{\circ} \mathrm{C}$ o tempo de emergência foi de cerca de 33 dias, caindo pela metade com atingiu $34^{\circ} \mathrm{C}$ (16 dias). Este resultado mostra a importância da termorregulação da colônia, de maneira a manter as temperaturas mais elevadas, acelerando o desenvolvimento dos imaturos como uma das consequências. Um rápido desenvolvimento pode ser muito importante na fundação de uma nova colônia, i.e., em uma enxameação, uma vez que nesta condição é fundamental que a população aumente. Este pode ser um dos motivos pelo qual as enxameações acontecem durante períodos com a temperatura mais elevada (Winston, 1987). Já em uma colônia completamente estabelecida, o tempo de desenvolvimento não influenciaria tanto no crescimento da população, uma vez que, em uma situação hipotética em que a taxa de produção de cria fosse constante, a taxa de emergência seria constante. Como esta situação não acontece e a taxa de produção de cria varia (em consequência da própria temperatura e da disponibilidade de recursos; Pereira et al., 2009), o tempo de desenvolvimento é também importante em colônias estabelecidas, de forma a aumentar o tamanho populacional com mais rapidez.

Outra consequência do menor tempo de desenvolvimento é que, na maioria dos casos, o tamanho dos organismos ectotérmicos que se desenvolvem em temperaturas mais altas (e consequentemente em menos tempo) serão relativamente menores quando adultos. Este padrão foi verificado por Atkinson (1994), que observou esta fenômeno em mais de $80 \%$ dos casos analisados 
(temperature-size rule). Esta consequência é muito discutida em termos adaptativos, uma vez que em alguns casos um tamanho maior é mais vantajoso que um menor, criando um paradoxo (Kingsolver e Huey, 2008). Adicionalmente o aumento da taxa de desenvolvimento com o aumento da temperatura pode ter outras consequências que não foram testadas, alterando a fisiologia e a anatomia das abelhas emergidas, e consequentemente o desempenho destas quando adultas.

A relação da diminuição do tempo de desenvolvimento com o aumento da temperatura de incubação está de acordo com o esperado para a grande maioria dos animais ectotérmicos, que respondem a um aumento na temperatura com um aumento na taxa de desenvolvimento (Kingsolver e Huey, 2008). Esta relação baseia-se, em essência, em uma premissa termodinâmica de que as taxas das reações químicas aumentam junto com a temperatura (Savage et al., 2004), o que aumentaria todas as reações metabólicas e fisiológicas do organismo, acelerando o desenvolvimento das pupas (Hotter is Better - Angilletta et al., 2010).

Porém quando comparado com o desenvolvimento dos imaturos do gênero Apis, S. depilis apresenta uma taxa de desenvolvimento consideravelmente menor (i.e., um desenvolvimento mais lento). Verificamos que a duração mínima de desenvolvimento da pupa até o adulto, em $S$. depilis, está entre 15,7 e 16,2 dias, a $38^{\circ} \mathrm{C}$ e $34^{\circ} \mathrm{C}$ ), respectivamente. Em Apis mellifera, esse período de desenvolvimento da pupa até o adulto é de 8 a 11 dias, porém este dado não foi obtido em uma situação com a temperatura controlada e constante, mas em uma situação natural de desenvolvimento (Michener, 1974). Já em A. dorsata, Mardan \& Kevan (2002) verificaram que o tempo de desenvolvimento pupal mínimo em uma situação controlada (incubação em estufa, da mesma forma como feito neste trabalho) foi de 5 a 7 dias (entre 34 e $36^{\circ} \mathrm{C}$ ). Fica claro, portanto, que a taxa de desenvolvimento no gênero Apis é consideravelmente maior que em $S$. depilis nas temperaturas ótimas para cada uma delas.

Nossa hipótese é que esta diferença apresentada no tempo de desenvolvimento (e, provavelmente, no desempenho de outras atividades) é consequência da diferença entre as capacidades termorregulatórias das espécies. Como as abelhas do gênero Apis mantêm a temperatura do ninho precisamente dentro de uma faixa de 33 a $36^{\circ} \mathrm{C}$, consideravelmente maior e mais precisa que a encontrada para S. depilis (ver Capítulo 1; Engels et al., 1995), acreditamos que sua 
performance (no caso, a taxa de desenvolvimento) seria maior por dois motivos: (1) como a temperatura mantida pelas abelhas melíferas é maior, a taxa de desenvolvimento vai ser maior pela mesma razão que ela aumenta para $S$. depilis, conforme a temperatura de incubação aumenta, as taxas das reações químicas aumentam junto com a temperatura (Savage et al., 2004), o que aceleraria todas as reações metabólicas e fisiológicas do organismo e, consequentemente, o seu desenvolvimento (Hotter is Better - Angilletta et al., 2010) - porém, como explicar diferentes taxas de desenvolvimento em uma mesma temperatura? (2) a fisiologia térmica das abelhas melíferas estariam mais adaptadas a altas temperaturas, principalmente por conta de poderem mantê-las precisamente dentro de uma estreita faixa e com valores altos, de forma que seu desempenho máximo é maior do que em S. depilis, que deve possuir uma fisiologia que funcione (ao menos suporte) de forma regular (e consequentemente menor que em Apis) em uma amplitude maior de temperatura, por causa de sua baixa capacidade termorregulatória, i.e., devem possuir um aparato metabólico bem menos especializado, onde apenas uma fração dele deve funcionar em cada uma das temperaturas (Angilletta, 2009).

Para dar suporte ao segundo argumento, deveríamos esperar que o desempenho da taxa de desenvolvimento em $S$. depilis fosse regular em uma amplitude maior de temperaturas, ou seja, que as pupas se desenvolvessem (mesmo que muito lentamente) em uma faixa maior de temperaturas que as abelhas melíferas. Himmer (1927) incubou pré-pupas (no fim desse estágio) e pupas de $A$. mellifera em várias temperaturas e encontrou que a $26{ }^{\circ} \mathrm{C}$ poucas operárias emergiram. As que emergiram a 28 e $30^{\circ} \mathrm{C}$ apresentaram grande incidência de malformações nas asas e peças bucais. De 32 a $36^{\circ} \mathrm{C}$, as operárias nasceram normais. A $37^{\circ} \mathrm{C}$, algumas morreram, e a partir de $38^{\circ} \mathrm{C}$ todas morreram. Em um experimento semelhante com A. dorsata, Mardan \& Kevan (2002) verificaram que a mortalidade aumenta significativamente a $36^{\circ} \mathrm{C}$ (de duas repetições, uma delas apresentou mortalidade de $50 \%$ e na outra a mortalidade foi $>95 \%)$ e é total $(100 \%)$ a $38^{\circ} \mathrm{C}$. A $34{ }^{\circ} \mathrm{C}$, a mortalidade apresentou os menores índices e a $30^{\circ} \mathrm{C}$ foi menor que $20 \%$. Os autores não realizaram a metodologia-padrão em temperaturas abaixo de $30^{\circ} \mathrm{C}$, que consistia em colocar os favos com as pupas em câmaras climáticas que regulavam a temperatura, mas deixaram favos à temperatura ambiente e consideraram que a temperatura de 25 a $28^{\circ} \mathrm{C}$ apresentou mortalidade menor que a 
condição de $30^{\circ} \mathrm{C}$. Neste mesmo trabalho, eles mostraram que o tempo de desenvolvimento também cai consideravelmente conforme a temperatura de incubação aumenta, passando de cerca de 11 a 12 dias $\left(25-28^{\circ} \mathrm{C}\right)$ para 5 a 7 dias $\left(34-36^{\circ} \mathrm{C}\right)$.

Comparando esses dados do gênero Apis com os obtidos para $S$. depilis, verificamos que nas temperaturas mais baixas, $S$. depilis aparentemente possui um melhor desempenho $\left(94,4 \%\right.$ de sobrevivência a $\left.26^{\circ} \mathrm{C}\right)$ do que $A$. mellifera (emergência de poucos indivíduos, segundo Himmer, 1927). A comparação com as temperaturas mínimas de $A$. dorsata não foi feita por conta da metodologia não estar padronizada e poder conter alguns erros para as temperaturas mais baixas (por conta de considerarem um tratamento experimental, de 25 a $28^{\circ} \mathrm{C}$, o que ficou à temperatura ambiente). Nas temperaturas mais altas não é possível tirar a mesma conclusão, uma vez que, em todas as espécies, $34^{\circ} \mathrm{C}$ foi a temperatura ótima, e a $38^{\circ} \mathrm{C}$ a mortalidade foi maior que $95 \%$. Realizar o experimento em $S$. depilis para as temperaturas intermediárias $\left(36\right.$ e $37^{\circ} \mathrm{C}$ ) poderia resolver este problema, assim como para temperatura menores $\left(22\right.$ e $\left.24^{\circ} \mathrm{C}\right)$. Também será necessário para tirar conclusões mais robustas sobre a amplitude de temperaturas em que ocorre o desenvolvimento das pupas de $S$. depilis. Adicionalmente, é necessário verificar a influência de temperaturas flutuantes (com variação diária de temperatura) em comparação com temperaturas constantes de incubação. Radmacher e Strohm (2011) verificaram que temperaturas flutuantes de incubação aceleraram o desenvolvimento dos imaturos de Osmia bicornis (Megachilidae) em comparação com temperaturas constantes que refletiam as médias das temperaturas flutuantes. Além disso, será necessário avaliar como o desempenho de outros parâmetros (além da mortalidade e taxa de desenvolvimento) é influenciado pela temperatura nessas espécies para testar esta hipótese com maior precisão.

Macías-Macías et al. (2011), comparando as temperaturas letais das pupas e adultos (durante 24 horas) de três espécies de regiões geográficas distintas, Melipona colimana, M. beecheii e Scaptotrigona hellwegeri, verificaram que a primeira mostrou menor taxa de mortalidade e tolerou uma amplitude maior de temperaturas. Apesar dos autores não relacionarem estes resultados com a capacidade termorregulatória (provavelmente desconhecida para as espécies), eles sugeriram que esses resultados podem ser uma resposta da espécie dada as 
condições de temperatura mais extremas de sua região natural de ocorrência. Estes resultados suportam nossa hipótese, supondo que $M$. colimana experimente uma amplitude maior de temperaturas, deve apresentar adaptações para suportar temperaturas mais extremas. De acordo com nossas previsões, $M$. colimana deve ter uma capacidade termorregulatória parecida com as outras espécies comparadas, ou seja, deve controlar a temperatura tanto quanto ou menos que as outras espécies, porém possui adaptações que fazem suportar as temperaturas extremas a que é submetida em sua região geográfica de ocorrência.

Portanto, considerando apenas os parâmetros aqui analisados (taxa de desenvolvimento e mortalidade dos imaturos), é possível concluir que o controle de temperatura no sentido de esquentar o ninho é muito importante para controlar o tempo de desenvolvimeto da cria, uma vez que é muito maior em baixas temperaturas. Já a capcidade de resfriamento do ninho é importante para evitar a mortalidade da cria em larga escala, uma vez que apenas $4^{\circ} \mathrm{C}$ acima da temperatura ótima de desenvolvimento a mortalidade é quase $100 \%$, enquanto que $8^{\circ} \mathrm{C}$ abaixo da temperatura ótima ocasionam uma mortalidade de apenas 5,6\%. É importante ressaltar que outros parâmetros importantes para o ótimo desempenho de uma operária adulta não foram medidos (como a longevidade da operária emergida, sua capacidade cognitiva, sua velocidade e muitos problemas fisiológicos e morfológicos que poderiam surgir em condições desfavoráveis de temperaturas de desenvolvimento), e podem ser afetados pelas temperaturas de desenvolvimento em diferentes graus, alterando completamente nossas conclusões.

\section{Produção de células de cria}

Nossos resultados mostraram que a produção de células de cria está mais relacionada com a temperatura ambiente a qual a colônia está submetida (TCONTR) do que com a temperatura interna do ninho ( $\left.T_{\text {CRIA }}\right)$. Esta conclusão está baseada na correlação negativa significativa exibida entre a $\mathrm{T}_{\text {CONTR }}$ e $0 \mathrm{~N}_{\mathrm{CEL}}$ relativo, em contraste com a ausência de relação entre a $T_{\text {CRIA }}$ e o $\mathrm{N}_{\text {CEL }}$ relativo.

Portanto, observamos uma relação inversamente proporcional que, a partir de um limite máximo da temperatura ambiente média ( $T_{\text {CONTR }}$ entre 25 e $26^{\circ} \mathrm{C}$; Fig. 5), a produção de células de cria começa a cair conforme a temperatura aumenta. Já a temperatura do ninho não possui a mesma relação com a produção de células de 
cria, aparentemente não influenciando a produção de cria. Para explicar esta aparente contradição entre os dados, nossa hipótese é que o motivo da diminuição do número de células de cria produzidas em temperaturas ambientais elevadas seria por conta de que nas condições de superaquecimento as operárias parariam de trabalhar no processo de produção de células de cria. Concomitantemente outras operárias trabalhariam no controle de temperatura (ventilação e coleta de água; ver Capítulo 2) e diminuiriam a temperatura do ninho, de forma a fazer com que as temperaturas internas ( $\left.T_{\text {CRIA }}\right)$ não se correlacionem com a produção de células de cria.

As operárias que deixaram de participar do processo de produção de células de cria poderiam o fazer por dois motivos: (1) alguma componente do processo pode ser muito sensível às altas temperaturas, como os ovos, o alimento larval, as operárias ou mesmo a rainha. A própria cera pode ficar impossibilitada de ser manipulada, ou mesmo algum problema fisiológico pode ser causado nas operárias, afetando a manipulação da cera. Engels et al. (1995) verificaram que durante episódios extremos de calor $\left(44^{\circ} \mathrm{C}\right)$, as operárias de S. postica cessam as atividades de construção de células de cria e as operárias evacuam a região dos favos. Os autores sugerem que isto pode diminuir a temperatura também, pelo fato de retirar as fontes de calor de perto das crias. Após um período maior de exposição ao calor algumas operárias voltam para os favos e abrem algumas células de cria que contêm ovos e sugam o alimento larval. O fato das operárias abrirem somente células que continham ovos pode ser uma evidência da sensibilidade dos ovos ao calor. Outro motivo pelo qual as operárias poderiam deixar de produzir células de cria (2) seria para trabalhar no próprio processo de resfriamento, uma vez que durante uma condição de superaquecimento o limiar de resposta de uma grande parte das operárias seria atingido. Isto já foi verificado para Bombus terrestris, porém durante o comportamento de aquecimento da cria. Vogt (1986) verificou que as operárias de $B$. terrestris deixam de participar de atividades relacionadas com 0 cuidado com a cria para realizar a incubação das crias durante condições de baixas temperaturas.

Vollet-Neto et al. (2011) verificaram que a produção de cria em Nannotrigona testaceicornis é menor em baixas temperaturas ambientais e sugeriram que a sensibilidade das operárias (ou de alguma parte do processo de produção de cria) 
ou a transição para tarefas relacionadas com o aquecimento da cria, poderiam explicar a diminuição na produção de crias. O mesmo poderia acontecer, porém sob altas temperaturas.

Apesar da correlação significativa apresentada entre a TCONTR e o $\mathrm{N}_{\text {CEL }}$ relativo, é preciso cautela ao analisar os resultados e tecer conclusões. Em primeiro lugar, o valor do coeficiente de correlação encontrado é baixo $(\rho=-0,29)$, indicando que a produção de células de cria diminui pouco com o aumento da temperatura ambiente. Além disso as colônias foram submetidas a temperaturas extremas durante intervalos pequenos de tempo (10:00 às 16:00 h), de forma que o tratamento experimental é sucedido por uma condição normal, o que pode gerar resultados diferentes, bem como conclusões precipitadas. Portanto, não foi possível isolar completamente o efeito das altas temperaturas na produção de células de cria. Sugerimos que experimentos posteriores sejam realizados em temperaturas externas controladas. 


\section{REFERÊNCIAS BIBLIOGRÁFICAS}

ANGILLETTA, M. J. et al. Coadaptation: a unifying principle in evolutionary thermal biology. Physiological and Biochemical Zoology, v. 79, n. 2, p. 282-294, 2006.

ANGILLETTA, M. J.; HUEY, R. B.; FRAZIER, M. R. Thermodynamic effects on organismal performance: is hotter better. Physiological and Biochemical Zoology, v. 83, n. 2, 197-206, 2010.

ANGILLETTA, M. J. The evolution of thermal physiology in ectotherms. Journal of Thermal Biology, v. 27, n. 4, p. 249-268, 2002. USA, 2009.

Thermal adaptation: a theoretical and empirical synthesis. Oxford University Press,

ATKINSON, D. Temperature and Organism Size--A Biological Law for Ectotherms? Advances in Ecological Research, v. 25, p. 1-58, 1994.

ATKINSON, D.; SIBLY, R. M. Why are organisms usually bigger in colder environments? Making sense of a life history puzzle. Trends in Ecology \& Evolution, v. 12, n. 6, p. 235-239, 1997.

BECHER, M. A.; SCHARPENBERG, H.; MORITZ, R. F. A. Pupal developmental temperature and behavioral specialization of honeybee workers (Apis mellifera L.). Journal of Comparative Physiology a-Neuroethology Sensory Neural and Behavioral Physiology, v. 195, n. 7, p. 673-679, Jul 2009.

BORGES, F. V. B.; BLOCHTEIN, B. Seasonal variations in the internal conditions of colonies of the Melipona marginata obscurior Moure, at Rio Grande do Sul, Brazil. Revista Brasileira de Zoologia, v. 23, n. 3, p. 711-715, 2006.

CEPEDA, O. I. Division of labor during brood production in stingless bees with special reference to individual participation. Apidologie, v. 37, n. 2, p. 175-190, 2006.

COUTO, R.; CAMILLO, E. Influência da temperature na mortalidade de imaturos de Centris (Heterocentris) analis (Hymenoptera, Apidae, Centridini). Iheringia. Série Zoologia, v. 97, p. 51-55, 2007.

DEUTSCH, C. A. et al. Impacts of climate warming on terrestrial ectotherms across latitude. Proceedings of the National Academy of Sciences, v. 105, n. 18, p. 6668, 2008.

ENGELS, W.; ROSENKRANZ, P.; ENGELS, E. Thermoregulation in the nest of the neotropical stingless bee Scaptotrigona postica and a hypothesis on the evolution of temperature homeostasis in highly eusocial bees. Studies on Neotropical Fauna and Environment, v. 30, n. 4, p. 193-205, 1995.

FRAZIER, M.; HUEY, R. B.; BERRIGAN, D. Thermodynamics constrains the evolution of insect population growth rates: "warmer is better". American Naturalist, v. 168, n. 4, p. 512-520, 2006. ISSN 0003-0147.

HIMMER, A. Ein Beitrag zur Kenntnis des Wärmehaushalts im Nestbau sozialer Hautflügler. Journal of Comparative Physiology A: Neuroethology, Sensory, Neural, and Behavioral Physiology, v. 5, n. 2, p. 375-389, 1927.

HOCHACHKA, P. W.; SOMERO, G. N. Biochemical adaptation: mechanism and process in physiological evolution. Oxford University Press, USA, 2002.

HUEY, R. B.; KINGSOLVER, J. G. Evolution of thermal sensitivity of ectotherm performance. Trends in Ecology \& Evolution, v. 4, n. 5, p. 131-135, 1989. 
JONES, J. C. et al. The effects of rearing temperature on developmental stability and learning and memory in the honey bee, Apis mellifera. Journal of Comparative Physiology a-Neuroethology Sensory Neural and Behavioral Physiology, v. 191, n. 12, p. 1121-1129, 2005.

JONES, J. C.; OLDROYD, B. P. Nest thermoregulation in social insects. Advances in Insect Physiology, v. 33, p. 153-191, 2007.

KEMP, W.; BOSCH, J. Effect of temperature on Osmia lignaria (Hymenoptera : Megachilidae) prepupa-adult development, survival, and emergence. Journal of Economic Entomology, v. 98, n. 6, p. 1917-1923, 2005.

KINGSOLVER, J. G.; HUEY, R. B. Size, temperature, and fitness: three rules. Evolutionary Ecology Research, v. 10, n. 2, p. 251-268, 2008.

KLEINHENZ, M. et al. Hot bees in empty broodnest cells: heating from within. Journal of Experimental Biology, v. 206, n. 23, p. 4217-4231, 2003.

MACÍAS-MACÍAS, J. O. et al. Comparative temperature tolerance in stingless bee species from tropical highlands and lowlands of Mexico and implications for their conservation (Hymenoptera: Apidae: Meliponini). Apidologie, p. 1-11, 2011.

MARDAN, M.; KEVAN, P. G. Critical temperatures for survival of brood and adult workers of the giant honeybee, Apis dorsata (Hymenoptera: Apidae). Apidologie, v. 33, n. 3, p. 295-302, 2002.

MCMULLAN, J. B.; BROWN, M. J. F. Brood pupation temperature affects the susceptibility of honeybees (Apis mellifera) to infestation by tracheal mites (Acarapis woodi). Apidologie, v. 36, n. 1, p. 97-105, 2005.

MICHENER, C. D. The Social Behavior of the Bees. Massachusetts: Harvard University Press, 1974.

The bees of the world. Johns Hopkins Univ Pr, 2000.

PEREIRA, R. A. et al. Intrinsic colony conditions affect the provisioning and oviposition process in the stingless bee Melipona scutellaris. Genetics and Molecular Research, v. 8, n. 2, p. 725-729, 2009.

RADMACHER, S.; STROHM, E. Factors affecting offspring body size in the solitary bee Osmia bicornis (Hymenoptera, Megachilidae). Apidologie, v. 41, n. 2, p. 169-177, 2010.

. Effects of constant and fluctuating temperatures on the development of the solitary bee Osmia bicornis (Hymenoptera: Megachilidae). Apidologie, p. 1-10, 2011.

RIBEIRO, M. F.; IMPERATRIZ-FONSECA, V. L.; SANTOS-FILHO, P. S. A interrupção da construção de células de cria e postura em Plebeia remota (Holmberg) (Hymenoptera, Apidae, Meliponini). In: MELO, G. A. R. e ALVES-DOS-SANTOS, I. (Ed.). Apoidea Neotropica: Homenagem aos 90 Anos de Jesus Santiago Moure. Criciúma: Editora UNESC, 2003. p.177-188.

SAKAGAMI, S. F. Stingless bees. In: HERMANN, H. R. (Ed.). Social Insects, Vol. III. London: Academic Press, v.III, 1982. p.361-423.

SAVAGE, V. M. et al. Effects of body size and temperature on population growth. American Naturalist, v. 163, p. 429-441, 2004.

TAUTZ, J. et al. Behavioral performance in adult honey bees is influenced by the temperatura experienced during their pupal development. Proceedings of the National Academy of USA, v. 100, n. 12, p. 7343-7347, 2003.

UNDURRAGA, J.; STEPHEN, W. Effect of temperature on development and survival in postdiapausing leafcutting bee pupae (Megachile rotundata (F.)). II. Low temperature. Journal of the Kansas Entomological Society, p. 677-682, 1980. 
VAN BENTHEM, F. D. J.; IMPERATRIZ-FONSECA, V. L.; VELTHUIS, H. H. W. Biology of the stingless bee Plebeia remota (Holmberg): Observations and evolutionary implications. Insectes Sociaux, v. 42, n. 1, p. 71-87, 1995.

VELTHUIS, H. H. W.; KOEDAM, D.; IMPERATRIZ-FONSECA, V. L. The rate of brood cell production in the stingless bee Melipona bicolor fluctuates with nest box temperature. Revista de Etologia, v. 2, n. 1, p. 141-145, 1999.

VOGT, F. D. Thermoregulation in bumble bee colonies. I. Thermoregulatory versus brood maintenance behaviors during acute changes in ambient temperatures. Physiol. Zool., v. 59 (1), p. 55-59, 1986.

VOLLET-NETO, A.; MENEZES, C.; IMPERATRIZ-FONSECA, V. L. Brood production increases when artificial heating is provided to colonies of stingless bees. Journal of Apicultural Research, v. 50, n. 3, p. 242-247, 2011.

WINSTON, M. L. The Biology of the Honey Bee. Cambridge, Massachusetts: Harvard University Press, 1987.

YOUNG, J. Humidity control in the laboratory using salt solutions - a review. Journal of Applied Chemistry, v. 17, n. 9, p. 241-245, 1967.

ZUCCHI, R.; SAKAGAMI, S.; CRUZ-LANDIM, C. Capacidade termoreguladora em Trigona spinipes e em algumas outras espécies de abelhas sem ferrão (Hymenoptera: Apidae: Meliponinae). Homenagem à WE Kerr, p. 301-309, 1972. 


\section{CONSIDERAÇÕES FINAIS}

Esta dissertação proporcionou informações inéditas sobre as adaptações térmicas de Scaptotrigona depilis, principalmente em relação às altas temperaturas. Verificamos que a espécie é capaz de resfriar o ninho (Capítulo 1) e para isto, utiliza pelo menos dois mecanismos: a ventilação, já reconhecida como mecanismo de resfriamento nas abelhas sem ferrão (Nogueira-Neto, 1948; Jones e Oldroyd, 2007), porém nunca antes relacionada com dados sobre a temperatura interna e externa ao ninho; e a coleta de água para resfriamento evaporativo, comportamento já observado em condições experimentais artificiais com indivíduos isolados (MacíasMacías et al., 2011), porém nunca observados em um contexto colonial e natural, conforme verificamos (Capítulo 2). Adicionalmente foi verificado que a umidade relativa do ar dentro dos ninhos varia consideravelmente menos que a umidade relativa do ar ambiente, muito provalvemente por conta das fontes de umidade (néctar e água) e do isolamento da cavidade de nidificação, no caso a caixa de madeira (Capítulo 1). Também sugerimos que $S$. depilis (e provavelmente outras espécies de abelhas sem ferrão) utilizam mecanismos de refrigeração análogos aos dos mamíferos, de forma que a evaporação da água é responsável pela perda de calor (semelhante à sudorese), ao passo que a ventilação diminui a umidade relativa do ar dentro do ninho para facilitar a evaporação (Capítulo 2).

Sabendo que a eficiência dos mecanismos de termorregulação (tanto de resfriamento quanto de aquecimento do ninho) não são completamente precisos, permitindo uma certa variação da temperatura ao longo do dia (e em graus diferentes ao longo do ano), investigamos como $S$. depilis reage à variação de temperatura. Verificamos que a taxa de construção de células de cria sofre uma influência sutil da temperatura ambiente e quase nenhuma da temperatura do ninho (quando submetidas a altas temperaturas). Provavelmente isso ocorra por conta da capacidade colonias de regulação da temperatura do ninho, de forma a evitar que a temperatura ultrapasse valores letais para a cria e adultos, porém prejudicando de alguma forma os processos de produção de cria (Capítulo 3). Adicionalmente, verificamos que o tempo de desenvolvimento do estágio pupal até o adulto diminui conforme a temperatura de incubação aumenta. Da mesma forma acontece com a mortalidade, porém esta aumenta drasticamente após atingir uma temperatura limite 
(Capítulo 3). O desenvolvimento pupal e a produção de células de cria parecem ter um desempenho regular em uma grande amplitude de temperaturas (maior que em Apis mellifera, por exemplo). Sugerimos que esta aparente capacidade de suportar maiores variações de temperaturas em $S$. depilis é complementar à sua baixa precisão de controle da temperatura do ninho (quando compara à de A. mellifera).

Dessa forma, sugerimos uma nova abordagem para compreensão das estratégias de adaptações térmicas utilizadas pelas abelhas sem ferrão. Conforme sugerido anteriormente, a única explicação para a baixa capacidade termorregulatória nas abelhas sem ferrão seria a nidificação em cavidades isoladas termicamente, que juntamente com a termorregulação realizada pelas abelhas, seria capaz de manter a temperatura em níveis relativamente constantes e precisos, necessários para o crescimento e manutenção da colônia (Zucchi et al., 1972; Roubik e Peralta, 1983; Engels et al., 1995; Jones e Oldroyd, 2007). Nós sugerimos que mesmo com $\mathrm{O}$ isolamento das cavidades a temperatura dos ninhos varia consideravelmente (dependendo da capacidade de controle da espécie), porém o desempenho de suas atividades é regular dentro de uma ampla faixa de temperaturas. Esta relação poderia se tornar estável em um cenário evolutivo em que o custo da termorregulação seja maior que os benefícios, de forma que adaptações para uma menor sensibilidade térmica tragam maiores vantagens adaptativas (Angilletta, 2009).

Além disso, os resultados deste trabalho podem ajudar a prever como esta espécie vai reagir às mudanças climáticas previstas para o futuro (Hochachka e Somero, 2002), além de nortearem estudos para outras espécies de abelhas sem ferrão. 


\section{REFERÊNCIAS BIBLIOGRÁFICAS}

ANGILLETTA, M. J. Thermal adaptation: a theoretical and empirical synthesis. Oxford University Press, USA, 2009.

ENGELS, W.; ROSENKRANZ, P.; ENGELS, E. Thermoregulation in the nest of the neotropical stingless bee Scaptotrigona postica and a hypothesis on the evolution of temperature homeostasis in highly eusocial bees. Studies on Neotropical Fauna and Environment, v. 30, n. 4, p. 193-205, 1995.

HOCHACHKA, P. W.; SOMERO, G. N. Biochemical adaptation: mechanism and process in physiological evolution. Oxford University Press, USA, 2002.

JONES, J. C.; OLDROYD, B. P. Nest thermoregulation in social insects. Advances in Insect Physiology, v. 33, p. 153-191, 2007.

MACÍAS-MACÍAS, J. O. et al. Comparative temperature tolerance in stingless bee species from tropical highlands and lowlands of Mexico and implications for their conservation (Hymenoptera: Apidae: Meliponini). Apidologie, p. 1-11, 2011.

NOGUEIRA-NETO, P. Notas bionomicas sobre meliponineos. I. Sobre ventilação dos ninhos e as constucões com ela relationadas. Rev. Bras. Biol, v. 8, p. 465-488, 1948.

ROUBIK, D. W.; PERALTA, F. J. A. Thermodynamics in Nests of 2 Melipona-spp in Brazil. Acta Amazonica, v. 13, n. 2, p. 453-466, 1983.

ZUCCHI, R.; SAKAGAMI, S.; CRUZ-LANDIM, C. Capacidade termoreguladora em Trigona spinipes e em algumas outras espécies de abelhas sem ferrão (Hymenoptera: Apidae: Meliponinae). Homenagem à WE Kerr, p. 301-309, 1972. 